Jéssica Peres de Medeiros

\title{
Monitoramento e avaliação da regulamentação sobre rotulagem e bulas de agrotóxicos, afins e preservativos de madeira no Brasil: proposição de indicadores e
} métricas

Dissertação de Mestrado

Dissertação apresentada como requisito parcial para obtenção do grau de Mestre em Metrologia pelo Programa de Pós-Graduação em Metrologia (Área de concentração: Metrologia para Qualidade e Inovação) da PUC-Rio.

Orientadora: Maria Fatima Ludovico de Almeida

Rio de Janeiro, abril de 2021 


\section{Jéssica Peres de Medeiros}

\section{Monitoramento e avaliação da regulamentação sobre rotulagem e bulas de agrotóxicos, afins e preservativos de madeira no Brasil: proposição de indicadores e métricas}

Dissertação apresentada como requisito parcial para obtenção do grau de Mestre pelo Programa de PósGraduação em Metrologia (Área de concentração: Metrologia para Qualidade e Inovação) da PUC-Rio. Aprovada pela Comissão Examinadora abaixo:

Prof. ${ }^{a}$ Maria Fatima Ludovico de Almeida

Orientadora

Programa de Pós-Graduação em Metrologia - PUC-Rio

Prof. Carlos Augusto Caldas de Moraes

Universidade Cândido Mendes - UCAM

Prof. Rodrigo Floral Calili

Programa de Pós-Graduação em Metrologia - PUC-Rio 
Todos os direitos reservados. É proibida a reprodução total ou parcial do trabalho sem autorização da universidade, da autora e da orientadora.

\section{Jéssica Peres de Medeiros}

Graduou-se em Engenharia Ambiental e Sanitarista pela Universidade Estácio de Sá. Atua como Engenheira de Segurança do Trabalho na empresa Neobpo Serviços de Processos de Negócios e Tecnologia S.A., localizada no Rio de Janeiro.

Ficha Catalográfica

Medeiros, Jéssica Peres de

Monitoramento e avaliação da regulamentação sobre rotulagem e bulas de agrotóxicos, afins e preservativos de madeira no Brasil: proposição de indicadores e métricas / Jéssica Peres de Medeiros; orientadora: Maria Fatima Ludovico de Almeida. - Rio de Janeiro: PUC, Programa de Pós-Graduação em Metrologia, 2021.

129 f. ; $30 \mathrm{~cm}$

1. Dissertação (mestrado) - Pontifícia Universidade Católica do Rio de Janeiro, Centro Técnico Científico, Programa de Pós-Graduação em Metrologia.

Inclui referências bibliográficas.

1. Metrologia - Teses. 2. Regulamentação. 3. Rotulagem e bulas de agrotóxicos. 4. Monitoramento e avaliação. 5 . Indicadores e métricas. 6. Métodos multicritério de apoio à decisão. Almeida, Maria Fatima Ludovico de. II. Pontifícia Universidade Católica do Rio de Janeiro. Centro Técnico Científico. Programa de Pós-Graduação em Metrologia. III. Título. 
Com muita gratidão, dedico este trabalho à minha família. Em especial à minha mãe Janice Peres, que me apoiou em todos os momentos para que eu concluísse esta etapa em minha vida.

À memória da minha querida e doce Alice Rubes. 


\section{Agradecimentos}

Agradeço a Deus por guiar os meus caminhos, por me dar forças e sabedoria para que eu concluísse este trabalho.

Ao carinho, afeto, dedicação e cuidado dos meus pais, por sempre incentivarem a minha formação acadêmica.

Agradeço do fundo do meu coração à minha mãe Janice Peres, pela sua grande força que foi a mola propulsora que permitiu o meu avanço, mesmo durante os momentos mais difíceis.

Quero agradecer imensamente à minha professora orientadora Maria Fatima Ludovico de Almeida, que me manteve focada e na trilha certa para a conclusão satisfatória deste projeto. Grata pela sua orientação preciosa e por toda dedicação para que o melhor fosse desenvolvido.

A todos os professores do Programa de Pós-graduação em Metrologia para Qualidade e Inovação (PósMQI), que contribuíram para o meu aperfeiçoamento pessoal e profissional, e um agradecimento especial ao Prof. Rodrigo Flora Calili pelos ensinamentos em análise multicritério, fundamentais para o desenvolvimento da parte aplicada da pesquisa.

À psicopedagoga do Núcleo de Orientação e Atendimento Psicopedagógico (NOAP) da PUC-Rio, Lena Hirsch, pelo acompanhamento, suporte e carinho na reta final da pesquisa, para que eu pudesse me manter firme e organizada.

Aos meus amigos de mestrado pela amizade, cafés e companheirismo nesse período de estudo e dedicação. Em especial, à minha mana Carol e aos brilhantes amigos Ton e Lippe. Isso fez toda a diferença, obrigada.

O presente trabalho foi realizado com apoio da Coordenação de Aperfeiçoamento de Pessoal de Nível Superior - Brasil (CAPES) - Código de Financiamento 001. 


\section{Resumo}

Medeiros, Jéssica Peres de; Almeida, Maria Fatima Ludovico de. Monitoramento e avaliação da regulamentação sobre rotulagem e bulas de agrotóxicos, afins e preservativos de madeira no Brasil: proposição de indicadores e métricas. Rio de Janeiro, 2021. 129p. Dissertação de Mestrado - Programa de Pós-Graduação em Metrologia, Pontifícia Universidade Católica do Rio de Janeiro.

Rótulos e bulas de agrotóxicos e afins são importantes instrumentos de comunicação entre as empresas que colocam esses produtos no mercado, os profissionais de saúde, os agricultores e os consumidores de produtos finais da cadeia agroalimentar. No sentido de minimizar possíveis riscos à saúde humana $\mathrm{e}$ ao meio ambiente, o emprego desses produtos deve ser realizado de forma adequada e segundo regulamentação em vigor. Com esse propósito, a Agência Nacional de Vigilância Sanitária (Anvisa) aprovou em meados de 2019 um novo marco regulatório para agrotóxicos, que incluiu a Resolução da Diretoria Colegiada - RDC n ${ }^{\circ}$ 296, de 29 de julho de 2019, dispondo sobre as informações toxicológicas para rótulos e bulas de agrotóxicos, afins e preservativos de madeira. Nesse contexto, o objetivo da dissertação é propor um conjunto de indicadores e métricas para monitorar e avaliar a regulamentação sobre rotulagem e bulas de agrotóxicos, afins e preservativos de madeira no Brasil, durante sua implementação. A pesquisa pode ser classificada como aplicada, metodológica e descritiva. Durante a fase aplicada propriamente dita, adotou-se a abordagem metodológica de construção de indicadores propostos pelo Ministério do Planejamento, Orçamento e Gestão, com incorporação de métodos multicritério de apoio à decisão, combinados com lógica fuzzy. Destacam-se como resultados: (i) o modelo lógico para proposição de indicadores para o monitoramento e avaliação da implementação da regulamentação em foco; (ii) a ferramenta fuzzy multicritério para seleção e hierarquização dos indicadores inicialmente propostos; e (iii) um conjunto consistente de indicadores hierarquizados por categoria de requisitos legais da $\mathrm{RDC} \mathrm{n}^{\circ}$ 296/2019, a serem selecionados posteriormente pela Anvisa.

\section{Palavras-chave}

Metrologia; regulamentação; rotulagem e bulas de agrotóxicos e afins; monitoramento e avaliação; indicadores e métricas; métodos multicritério de apoio à decisão; lógica fuzzy. 


\section{Abstract}

Medeiros, Jessica Peres de; Almeida, Maria Fatima Ludovico de (Advisor). Monitoring and evaluation of regulation on pesticides, related products, and wood preservatives labeling and packaging leaflets in Brazil: proposition of indicators and metrics. Rio de Janeiro, 2021. 129p. Dissertação de Mestrado - Programa de Pós-Graduação em Metrologia, Pontifícia Universidade Católica do Rio de Janeiro.

Pesticide labeling and packaging leaflets are essential communication instruments between pesticide companies, health professionals, farmers, and consumers of final products in the agri-food chain. To minimize possible risks to human health and the environment, the use of these products must be carried out appropriately. With this purpose, the National Health Surveillance Agency (Anvisa) approved in mid-2019 a new regulatory framework for pesticides and wood preservatives, which included the Resolution of the Collegiate Board - RDC No. 296, of July 29, 2019, concerning toxicological information for labeling and packaging leaflets of these products. In this context, this dissertation aims to propose a set of indicators and respective metrics for monitoring and evaluating (ME) the regulation on pesticide and wood preservative labeling and packaging leaflets in Brazil during its implementation. This research can be classified as applied, methodological and descriptive. During the applied phase, the methodological approach proposed by the Ministry of Planning, Budget, and Management for building indicators was adopted, incorporating multicriteria methods of decision support combined with fuzzy logic. The main results are highlighted as follows: (i) a logic model to frame evaluation questions concerning the focused regulation; (ii) a fuzzy multicriteria tool for the ranking indicators associated with the evaluation questions; and (iii) a set of indicators ranked by category of legal requirements of RDC No. 296/2019 to be subsequently chosen by the Regulatory Agency.

\section{Keywords}

Metrology; regulation; pesticide labeling and packaging leaflets; monitoring and evaluation; indicators and metrics; multicriteria decision-making methods; fuzzy logic. 


\section{Sumário}

1. Introdução

1.1 Definição do problema de pesquisa................................................ 16

1.2 Objetivos: geral e específicos.......................................................... 17

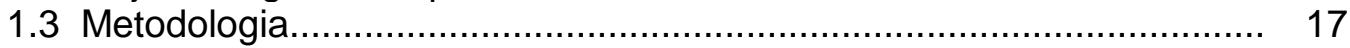

1.3.1 Fase exploratória e descritiva................................................... 18

1.3.2 Pesquisa aplicada...................................................................... 20

1.3.3 Fase conclusivo-propositiva...................................................... 20

1.4 Estrutura da dissertação................................................................ 20

2. Segurança química e avaliação toxicológica de agrotóxicos e afins: conceitos e sistemas de classificação.

2.1 Segurança química e a gestão do uso de agrotóxicos......................... 22

2.2 Sistemas de classificação de perigo aplicáveis a agrotóxicos .............. 26

2.2.1 Globally Harmonized System of Classification and Labelling of Chemicals - GHS (ONU).

2.2.2 Classification of Pesticides by Hazard (WHO).

2.2.3 Classificação pela International Agency for Research on Cancer Monographs (IARC)

2.2.4 International Chemical Safety Cards (ICSC)................................... 28

2.2.5 Guidelines on Highly Hazardous Pesticides (FAO/OMS).................. 29

2.2.6 EU Pesticides Database (Europa)................................................ 29

2.2.7 European Chemicals Agency - C\&L Inventory (Europa).................... 29

2.2.8 US EPA Carcinogenicity Evaluation - Database for Chemical Information (US EPA)

2.2.9 Hazardous Chemical Information System (HCIS) (Austrália)........... 30

2.2.10 Chemical Classification and Information Database (CCID)........... 31

2.2.11 Análise comparativa dos sistemas de classificação de perigo.......... 31

2.3 Marco regulatório da avaliação toxicológica de agrotóxicos no Brasil... 32

2.3.1 Arcabouço legal para registro de agrotóxicos no Brasil .................... 33

2.3.2 Sistema tripartite para registro de agrotóxicos no Brasil................... 35

2.3.3. Objetivos do novo marco regulatório para avaliação toxicológica de agrotóxicos

2.3.4 Classificação do sistema GHS versus Portaria MS no3/1992............ 39

2.3.5 Comunicação de perigo: pictogramas do GHS utilizados em rótulos e bulas de agrotóxicos, afins e preservativos de madeira................... 44

2.4 Estudos Empíricos sobre a adoção do GHS..................................... 46

2.5 Considerações finais sobre o capítulo................................................ 52

3. Monitoramento e avaliação como instrumentos de gestão pública... 54

3.1 Marco conceitual de monitoramento e avaliação.................................... 54

3.2 Elaboração do modelo lógico......................................................... 55

3.3 Conceituação e função básica dos indicadores................................... 56

3.4 Taxonomias de indicadores........................................................ 57

3.5 Construção de indicadores...................................................... 58

3.6 Métodos multicritério de apoio à decisão.......................................... 64 
3.6.1 Visão geral e quadro comparativo.

3.7 Descrição da abordagem multicritério fuzzy AHP-TOPSIS................... 66

3.7.1 Atribuição de pesos aos critérios pelo método fuzzy AHP................ 67

3.7.2 Avaliação quantitativa do grau de atendimento dos indicadores aos critérios pelo método fuzzy TOPSIS.

3.7.3 Avaliação qualitativa dos indicadores propostos aos critérios previamente estabelecidos.

3.8 Considerações finais sobre o capítulo

4. Monitoramento e avaliação da regulamentação para rotulagem e bulas de agrotóxicos, afins e preservativos de madeira no Brasil: proposição de indicadores e métricas

4.1 Desenho do modelo lógico da regulamentação para rotulagem e bulas de agrotóxicos, afins e preservativos de madeira no Brasil

4.1.1 Explicação do problema e referências básicas da regulamentação... 76

4.1.2 Estruturação da regulamentação para o alcance de resultados......... 77

4.1.3 Identificação dos fatores de contexto............................................... 77

4.1.4 Modelo lógico da regulamentação para rotulagem e bulas de agrotóxicos, afins e preservativos de madeira............................... 78

4.2 Fluxograma do modelo................................................................... 79

4.3 Construção da matriz de indicadores de MA para nova regulamentação de rotulagem e bulas de agrotóxicos................... 81

4.3.1 Avaliação do objetivo da regulamentação e resultados esperados...... 84

4.3.2 Identificação das partes interessadas........................................... 84

4.3.3 Definição dos tipos de indicadores................................................. 86

4.3.4 Definição dos critérios de seleção dos indicadores......................... 86

4.3.5 Proposição de indicadores candidatos.......................................... 87

4.4 Pré-teste da matriz de avaliação quantitativa de indicadores de MA..... 88

4.5 Resultados da atribuição dos pesos aos critérios pelo método fuzzy AHP

4.6 Resultados da avaliação quantitativa do grau de atendimento dos indicadores aos critérios pelo método fuzzy TOPSIS.

4.7 Conclusões finais sobre o capítulo

5. Conclusões

6. Referências bibliográficas.

Apêndice 1 - Listas de indicadores candidatos para as categorias 'Modelo de rótulo', 'Modelo de bula, e 'Instruções para preenchimento do quadro de informações médicas'.

Apêndice 2 - Instrumento de coleta de dados - Matriz de avaliação quantitativa de indicadores candidatos. 


\section{Siglas}

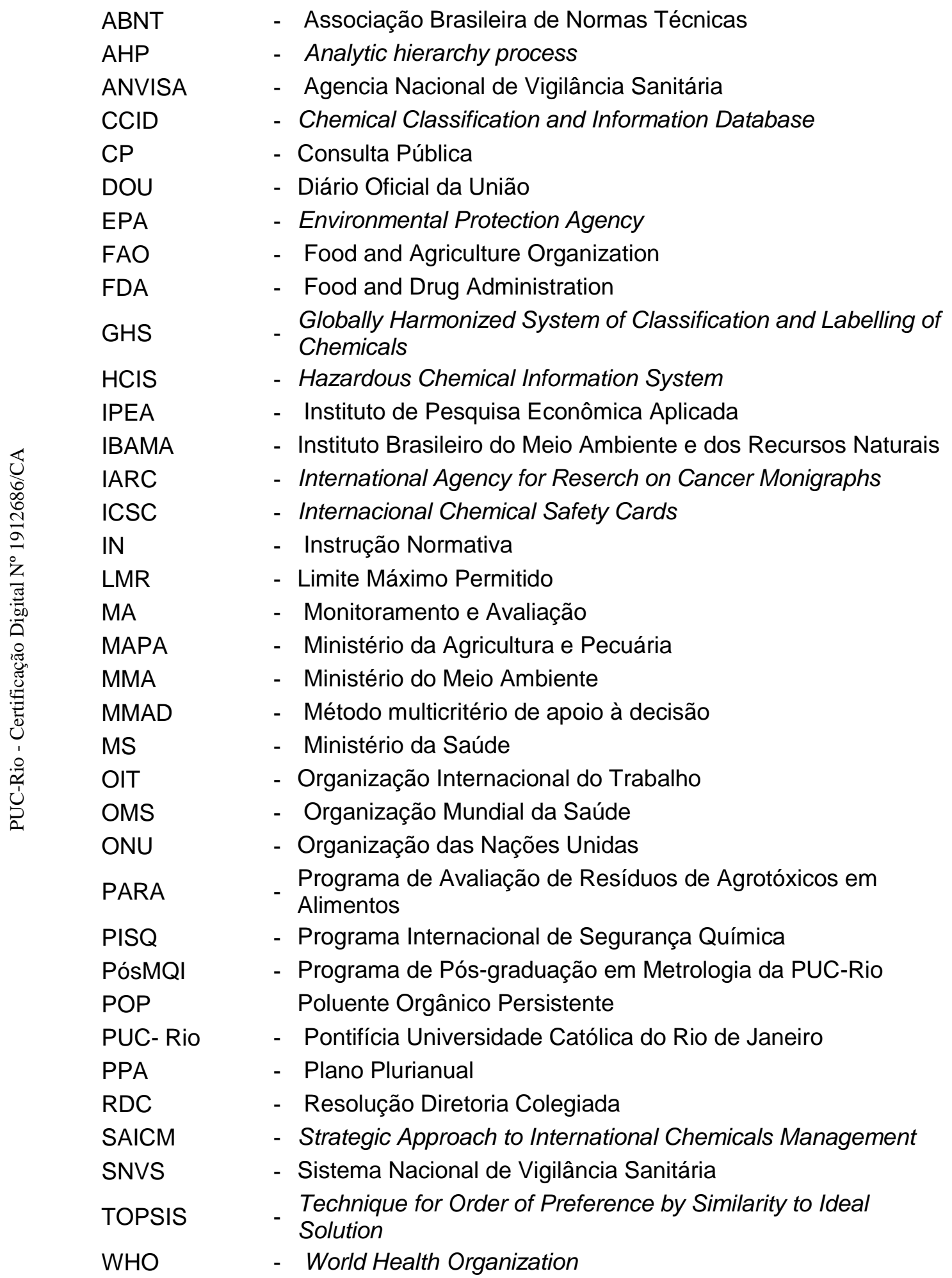




\section{Lista de figuras}

Figura 1.1 - Desenho da pesquisa, seus componentes e métodos 18

Figura 1.2 - Mapa conceitual da pesquisa................................... 19

Figura 2.1 - Sistema tripartite para registro de agrotóxicos no Brasil.............................................................. 36

Figura 2.2 - Apresentação dos pictogramas e classes de perigo, de acordo com o sistema GHS.

Figura 3.1 - Gestão do processo de implementação de uma iniciativa/programa................................................ 57

Figura 3.2 - Ciclo de gestão de programas governamentais.......... 58

Figura 3.3 - Fluxograma de construção de indicadores de um programa governamental.

Figura 3.4 - Estrutura hierárquica de decisão referente à regulamentação de rotulagem e bulas de agrotóxicos, afins e preservativos de madeira no Brasil

Figura 4.1 - Fatores relevantes de contexto para implementação da regulamentação para rotulagem e bulas de agrotóxicos, afins e preservativos de madeira no Brasil.

Figura 4.2 - Modelo lógico da regulamentação para rotulagem e bulas de agrotóxicos, afins e preservativos de madeira no Brasil

Figura 4.3 - Fluxograma do modelo para regulamentação em foco 80 


\section{Lista de quadros}

Quadro 2.1 - Quadro comparativo dos sistemas de classificação de perigo de produtos químicos

Quadro 2.2 - Arcabouço legal para registro de agrotóxicos no Brasil........ 35

Quadro 2.3 - Estudos empíricos sobre adoção do GHS ......................... 47

Quadro 3.1 - Exemplos de critérios para seleção de indicadores.............. 61

Quadro 3.2 - Quadro-resumo dos métodos multicritério de apoio à

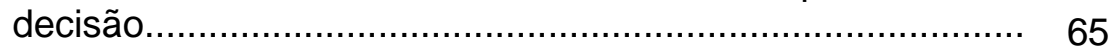

Quadro 3.3 - Proposição de critérios para validação dos indicadores.

Quadro 3.4 - Termos linguísticos e correspondentes números fuzzy triangulares para comparação pareada dos critérios............. 68

Quadro 4.1 - Base para a construção da matriz de indicadores de MA da regulamentação sobre rotulagem e bulas de agrotóxicos, afins e preservativos de madeira no Brasil.

Quadro 4.2 - Síntese da avaliação dos objetivos da regulamentação e resultados esperados.

Quadro 4.3 - Proposição de critérios para validação dos indicadores. 


\section{Lista de tabelas}

Tabela 2.1 - Critérios para a classificação toxicológica de acordo com a Portaria № 03, de 16 de janeiro de 1992.

Tabela 2.2 - Critérios para a classificação toxicológica de agrotóxicos de acordo com a RDC no 294/2019 da Anvisa.

Tabela 3.1 Indice de consistência aleatória (IR)

Tabela 4.1 -

Comparação pareada dos critérios de decisão.

Tabela 4.2 -

Pesos dos critérios e razões de consistência $(R C)$ das matrizes com os julgamentos respondentes (R1 a R5).

Tabela 4.3 Matriz de comparação pareada dos critérios de decisão com números fuzzy triangulares (NFT).

Tabela 4.4 Pesos atribuídos aos critérios de decisão.

Tabela 4.5 Matriz de decisão dos Indicadores para Modelo de Rótulo, avaliados à luz dos critérios C1 a C5.

Tabela 4.6 - Hierarquização dos Indicadores para Modelo de Rótulo pelo coeficiente de proximidade.

Tabela 4.7 - Matriz de decisão dos Indicadores para Modelo de Rótulo avaliados à luz dos critérios C1 a C5.

Tabela 4.8 - Hierarquização dos Indicadores para Modelo de Rótulo pelo coeficiente de proximidade.

Tabela 4.9 - Matriz de decisão dos Indicadores para Modelo de Bula, avaliados à luz dos critérios $\mathrm{C} 1 \mathrm{a} \mathrm{C} 5$.

Tabela 4.10 - Hierarquização dos Indicadores para Modelo de Bula pelo coeficiente de proximidade.

Tabela 4.11 - Matriz de decisão dos Indicadores de Instruções Médicas, avaliados à luz dos critérios $\mathrm{C} 1$ a $\mathrm{C} 5$.

Tabela 4.12 - Hierarquização dos Indicadores de Instruções Médicas pelo coeficiente de proximidade. 


\section{Introdução}

Atualmente, nos diversos setores da sociedade cresce a preocupação em relação ao uso de substâncias químicas na produção de alimentos, especialmente quanto ao emprego de agrotóxicos, considerados insumos essenciais à produção agrícola e à manutenção de altos níveis de produtividade do setor. Pessoas de qualquer idade, de diferentes nacionalidades e pertencentes a várias condições sociais, entram em contato diariamente com produtos perigosos ou ingerem alimentos com número alto de resíduos de agrotóxicos.

No Brasil, nos últimos anos ocorreram vários casos de intoxicação devido à utilização inadequada de agrotóxicos. Segundo o Relatório Nacional de Vigilância em Saúde de Populações Expostas a Agrotóxicos, elaborado pelo Ministério da Saúde e publicado em 2018, foram notificados mais de 86 mil casos de intoxicação pelo uso inadequado de agrotóxicos por parte dos produtores rurais. Ressalta-se que o número de casos de intoxicação pode ser maior, dependendo da capacidade de atuação das áreas de vigilância e assistência à saúde nos estados para detectar e notificar os casos (Brasil. Ministério da Saude, 2018).

Frente à repercussão dos eventos e a constante exposição dos indivíduos que manipulam e aplicam tais produtos químicos, a Agência Nacional de Vigilância Sanitária aprovou em 2019 um conjunto de Resoluções da Diretoria Colegiada (RDC) e uma Instrução Normativa (IN), a saber: RDC no 294/2019, RDC no 295/2019, RDC no 296/2019 e a IN 34/2019.

Destaca-se para fins da presente pesquisa a Resolução da Diretoria Colegiada RDC no 296/2019, aprovada em 29 de julho de 2019, que dispõe sobre as informações toxicológicas para rótulos e bulas de agrotóxicos, afins e preservativos de madeira (Anvisa, 2019a). Complementa esta Resolução, um guia para elaboração de rótulo e bula de agrotóxicos, afins e preservativos de madeira, revisado e publicado em 30 de setembro de 2019 (Anvisa, 2019b).

A RDC no 296/2019 estabelece mudanças importantes na rotulagem e bulas dos agrotóxicos, afins e preservativos de madeira no país, visando à adoção do uso 
de informações, palavras de alerta e imagens (pictogramas), buscando facilitar a identificação, por parte dos agricultores, dos potenciais perigos à vida e à saúde humana. Após publicação em Diário Oficial da União (DOU) na referida data, as empresas fabricantes de agrotóxicos tiveram um ano para se adequar aos novos padrões de rótulos e bulas. Essa iniciativa encontra-se em linha com uma das seis áreas programáticas endossadas pela Assembleia Geral das Nações Unidas para fortalecer os esforços internacionais relativos à gestão ambientalmente segura de produtos químicos.

De acordo com a Anvisa, o Brasil é um dos países que mais produz e exporta alimentos e sua legislação precisa atender, de forma segura e eficiente, o avanço do setor agropecuário. Para este setor, a Agência declara seu propósito de fazer com que os agricultores nos próximos anos tenham mais conhecimento sobre os produtos utilizados, tornando-os parceiros no controle de utilização dos agrotóxicos.

Compete à Anvisa avaliar as informações relativas à saúde humana submetidas pelas empresas em seus textos-bulas, quanto à adequabilidade do seu conteúdo e à relevância da informação veiculada. As informações avaliadas pela Anvisa referem-se a: (i) possíveis efeitos prejudiciais sobre a saúde humana; (ii) precauções para evitar danos às pessoas que aplicam ou manipulam agrotóxicos e afins, bem como a terceiros; (iii) símbolos de perigo e frases de advertência padronizadas; e (iv) instruções para casos de acidentes, abrangendo inclusive primeiros socorros, sintomas de alarme, antídotos e recomendações para os profissionais de saúde.

A revisão bibliográfica e a análise documental, conduzidas sob a perspectiva do tema central desta dissertação, confirmaram a oportunidade de se desenvolver uma sistemática de monitoramento e avaliação para que a Anvisa possa cumprir o propósito acima declarado e aperfeiçoar continuamente esta regulamentação. Pesquisas anteriores desenvolvidas por Mello (2015) e Criollo (2016) no âmbito do Programa PósMQI da PUC-Rio propuseram o emprego de métodos multicritério de apoio à decisão para a hierarquização de indicadores de monitoramento e avaliação de regulamentações na área de alimentos, focalizando, respectivamente a regulamentação de recolhimento de alimentos e da rotulagem de alimentos alergênicos, ambas aprovadas pela Anvisa. 
No contexto institucional no qual esta pesquisa se insere, considera-se que seus resultados propiciarão ao órgão regulador, bem como aos diversos atores envolvidos na implementação da regulamentação em foco, o ferramental adequado para que o cumprimento dos requisitos legais da RDC no 269/2019 possa ser efetivamente monitorado e avaliado.

Para a Anvisa, os resultados da pesquisa aqui reportados constituem elementos centrais para o desenvolvimento e implantação de uma sistemática de monitoramento e avaliação, na perspectiva de minimizar possíveis efeitos prejudiciais sobre a saúde humana e evitar danos às pessoas que aplicam ou manipulam agrotóxicos e afins, bem como a terceiros.

Finalmente, acredita-se que a ferramenta de classificação e hierarquização de indicadores por categoria de poderá ser útil para definição futura de indicadores de monitoramento e avaliação de outras regulamentações voltadas para a garantia de segurança do consumidor.

\section{1. Definição do problema de pesquisa}

Considerando-se a importância do monitoramento e avaliação como instrumento da gestão pública e a necessidade da Anvisa de dispor de indicadores para monitorar e avaliar a regulamentação sobre rotulagem e bulas de agrotóxicos no Brasil, definiu-se a seguinte questão principal a ser respondida ao longo da pesquisa:

"Que indicadores e respectivas métricas devem ser considerados pela Anvisa para monitorar e avaliar os resultados da regulamentação referente à rotulagem e bulas de agrotóxicos no Brasil, durante sua implementação"?

\section{2.}

\section{Objetivos: geral e específicos}

$\mathrm{Na}$ perspectiva de contribuir para a Anvisa implementar efetivamente uma sistemática de monitoramento e avaliação da regulamentação sobre rotulagem e bulas de agrotóxicos, afins e preservativos de madeira no Brasil, o objetivo geral desta dissertação é propor um conjunto de indicadores e métricas para o monitoramento e avaliação desta regulamentação, durante sua implementação. Em termos específicos, a dissertação busca: 
- Discutir a importância da regulamentação para rotulagem e bulas de agrotóxicos, afins e preservativos de madeira no contexto do novo marco regulatório da avaliação toxicológica de agrotóxicos no Brasil, como aprovado pela Anvisa em 2019;

- Identificar os aspectos da regulamentação sobre rotulagem e bulas de agrotóxicos, afins e preservativos de madeira no Brasil que necessitam de monitoramento e avaliação durante sua implementação;

- Elaborar o modelo lógico para fins da construção da matriz de indicadores de monitoramento e avaliação da regulamentação em foco;

- Desenvolver a ferramenta de seleção e classificação de indicadores de monitoramento e avaliação, com suporte de métodos de apoio à decisão multicritério combinados com lógica fuzzy;

- Propor indicadores e métricas para a Anvisa monitorar e avaliar a os resultados da regulamentação em foco, visando à efetiva adoção do uso de informações, palavras de alerta e imagens que facilitem a identificação, por parte dos agricultores, dos potenciais perigos à vida e à saúde humana.

\section{3. \\ Metodologia}

De acordo com a taxonomia proposta por Vergara (2002), a pesquisa pode ser considerada metodológica, descritiva e aplicada, quanto aos fins. A figura 1.1 apresenta a sequência da pesquisa em suas três grandes fases: (i) exploratória e descritiva; (ii) pesquisa aplicada; (iii) conclusivo-propositiva.

Quanto aos meios de investigação, a metodologia compreendeu pesquisa bibliográfica e análise documental sobre os temas centrais da pesquisa, como indicado na fase exploratória e descritiva da figura 1.1.

Quanto aos meios de investigação, a metodologia compreendeu pesquisa bibliográfica e documental sobre os temas centrais da pesquisa, como indicado na fase exploratória e descritiva da figura 1. Já na fase aplicada, utilizou-se o método de construção de indicadores proposto pelo Ministério do Planejamento, Orçamento e Gestão, integrado a dois métodos de apoio à decisão, combinados com lógica fuzzy: (i) o método fuzzy AHP para definição dos pesos dos critérios classificatórios; e (ii) fuzzy TOPSIS para hierarquização dos indicadores propostos 
por categoria de requisitos da regulamentação, a partir dos graus atribuídos pelos especialistas. Destacam-se como resultados da fase aplicada: (i) modelo lógico para proposição de indicadores para monitorar e avaliar a implementação da regulamentação em foco; (ii) ferramenta fuzzy multicritério para seleção e hierarquização dos indicadores inicialmente proposto; e (iii) um conjunto consistente de indicadores hierarquizados por categoria de requisitos legais da $\mathrm{RDC} \mathrm{n}^{\circ}$ 296/2019 a serem selecionados posteriormente pela Anvisa.
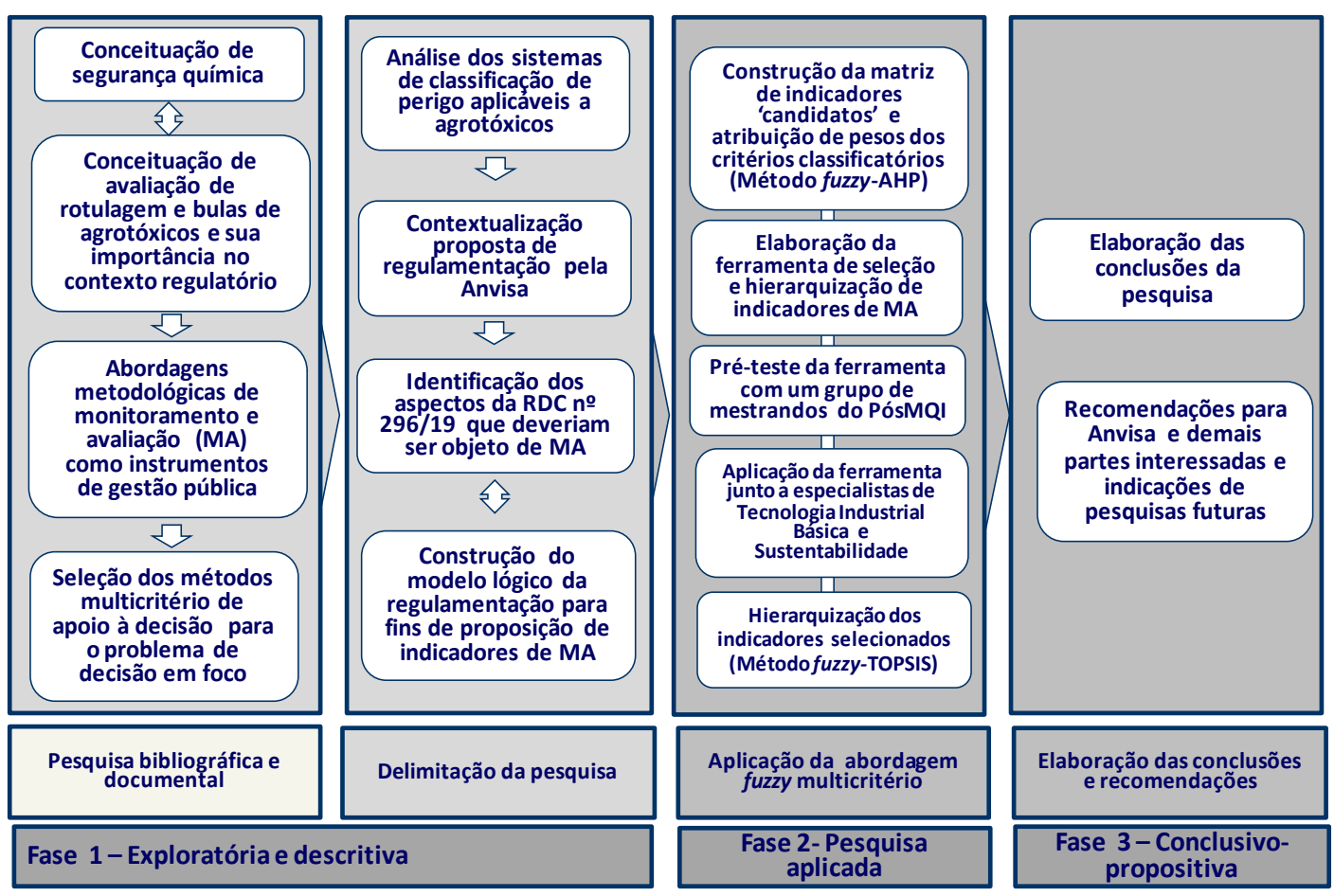

Figura 1.1 - Desenho da pesquisa, seus componentes e métodos Fonte: Elaboração própria.

\subsection{1.}

\section{Fase exploratória e descritiva}

Esta fase foi iniciada com pesquisa bibliográfica e análise documental, com o objetivo de levantar trabalhos conceituais e documentos de referência para delimitação do tema central da pesquisa - monitoramento e avaliação de regulamentação sobre rotulagem e bulas de agrotóxicos, afins e preservativos de madeira. Apresenta-se na figura 1.2 uma visão geral e esquemática dos resultados desta fase, representada no formato de um mapa conceitual, no qual o tema principal e os subtemas específicos contemplados no referencial teórico e normativo são integrados para responder a questão principal da pesquisa (enunciada no item 1.1). 


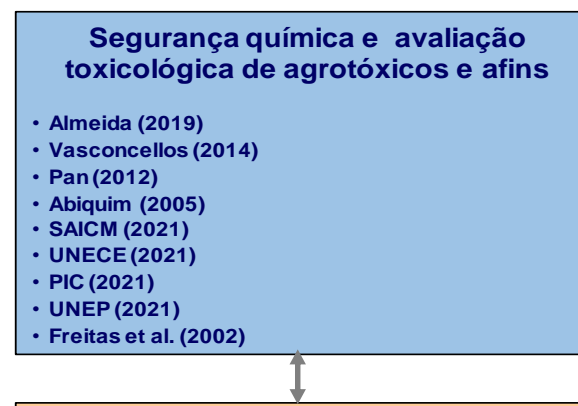

Revisão de sistemas de classificação
de perigo aplicáveis a agrotóxicos e
- GHS(UNECE) afins
- Classification of Pesticides by Hazard (WHO)
- International Agency for Research on Cancer
Monographs (IARC)
- International Chemical Safety Cards (ICSC)
- Guidelines on Highly Hazardous Pesticides
(FAO/OMS)
- EU Pesticides Database
- European Chemicals Agency - C\&L Inventory
- Carcinogenicity Evaluation - Database for
Chemical Information (UE EPA)
- Hazardous Chemical Information System (HCIS)
- Chemical Classification and Information Database
(CCID)
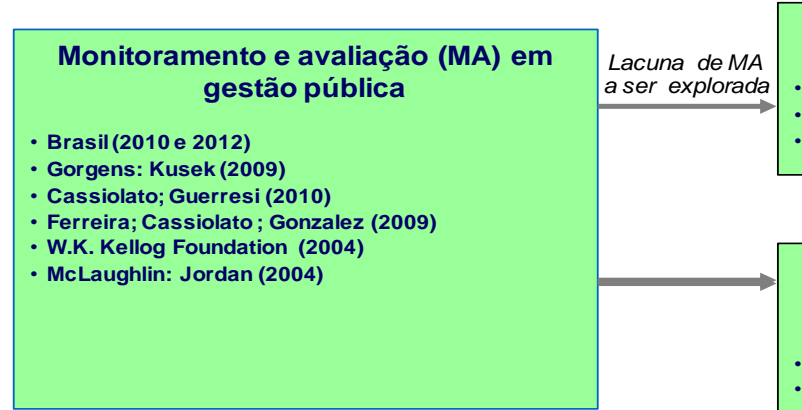

Figura 1.2 - Mapa conceitual da pesquisa métodos Fonte: Elaboração própria.

\begin{tabular}{l}
$\begin{array}{l}\text { Regulamentação sobre rotulagem e } \\
\text { bulas de agrotóxicos, afins e } \\
\text { preservativos de madeira no } \\
\text { contexto brasileiro }\end{array}$ \\
\begin{tabular}{l|l} 
- RDC no 296/19 elaborada pela Anvisa \\
- GHS (2019)
\end{tabular} \\
$\begin{array}{l}\text { entos } \\
\text { yais e } \\
\text { os }\end{array}$ \\
\hline
\end{tabular}

Construção do modelo lógico da regulamentação e proposição de indicadores de MA para a regulamentação em foco

- Modelo lógico da regulamentação

- Definição de critérios e atribuição de pesos aos critérios classificatórios para seleção dos Elaboracão de MA candidatos seleção e hierarquização de indicadores de

- Aplicação da abordagem híbrida fuzzy AHP. seleção Pela Anvisa$$
\text { Métodos fuzzy multicritério }
$$$$
\begin{aligned}
& \text { multicritério mais } \\
& \text { adequada }
\end{aligned}
$$

Métodos

aplicaveis
Saaty $(1977 ; 1990 ; 1991 ; 2000)$

- Hwang; Yoon (1981)

- Zadeh $(1965 ; 1973)$

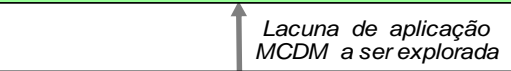

Estudos empíricos sobre MA para regulamentação na
alimentos Criollo (2016)
Mello (2015)

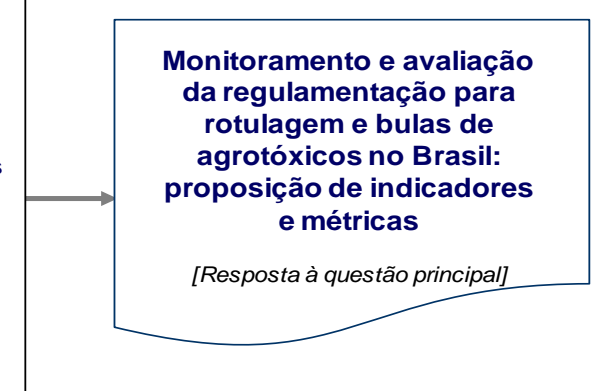

nitoramento e avaliação rotulagem e bulas de agrotóxicos no Brasil: e métricas r

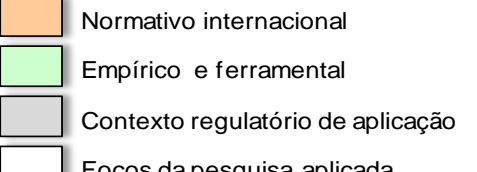




\subsection{2.}

\section{Fase de pesquisa aplicada}

A partir dos resultados da pesquisa bibliográfica e análise documental, desenvolveu-se a fase da pesquisa aplicada, conforme representado na figura 1,1 (fase 2 - Pesquisa Aplicada). Esta fase compreendeu as seguintes etapas: (i) construção da matriz de indicadores de MA e definição dos pesos dos critérios de classificação, utilizando-se o método fuzzy Analytical Hierarchy Process (fuzzy AHP); (ii) elaboração da ferramenta de seleção e hierarquização de indicadores de monitoramento e avaliação, conforme metodologia proposta pelo Ministério do Planejamento, Orçamento e Gestão (Brasil, 2010; 2012); (iii) realização de préteste da ferramenta com um grupo de cinco mestrandos do Programa de Pósgraduação em Metrologia da PUC-Rio, que estavam cursando no segundo semestre de 2020 a disciplina de 'Métodos Multicritério de Apoio à Decisão', visando sua melhoria e adequação para uso pelos especialistas; (iv) aplicação da ferramenta junto a outro grupo de cinco mestrandos do referido Programa, que haviam cursado junto com a autora as disciplinas de 'Sistemas de Avaliação da Sustentabilidade' e 'Fundamentos da Tecnologia Industrial Básica'; (v) aplicação dos métodos fuzzy AHP e fuzzy TOPSIS, a partir das respostas dos mestrandos, com o objetivo de selecionar e hierarquizar os indicadores, por categoria de requisitos da regulamentação em foco; e (vi) apresentação e discussão dos resultados.

\subsection{3.}

\section{Fase conclusivo-propositiva}

Formularam-se nesta última fase da pesquisa as conclusões e um conjunto de recomendações à Anvisa e aos diversos atores interessados na aplicação dos indicadores propostos e na efetiva implementação da regulamentação em foco. Encaminharam-se nesta fase propostas de estudos futuros, como desdobramentos naturais da presente pesquisa.

\section{4.}

\section{Estrutura da dissertação}

A dissertação encontra-se estruturada em cinco capítulos, incluindo esta introdução. 
No capítulo 2, discute-se a importância da segurança química, em geral, e da gestão do uso de agrotóxicos, em particular. Na sequência, apresentam-se e comparam-se dez sistemas de classificação de perigo aplicáveis a agrotóxicos, sendo cinco internacionais, com destaque para o sistema Globally Harmonized System of Classification and Labelling of Chemicals (GHS). Contextualizam-se o registro de agrotóxicos no Brasil e a atuação tripartite de três Ministérios (Agricultura, Saúde e Meio Ambiente) responsáveis, respectivamente, pela avaliação do desempenho agronômico, da toxicologia humana e da toxicologia ambiental. Tendo em vista o objetivo geral da presente pesquisa, apresenta-se como pano de fundo para o desenvolvimento da sua fase aplicada, o novo marco regulatório da avaliação toxicológica de agrotóxicos no Brasil.

No capítulo 3, caracterizam-se as atividades e ferramentas de monitoramento e avaliação (MA) como instrumentos da gestão pública, abordando-se a inicialmente conceituação e a função básica dos indicadores nessas atividades. Descreve-se a metodologia para construção de indicadores de MA, proposta pelo Ministério do Planejamento, Orçamento e Gestão (Brasil, 2010; 2012), como abordagem de escolha para a fase aplicada da presente pesquisa. Na sequência, apresenta-se uma visão geral dos principais métodos multicritério de apoio à decisão, com destaque para os métodos fuzzy AHP e fuzzy TOPSIS.

O capítulo 4 tem por objetivo apresentar e discutir os resultados da fase aplicada da pesquisa até a proposição de um conjunto consistente de indicadores para MA da referida regulamentação, respondendo a questão principal da dissertação. Neste capitulo apresenta-se o processo de construção da matriz quantitativa de indicadores de MA, com suporte dos referidos métodos multicritério de apoio à decisão e os seguintes resultados: (i) modelo lógico para proposição de indicadores para o monitoramento e avaliação da implementação da regulamentação em foco; (ii) abordagem metodológica fuzzy multicritério para hierarquização dos indicadores inicialmente propostos; e (iii) um conjunto de indicadores hierarquizados por categoria de requisitos legais da RDC n 296/2019 a serem selecionados posteriormente pela Anvisa.

Finalmente, no capítulo 5, formulam-se as conclusões da pesquisa e endereçam-se propostas para estudos futuros, como desdobramentos naturais e aprofundamento de aspectos relevantes que emergiram desta dissertação. 


\section{2 \\ Segurança química e avaliação toxicológica de agrotóxicos e afins: conceitos e sistemas de classificação}

Inicialmente, discute-se a importância da segurança química, em geral, e da gestão do uso de agrotóxicos e afins, em particular. Na sequência, apresentam-se e comparam-se dez sistemas de classificação de perigo aplicáveis a agrotóxicos, sendo cinco internacionais, com destaque para o sistema Globally Harmonized System of Classification and Labelling of Chemicals (GHS). Contextualizam-se o registro de agrotóxicos no Brasil e a atuação tripartite de três Ministérios (Agricultura, Saúde e Meio Ambiente) responsáveis, respectivamente, pela avaliação do desempenho agronômico, da toxicologia humana e da toxicologia ambiental. Tendo em vista o objetivo geral da presente pesquisa, apresenta-se em detalhe o novo marco regulatório da avaliação toxicológica de agrotóxicos no Brasil, ressaltando-se as diferenças entre a classificação de perigo baseada no sistema GHS e a classificação anterior estabelecida na Portaria SNVS MS nº 3/92.

\section{1. \\ Segurança química e gestão do uso de agrotóxicos}

A segurança química é um conceito global, desenvolvido para assegurar a proteção da saúde, da vida e das condições normais do ambiente, frente aos riscos decorrentes das atividades compreendidas no ciclo de vida das substâncias químicas. Consiste na utilização racional e consciente das substâncias e produtos químicos com vistas à proteção da saúde humana e do meio ambiente.

A segurança química é operacionalizada por meio de dispositivos legais e voluntários, bem como de instrumentos, mecanismos e práticas, que são aplicados ao longo de todo o ciclo de vida da substância, em busca de um equilíbrio entre os aspectos sociais, econômicos e ambientais. Segundo Vasconcellos (2014), são diversas as iniciativas internacionais voltadas para a segurança química, como a Strategic Approach to International Chemicals Management (SAICM), de 2006 (SAICM, 2021); a Convenção de Roterdã, aprovada em fevereiro de 2004, criando obrigações legais para a implementação do Procedimento de Consentimento 
Prévio Informado (Vasconcellos, 2014); a Convenção de Estocolmo, que entrou em vigor em maio de 2004 para proteger a saúde humana e o ambiente dos poluentes orgânicos persistentes (POPs) (Vasconcellos, 2014); a Convenção de Basileia, aprovada em nível global em 1992, abordando o controle dos movimentos transfronteiriços de resíduos perigosos e sua eliminação (Vasconcellos, 2014); o Protocolo de Montreal, que foi uma ação regulamentadora coordenada globalmente para a gestão dos produtos químicos que destroem o ozônio (UNEP, 2021); e o sistema GHS - Globally Harmonized System of Classification and Labeling of Chemicals (GHS) que propõe elementos harmonizados de comunicação de perigos, incluindo rótulos e fichas de segurança (UNECE, 2021). Elaborado pelas Nações Unidas, este sistema é gerido pela Comissão Econômica para a Europa (UNECE) desde 2002 e foi adotado no Brasil como base para o novo marco regulatório da avaliação toxicológica de agrotóxicos, aprovado pela Anvisa em meados de 2019, após diversas consultas públicas.

Sendo assim, a segurança química é entendida como um conjunto de estratégias para o controle e a prevenção dos efeitos adversos de substâncias químicas para o ser humano e o meio ambiente (Freitas et al., 2002; Vasconcellos, 2014; Pan, 2021).

Efeitos adversos ao meio ambiente e à saúde ocasionados por agentes químicos dependem, dentre outras, das suas propriedades físicas e químicas, características toxicológicas e eco toxicológicas, da forma de uso, via e intensidade de exposição, bem como das especificidades dos seres vivos submetidos à tal exposição.

Segundo a Organização Mundial de Saúde, a Toxicologia é a ciência que estuda os efeitos nocivos decorrentes das interações de substâncias químicas com o organismo, abrangendo uma vasta área do conhecimento, onde atuam profissionais de diversas formações. A toxicologia estuda a interação entre os químicos e os sistemas biológicos com o objetivo de determinar quantitativamente o potencial do químico capaz de provocar efeitos adversos para os diferentes tipos de organismos. A toxicologia investiga, igualmente, a natureza destes efeitos adversos, a sua incidência, o seu mecanismo de produção, os fatores que influenciem o seu desenvolvimento e a sua reversibilidade. 
Inúmeros estudos têm comprovado a estreita relação entre agravos à saúde humana e danos aos ecossistemas naturais e urbanos decorrentes da exposição aos produtos químicos, com consequências socioeconômicas negativas para a sociedade como um todo. Os riscos associados aos produtos químicos são de natureza complexa, podendo ser globais e gerar efeitos a curto, médio e longo prazo, com possibilidade de afetar tanto as atuais quanto as futuras gerações. Além de exigir decisões emergenciais, dependendo da natureza e gravidade do problema e/ou impacto.

Como questão de interesse público, a segurança química envolve vários níveis e setores governamentais, em especial os que atuam em questões relativas ao ambiente, trabalho, saúde, transporte e o desenvolvimento econômico e tecnológico. Além de estabelecer normas, fiscalizar o cumprimento da legislação, tratar dos instrumentos punitivos, orientar o setor produtivo bem como a própria população, os órgãos públicos têm papel fundamental na elaboração e implementação da política de segurança química. A questão da segurança química tem para o Brasil importante relevância, tendo em vista o país estar entre os dez maiores produtores mundiais do setor e de ser o maior produtor e importador, no gênero, da América Latina.

Segundo Pan (2012), fica evidente que a segurança química é um tema de preocupação internacional. Em 1972, de acordo com as recomendações da Conferência Mundial das Nações Unidas sobre Meio Ambiente Humano (CNUMH) que ocorreu em Estocolmo, estabeleceu-se, em 1980, o Programa Internacional de Segurança Química (PISQ), uma parceria da Organização Mundial de Saúde (OMS), da Organização Mundial do Trabalho (OIT) e do Programa das Nações Unidas para o Meio Ambiente (PNUMA), cujo objetivo era promover uma base científica para que os países pudessem desenvolver suas próprias medidas de segurança química.

De acordo com Pan (2012), em 1990, a Organização Mundial do Trabalho (OIT) promulgou a Convenção 170, por considerar essencial a prevenção de doenças e acidentes causados por produtos químicos no trabalho e a redução de sua incidência. Essa Convenção foi um marco por levantar mundialmente a discussão sobre utilização de produtos químicos no trabalho. Neste documento, ficou estabelecida a necessidade dos países ou organizações de estabelecerem a 
aplicação de um sistema de comunicação de perigos por meio de fichas de informações e rótulos.

Sob esta demanda, em 1992 durante a Conferência das Nações Unidas sobre o Meio Ambiente e Desenvolvimento (UNCED - RIO 92), que teve como resultado a ratificação de uma agenda mundial com objetivos e metas objetivando a sustentabilidade global no século XXI, conhecida popularmente como Agenda 21, inclui-se na referida Agenda o capítulo 19 - "Manejo ecologicamente saudável das substâncias químicas tóxicas, incluída a prevenção do tráfico internacional ilegal dos produtos tóxicos e perigosos" - item B - Harmonização da classificação e da rotulagem dos produtos químicos (Ministério do Meio Ambiente).

Os sistemas de classificação e rotulagem definem os potenciais perigos dos produtos químicos para todos aqueles potencialmente expostos. Existem sistemas em níveis nacional, regional e internacional, como abordado adiante.

Segundo Abiquim (2005), esses sistemas nem sempre são compatíveis, o que obriga as empresas a manter vários esquemas para atender as exigências de diferentes agências reguladoras. Com o intuito de estabelecer critérios harmonizados para a classificação e rotulagem dos perigos de produtos químicos, internacionalmente, desenvolveu-se através da Organização das Nações Unidas (ONU) - o sistema Globally Harmonized System of Classification and Labelling of Chemicals (sigla em inglês, GHS) informando esses perigos aos seus usuários por meio de pictogramas, frases em rótulos e fichas de dados de segurança.

De acordo com uma pesquisa realizada pela Organização das Nações Unidas para Alimentação e Agricultura (sigla em inglês, FAO), em 2013, o Brasil ocupava o primeiro lugar no ranking de sete países, dentre eles: Estados Unidos, China, Japão, França e Canadá, como o maior consumidor de agrotóxicos em números absolutos, tendo gasto aproximadamente 10 bilhões com esses produtos no ano de 2013. Esta posição no ranking muda, de acordo com a perspectiva de análise, podendo ser por quantidade de agrotóxicos por área cultivada e volume de produção agrícola (FAO, 2013).

Segundo o Instituto Brasileiro do Meio Ambiente e dos Recursos Naturais Renováveis. (Ibama), o Brasil usou cerca de 540 mil toneladas de agrotóxicos no ano de 2017. Acredita-se então que o Brasil utiliza uma expressiva quantidade desses produtos, considerada necessária por diversos especialistas, para manter a 
produção no país, que possui, obviamente, condições ambientais diferentes de outros países (Ibama, 2018).

Muitos são os desafios encontrados sobre a utilização correta dos agrotóxicos, dentre eles, destacam-se: (i) o atendimento ao período de carência (período entre o plantio e colheita e colheita e comercialização); (ii) o uso de agrotóxicos não autorizados pela legislação brasileira; e (iii) observação aos Limites Máximos de Resíduos (LMR) autorizados.

A Anvisa considera que a adoção das novas regras advindas do novo marco regulatório para avaliação toxicológica de agrotóxicos, principalmente aquelas referentes aos rótulos e bulas desses produtos, fará com que o produtor rural esteja mais seguro durante sua aplicação no campo. De acordo com Almeida (2019), a Anvisa entende que a adoção do GHS na gestão de agrotóxicos padroniza a comparação da ação tóxica entre os produtos, tornando a avaliação dos estudos toxicológicos mais eficiente. Com isso, o Brasil passará a ter regras harmonizadas com aquelas adotadas em países da União Europeia e da Ásia, cuja regulamentação para rotulagem e bulas de agrotóxicos também seguem o sistema GHS.

\section{2.}

\section{Sistemas de classificação de perigo aplicáveis a agrotóxicos}

Nesta seção, descrevem-se a analisam-se dez sistemas de classificação de perigo aplicáveis a agrotóxicos, sendo cinco em nível internacional e os demais em nível regional (Europa) ou nacional (EUA, Nova Zelândia e Austrália).

\subsection{1. \\ Globally Harmonized System of Classification and Labelling of Chemicals - GHS (ONU)}

Segundo a Food and Agriculture Organization (FAO) da Organização das Nações Unidas (ONU), o sistema Globally Harmonized System of Classification and Labelling of Chemicals (GHS) estabelece critérios de classificação para riscos físicos, à saúde e ao meio ambiente de produtos químicos, juntamente com elementos de comunicação de risco associados, principalmente pictogramas, palavras de sinalização e declarações de perigo para uso em etiquetas. A classificação de perigo definida no GHS refere-se principalmente aos perigos 
decorrentes das propriedades intrínsecas dos produtos químicos e misturas de produtos químicos, incluindo os agrotóxicos.

O GHS visa garantir que informações sobre riscos físicos e toxicidade de produtos químicos estejam disponíveis, a fim de melhorar a proteção da saúde humana e do meio ambiente durante o manuseio, transporte e uso desses produtos químicos. Este sistema também fornece uma base para a harmonização de regras e regulamentos sobre produtos químicos nos níveis nacional, regional e mundial.

Diferentemente da classificação de pesticidas por risco recomendada pela OMS, o sistema GHS não classifica produtos químicos individualmente, pois parte do pressuposto básico que tal classificação deve ser conduzida pelas autoridades reguladoras nacionais ou regionais, com base nos critérios estabelecidos em seu sistema de classificação. Para tal, o GHS fornece critérios para a classificação dos produtos químicos puros, fórmulas sobre como calcular a classificação de produtos diluídos, bem como critérios de corte ou limites de concentração, indicando como os produtos diluídos podem ou não ser classificados (por exemplo, pela toxicidade crônica).

A primeira edição do GHS, que pretendia servir de base inicial para a implementação global do sistema, foi adotada em dezembro de 2002 e publicada em 2003. Desde então, o GHS tem sido atualizado, revisado e aprimorado a cada dois anos. A versão mais recente do GHS pode ser encontrada na sua página institucional na internet da United Nations Economic Commission for Europe (UNECE).

\subsection{2.}

\section{Classification of Pesticides by Hazard (WHO)}

É um documento elaborado pela World Health Organization (WHO) que estabelece um sistema de classificação para distinguir entre as formas mais e menos perigosas de pesticidas selecionados com base no risco agudo para a saúde humana, que é o risco de exposições únicas ou múltiplas em um período relativamente curto. Leva em consideração a toxicidade da substância ativa técnica e também descreve métodos para a classificação de formulações.

A classificação de pesticidas por perigo, recomendada pela OMS, categoriza os ingredientes ativos de pesticidas de acordo com sua toxicidade aguda por via 
oral e dérmica. Para alguns pesticidas, a toxicidade crônica também foi levada em consideração.

A classificação final de qualquer produto pesticida deve ser feita por formulação. A classificação dada nas tabelas no documento da OMS é de ingredientes ativos e constitui apenas o ponto de partida para a classificação final de uma formulação real. É preferível que a classificação final de uma formulação se baseie nos dados de toxicidade obtidos nessa formulação específica.

A Classificação da OMS 2009 foi alinhada com o sistema GHS, porém seus critérios de classificação são distintos daquele sistema. A classificação de pesticidas recomendada pela OMS por risco e as diretrizes para a classificação de 2009 estão disponíveis no site institucional da OMS.

\subsection{3.}

\section{Classificação pela International Agency for Research on Cancer Monographs (IARC)}

A International Agency for Research on Cancer Monographs (IARC) é uma instituição especializada da Organização Mundial da Saúde (OMS) que realiza análises de fatores ambientais que podem aumentar o risco de câncer humano, incluindo alguns pesticidas. Os agentes cancerígenos identificados pela Agência são classificados de acordo com o potencial carcinogênico e publicados em uma lista, que é atualizada regularmente e disponibilizada em formato digital no site institucional da Agência.

\subsection{4.}

\section{International Chemical Safety Cards (ICSC)}

O International Chemical Safety Cards (ICSC) é um banco de dados compilado por um grupo de cientistas que trabalham para instituições científicas especializadas em saúde e segurança ocupacional, coordenado pela Organização Mundial da Saúde (OMS) e pela Organização Internacional do Trabalho (OIT), com a cooperação da Comissão Europeia.

O ICSC fornece informações essenciais de segurança e saúde sobre produtos químicos de maneira clara e concisa e em formato fixo, podendo ser acessado pela internet através da International Labour Organization (ILO). Atualmente, adota três classificações distintas, a saber: (i) classificação de perigo da União Europeia; 
(ii) classificação da ONU para transporte de mercadorias perigosas; e (iii) classificação do GHS.

\subsection{5.}

\section{Guidelines on Highly Hazardous Pesticides (FAO/OMS)}

Em 2016, a FAO/OMS desenvolveu diretrizes sobre pesticidas altamente perigosos (sigla em inglês, HHPs) elaborando artigos específicos para integrar o Código de Conduta Internacional sobre Gerenciamento de Pesticidas. O documento que reúne as referidas diretrizes tem como objetivo fornecer orientação aos países sobre como interpretar e aplicar esses artigos de maneira eficaz, a fim de reduzir os riscos apresentados por estes pesticidas.

Os países são incentivados a identificar os HHPs em uso, avaliar os riscos envolvidos e decidir sobre as medidas apropriadas para mitigá-los. Essas diretrizes se aplicam a todos os pesticidas, incluindo agrotóxicos, saúde pública, uso doméstico, utilidades e pesticidas industriais.

\subsection{6.}

\section{EU Pesticides Database (Europa)}

A EU Pesticides Database é uma base de dados sobre pesticidas da União Europeia disponível para acesso na internet, contendo as avaliações e classificações de perigo de pesticidas usados como produtos fitofarmacêuticos. Se um pesticida for aprovado e nenhuma classificação de perigo estiver listada, isso implica que o composto não representa um dos perigos, conforme definido no Regulamento da UE 1272/2008 sobre classificação, rotulagem e embalagem.

Para pesticidas não aprovados ou avaliados por meio do sistema regional de registro de pesticidas da UE, a classificação de perigo pode estar ausente na $E U$ Pesticides Database. Nesse caso, o banco de dados European Chemicals Agency $(E C H A)$ pode ser consultado, pois fornece informações complementares às da $E U$ Pesticides Database.

\subsection{7.}

\section{European Chemicals Agency - C\&L Inventory (Europa)}

A classificação da UE de substâncias químicas segue o sistema GHS. No entanto, a ECHA também classifica produtos químicos individuais e dentre esses, os pesticidas. Essas classificações, palavras de sinalização associadas, símbolos de 
perigo e declarações de perigo podem ser acessadas no inventário de classificação e rotulagem da ECHA (C\&L), através de um banco de dados disponível na internet.

\subsection{8. \\ US EPA Carcinogenicity Evaluation - Database for Chemical Information (UE EPA)}

Trata-se de um banco de dados direcionado para pesquisa de informações científicas sobre produtos químicos específicos para pesticidas. A Environmental Protection Agency (EPA) dos EUA publica uma lista, atualizada anualmente, de produtos químicos avaliados por seu potencial cancerígeno.

Esta lista representa o risco potencial de carcinogenicidade para o produto químico, sem levar em consideração as informações de exposição. Por essa razão, a classificação não se destina a ser usada independentemente da avaliação de risco completa para o produto químico.

\subsection{9.}

\section{Hazardous Chemical Information System (HCIS) (Austrália)}

O Hazardous Chemical Information System (HCIS), da Austrália, é acessível no site intitucional da Safe Work Australia, que fornece classificações de perigo de produtos químicos de acordo com o GHS; com base em fontes nacionais e outras autorizadas, como por exemplo, a Agência Europeia de Produtos Químicos (ECHA) e o Esquema Nacional de Notificação e Avaliação de Químicos Industriais (NICNAS). O sistema também permite pesquisar padrões de exposição australianos no local de trabalho.

A Safe Work Australia monitora a qualidade das informações disponíveis no HCIS e atualiza as informações regularmente. No entanto, a Safe Work Australia não faz nenhuma representação ou garantia sobre a precisão, confiabilidade ou integridade de qualquer material contido no HCIS.

É de responsabilidade do fabricante e/ou importador australiano determinar se o produto é um produto químico perigoso e, se for o caso, classificá-lo corretamente. Sendo assim, o Hazardous Chemical Information System tem caráter informativo, e a avaliação das propriedades de risco são realizadas por fontes autorizadas. 


\subsubsection{0.}

\section{Chemical Classification and Information Database (CCID) (Nova Zelândia)}

O Chemical Classification and Information Database (CCID), da Nova Zelândia, encontra-se disponível no site da Environmental Protection Authority daquele país. Os produtos químicos no CCID são classificados de acordo com os regulamentos de Substâncias Perigosas e Novos Organismos (HSNO) da Nova Zelândia. A codificação das classes de perigo do HSNO é diferente da adotada no sistema GHS, embora os critérios de classificação sejam semelhantes.

\subsubsection{1.}

\section{Análise comparativa dos sistemas de classificação de perigo}

O quadro 2.1 sintetiza os sistemas de classificação de perigos aplicáveis a agrotóxicos que foram abordados neste capítulo.

Quadro 2.1 - Quadro comparativo dos sistemas de classificação de perigo de produtos químicos

\begin{tabular}{|c|c|c|}
\hline Sistema & $\begin{array}{l}\text { Classificação de } \\
\text { agrotóxicos }\end{array}$ & $\begin{array}{l}\text { Alinhamento ao } \\
\text { GHS }\end{array}$ \\
\hline $\begin{array}{l}\text { Globally Harmonized System of Classification and } \\
\text { Labelling of Chemicals - GHS (ONU) }\end{array}$ & Não & Sim \\
\hline Classification of Pesticide by Hazard (WHO) & Sim & Não \\
\hline $\begin{array}{l}\text { Agents Classified by the International Agency for } \\
\text { Research on Cancer Monographs (IARC) }\end{array}$ & Sim & Não \\
\hline International Chemical Safety Cards (ICSC) & Sim & Sim \\
\hline Guidelines on Highly Hazardous Pesticides (FAO) & Não & Sim \\
\hline EU Pesticides Database (Europa) & Sim & Sim \\
\hline C\&L Inventory - European Chemicals Agency (Europa) & Sim & Sim \\
\hline $\begin{array}{l}\text { US EPA Carcinogenicity Evaluation - Database for } \\
\text { Chemical Information (EUA) }\end{array}$ & Sim & Não \\
\hline $\begin{array}{l}\text { Hazardous Chemical Information System } \\
\text { (Austrália) }\end{array}$ & Sim & Sim \\
\hline $\begin{array}{l}\text { Chemical Classification and Information Database } \\
\text { (CCID) (Nova Zelândia) }\end{array}$ & Sim & Não \\
\hline
\end{tabular}

Fonte: www.fao.org/pesticide-registration-toolkit/tool/page/pret/hhp/hazard-classifications\#ghs

Conforme as informações do quadro 2.1, pode-se constatar que dois dos sistemas de classificação de perigo de produtos químicos - o Globally Harmonized System of Classification and Labelling of Chemicals (GHS) e as Guidelines on Highly Hazardous Pesticides não abordam especificamente os produtos agrotóxicos em seus sistemas classificatórios. Todavia, visando à proteção da saúde humana e do meio ambiente, durante o manuseio, transporte e uso de agrotóxicos, ambos os sistemas fornecem critérios para a classificação dos 
ingredientes ativos dos agrotóxicos, além de informações sobre toxicidade aguda e crônica e orientações de como diminuir os riscos físicos e de toxicidade desses produtos.

Os demais sistemas propõem classificações dos agrotóxicos, distinguindo-os entre as formas mais e menos perigosas, com base no risco agudo para a saúde humana, ou seja, o risco de exposições únicas ou múltiplas em um período relativamente curto. Destaca-se ainda que quatro dos dez sistemas não se alinham aos critérios de classificação do sistema GHS. São eles: Classification of Pesticide by Hazard (WHO), Agents Classified by the International Agency for Research on Cancer Monographs (IARC), US EPA Carcinogenicity Evaluation - Database for Chemical Information (EUA) e Chemical Classification and Information Database (CCID) (Nova Zelândia).

Considerando-se a realidade do grande volume de produtos químicos comercializados em nível global e a necessidade de se desenvolver programas nacionais para garantir seu uso, transporte e descarte seguros, reconhece-se que o alinhamento aos critérios do sistema GHS propicia uma abordagem internacionalmente harmonizada para classificação e rotulagem dos produtos químicos, em especial para a gestão do uso de agrotóxicos. Uma vez que os países tenham informações consistentes e apropriadas sobre os produtos químicos que importam ou produzem em seus próprios países, a infraestrutura para controlar a exposição aos agrotóxicos e proteger os seres humanos e o meio ambiente pode ser estabelecida de maneira abrangente.

\section{3.}

\section{Marco regulatório da avaliação toxicológica de agrotóxicos no Brasil}

Discute-se o arcabouço legal e a estrutura tripartite responsável pelo registro de agrotóxicos no Brasil como pano de fundo para descrever em maior profundidade as mudanças propostas na recente revisão do marco regulatório da avaliação toxicológica de agrotóxicos no país em geral, e em especial as informações toxicológicas que deverão contar dos rótulos e bulas, segundo a RDC $n^{\circ} 296 / 2019$. 


\subsection{1.}

\section{Arcabouço legal para registro de agrotóxicos no Brasil}

Segundo Pelaez (2011), a evolução da indústria de agrotóxicos está diretamente ligada ao processo de modernização da agricultura no período pós II Guerra, baseado no uso intensivo de insumos químicos, biológicos e mecânicos. No Brasil, este processo consolidou-se ao longo dos anos 1970, simultaneamente à constituição de um parque industrial de insumos para a agricultura, resultante da política de substituição de importações.

Alguns fatores contribuíram para o crescimento das indústrias de agrotóxicos no Brasil. Como a criação em 1975, do Programa Nacional de Defensivos Agrícolas, no âmbito do II Plano Nacional de Desenvolvimento, proporcionando recursos financeiros para a criação de empresas nacionais e a instalação de subsidiárias de empresas transnacionais no país. Outro fator importante foi a oferta de crédito de custeio, necessário à criação de uma demanda em larga escala de insumos para a agricultura, viabilizado pela criação do Sistema Nacional de Crédito Rural em 1965.

Além disso, a existência de um marco regulatório defasado e pouco rigoroso, baseado no Regulamento de Defesa Sanitária Vegetal de 1934, que sofreu alterações significativas em 1978, mas permaneceu em vigor até 1989, facilitou o rápido registro de substâncias agrotóxicas. Em 1989 entrou em vigor a Lei 7.802 que regulamenta a fabricação e o uso dos agrotóxicos no Brasil, substituindo o antigo regulamento de 1934, tornando o processo de registro de agrotóxicos mais exigente e detalhado (Pelaez, 2011).

Com a implantação da Lei 7.802/1989, conhecida como a Lei dos Agrotóxicos, regulamentada pelo Decreto 4.074/2002, a estrutura de registro dos agrotóxicos passou a ser compartilhada, de forma tripartite, pelos Ministérios da Agricultura, da Saúde e do Meio Ambiente. Conforme veremos na seção a seguir.

Como principais mudanças a partir da nova legislação, destacam-se: (i) a proibição do registro de novos agrotóxicos, caso a ação tóxica deste não seja igual ou menor do que a de outros produtos já existentes no mercado destinados ao mesmo fim, e (ii) a possibilidade de impugnação ou cancelamento do registro por solicitação de entidades representativas da sociedade civil (Brasil, 1989).

$\mathrm{Na}$ busca por uma rastreabilidade maior das infrações causadas pelos agrotóxicos, todos os agentes diretamente envolvidos no manuseio de agrotóxicos, 
desde os produtores até os aplicadores dos produtos, devem cadastrar-se nos órgãos competentes. Instituiu-se a obrigatoriedade do receituário agronômico para a venda de agrotóxicos e foram estabelecidas as normas e padrões das embalagens (Brasil, 1989).

Segundo Fonseca (2018), a Lei $7.802 / 1989$ trata-se de um sistema complexo e altamente regulado, que estabelece um conjunto de condutas a serem observadas tanto pelos entes estatais reguladores como pelas pessoas físicas e jurídicas do setor privado envolvidas em uma ou mais atividades. De acordo com Pelaez (2011), embora a lei tenha apresentado diversos avanços, demonstrando preocupação com os possíveis efeitos nocivos dos agrotóxicos sobre o meio ambiente e a saúde humana, ainda havia pontos críticos em relação aos parâmetros de avaliação e à atribuição de fiscalização do poder público.

No final da última década, a Anvisa identificou a necessidade de rever os processos de classificação e registros de agrotóxicos, do ponto de vista toxicológico. A Agência declarou um atraso de mais de vinte e seis anos, sendo necessária a incorporação de novas regras ao sistema já existente, para que o Brasil estivesse de acordo com o que é praticado em nível internacional.

Após amplos debates e consultas públicas, a Anvisa aprovou em julho de 2019 o novo marco regulatório para avaliação toxicológica de agrotóxicos. O novo marco é composto por três Resoluções da Diretoria Colegiada e uma Instrução Normativa, sendo elas: RDC no 294/2019, RDC no 295/2019. RDC n $296 / 2019$ e IN no $34 / 2019$.

O novo marco regulatório para avaliação toxicológica de agrotóxicos substitui a Portaria SNVS MS n03/1992 que fala sobre diretrizes e orientações referentes à autorização de registros, renovação de registro e extensão de uso de produtos agrotóxicos e afins. Dentre as principais mudanças propostas pelo novo marco regulatório para avaliação toxicológica de agrotóxicos, destacam-se as modificações nos rótulos e bulas dos produtos e a classificação toxicológica. Também tem grande visibilidade, a questão da revisão da lista de componentes não autorizados para uso em agrotóxicos e afins no Brasil.

As novas mudanças tiveram como base de padronização para produtos químicos o sistema GHS e as classificações toxicológicas passaram de quatro para seis. A Anvisa espera que com esse novo marco regulatório, o Brasil passe a adotar padrões de classificações similares aos já adotados internacionalmente, e 
que seja estabelecida uma comunicação mais clara dos perigos que os agrotóxicos oferecem à saúde humana.

O quadro 2.2 sumariza o arcabouço legal para o registro de agrotóxicos no Brasil, numa perspectiva histórica.

Quadro 2.2 - Arcabouço legal para registro de agrotóxicos no Brasil

\begin{tabular}{|c|c|}
\hline Documento normativo & Descrição \\
\hline Lei $7.802 / 89$ & $\begin{array}{l}\text { Dispõe sobre a pesquisa, a experimentação, a produção, a embalagem e } \\
\text { rotulagem, o transporte, o armazenamento, a comercialização, a } \\
\text { propaganda comercial, a utilização, a importação, a exportação, o destino } \\
\text { final dos resíduos e embalagens, o registro, a classificação, o controle, a } \\
\text { inspeção e a fiscalização de agrotóxicos, seus componentes e afins, e dá } \\
\text { outras providências. }\end{array}$ \\
\hline Decreto 4.074/02 & Decreto regulamentador da Lei 7.802/1989 \\
\hline Decreto 5.549/05 & $\begin{array}{l}\text { Dá nova redação e revoga dispositivos do Decreto 4.074/2002 em relação } \\
\text { aos critérios para a utilização de componentes. }\end{array}$ \\
\hline Decreto $5.981 / 06$ & $\begin{array}{l}\text { Dá nova redação e inclui dispositivos ao Decreto 4.074/2002 em relação } \\
\text { ao registro de produtos técnicos por equivalência. }\end{array}$ \\
\hline Decreto $6.913 / 09$ & $\begin{array}{l}\text { Acresce dispositivos ao Decreto } 4.074 / 2002 \text { sobre registro ou a } \\
\text { reavaliação de produtos fitossanitários com uso aprovado na agricultura } \\
\text { orgânica. }\end{array}$ \\
\hline Portaria MS 3/92 & $\begin{array}{l}\text { Ratifica os termos das "diretrizes e orientações referentes à autorização } \\
\text { de registros, renovação de registro e extensão de uso de produtos } \\
\text { agrotóxicos e afins - } \mathrm{n}^{\circ} 1 \text {, de } 9 \text { de dezembro de } 1991 \text {. }\end{array}$ \\
\hline Portaria IBAMA 84/96 & $\begin{array}{l}\text { Estabelece procedimentos a serem adotados junto ao IBAMA para efeito } \\
\text { de registro e avaliação do potencial de periculosidade ambiental de } \\
\text { agrotóxicos, seus componentes e afins. }\end{array}$ \\
\hline $\begin{array}{ll}\text { Instrução } & \text { Normativa } \\
\text { MAPA 36/09 }\end{array}$ & $\begin{array}{l}\text { Estabelece as diretrizes e exigências para a realização de pesquisa e } \\
\text { experimentação, para credenciamento de entidades que as realizam e } \\
\text { para submissão de pleitos de registro. }\end{array}$ \\
\hline $\begin{array}{l}\text { Instrução }{ }^{\text {Normativa }} \\
\text { Conjunta 25/05 }\end{array}$ & $\begin{array}{l}\text { Dispões sobre procedimentos a serem adotados junto ao MAPA, } \\
\text { ANVISA, IBAMA, para efeito das avaliações preliminares e de obtenção } \\
\text { de RET - Registro Especial Temporário. }\end{array}$ \\
\hline Resolução 4/12 & $\begin{array}{l}\text { Dispõe sobre os critérios para a realização de estudos de resíduos de } \\
\text { agrotóxicos para fins de registro de agrotóxicos no Brasil }\end{array}$ \\
\hline RDC 294/19 - Anvisa & $\begin{array}{l}\text { Dispõe sobre os critérios para avaliação e classificação toxicológica, } \\
\text { priorização da análise e comparação da ação toxicológica de agrotóxicos, } \\
\text { componentes, afins e preservativos de madeira, e dá outras providências. }\end{array}$ \\
\hline RDC 295/19 - Anvisa & $\begin{array}{l}\text { Dispõe sobre os critérios para avaliação do risco dietético decorrente da } \\
\text { exposição humana a resíduos de agrotóxicos, no âmbito da Anvisa, e dá } \\
\text { outras providências. }\end{array}$ \\
\hline RDC 296/19 - Anvisa & $\begin{array}{l}\text { Dispõe sobre as informações toxicológicas para rótulos e bulas de } \\
\text { agrotóxicos, afins e preservativos de madeira. }\end{array}$ \\
\hline $\begin{array}{l}\text { Instrução Normativa } \\
\text { 34/19-Anvisa }\end{array}$ & $\begin{array}{l}\text { Estabelece e dá publicidade à lista de componentes não autorizados para } \\
\text { uso em agrotóxicos e afins. }\end{array}$ \\
\hline
\end{tabular}

Fonte: Elaboração própria, mediante consulta às páginas institucionais da Anvisa, MAPA e IBAMA.

\subsection{2.}

\section{Sistema tripartite para registro de agrotóxicos no Brasil}

De acordo com o Decreto $n^{\circ} 4.074 / 2002$, os agrotóxicos, seus componentes e afins só poderão ser produzidos, manipulados, importados, exportados, comercializados e utilizados no território nacional se previamente registrados no órgão federal competente, atendidas as diretrizes e exigências dos órgãos federais 
responsáveis pelos setores de agricultura, saúde e meio ambiente. Exceto quando forem utilizadas quantidades de $25 \mathrm{~g}$ ou menos de produto; neste caso a molécula pode não ser caracterizada como agrotóxico, portanto, não seria regulada pela legislação específica para agrotóxicos e afins.

Para obter o registro de agrotóxicos no Brasil, a empresa precisa submeter o produto à avaliação de três órgãos do governo federal: Ministério da Agricultura, Pecuária e Abastecimento (MAPA), Instituto Brasileiro do Meio Ambiente e dos Recursos Naturais Renováveis (Ibama) e Agência Nacional de Vigilância Sanitária (Anvisa). Cada um desses órgãos realiza um determinado tipo de avaliação do produto, conforme figura 2.1.

Cabe ao Mapa a responsabilidade de avaliar a eficiência e o potencial de uso dos agrotóxicos na agricultura, por meio de um dossiê agronômico. Ao Ibama, a realização de um dossiê ambiental, no qual é avaliado o potencial poluidor do produto. Já a Anvisa realiza o dossiê toxicológico, avaliando o quão tóxico é o produto para a população e em quais condições o seu uso é seguro.

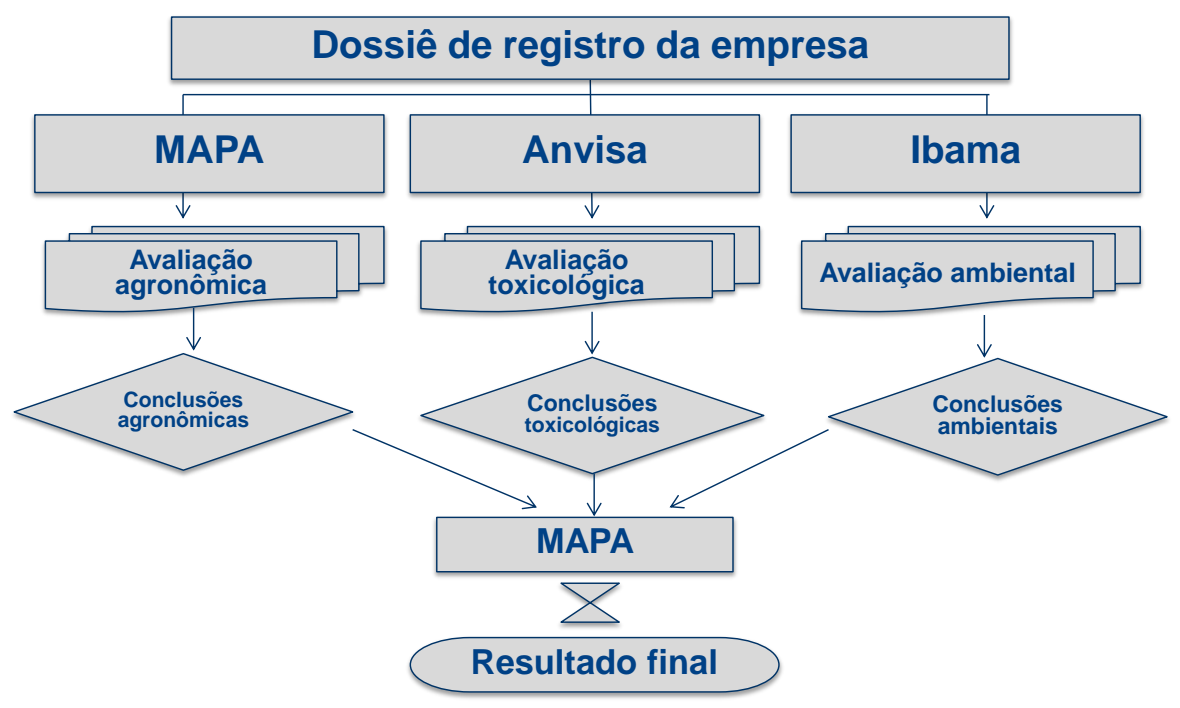

Figura 2.1 - Sistema tripartite para registro de agrotóxicos no Brasil Fonte: Fonseca (2018)

Segundo Fonseca (2018), o arcabouço legal brasileiro fornece elementos de autonomia técnico-programática a cada um dos órgãos envolvidos na análise dos agrotóxicos, por outro lado, a deficiência em infraestrutura e pessoal, a falta de autonomia para promover concursos públicos e utilizar as taxas cobradas do setor regulado apontam ser o principal limitador para o exercício e a implementação da regulamentação de forma efetiva e feita em um tempo razoável. 
De acordo com a Anvisa, o tempo médio para a conclusão da análise de novas moléculas de agrotóxicos é de aproximadamente oito anos, destacando o cenário descrito anteriormente sobre indisponibilidade de recursos. Já o registro de agrotóxicos, após concedido, possui validade indeterminada, podendo ser cancelado nos casos de reavaliação toxicológica ou quando são constatadas fraudes.

No entanto, o Brasil passou recentemente por uma reformulação nas leis e restruturação dos processos de registro de agrotóxicos, visando tornar o procedimento mais rápido, porém mantendo a segurança. Dentre as medidas adotadas, como remanejamento e contratação de servidores, destaca-se o novo marco regulatório para classificação de agrotóxicos, aprovado pela Diretoria Colegiada (Dicol) da Anvisa no dia 23 de julho de 2019.

O novo marco regulatório para classificação de agrotóxicos atualiza e torna mais claro os critérios de avaliação e de classificação toxicológica dos agrotóxicos no Brasil. Também estabelece mudanças importantes na rotulagem, com a adoção do uso de informações toxicológicas, palavras de alerta e imagens (pictogramas), baseadas no sistema GHS, tendo como objetivo facilitar a identificação de perigos à vida e à saúde humana. A presente dissertação focalizará a RDC nº 296/2019, que estabelece mudanças importantes na rotulagem e bulas dos agrotóxicos no país, visando à adoção do uso de informações, palavras de alerta e imagens (pictogramas) que facilitem a identificação, por parte dos agricultores, dos potenciais perigos à vida e à saúde humana.

\subsection{3.}

\section{Objetivos do novo marco regulatório para avaliação toxicológica de agrotóxicos}

O novo marco regulatório para avaliação toxicológica de agrotóxicos é composto por três Resoluções da Diretoria Colegiada e uma Instrução Normativa, conforme mencionado no quadro 2.2. A primeira RDC 294/19, é focada nos critérios para avaliação, classificação, priorização da análise e comparação da ação toxicológica. A segunda RDC 295/19, dispõe sobre os critérios para avaliação do risco dietético decorrente da exposição humana a resíduos de agrotóxicos. A terceira RDC 296/19, trata das informações toxicológicas para rótulos e bulas de agrotóxicos, afins e preservativos de madeira. Por último, a IN 
34/19, estabelece e dá publicidade à lista de componentes não autorizados para uso em agrotóxicos.

Antes disso, diversas iniciativas da Anvisa trataram sobre o tema agrotóxicos, com a realização de consultas em 2011, 2015 e 2016, além de uma audiência pública. No ano de 2018, a Diretoria Colegiada submeteu as propostas a Consultas Públicas (CPs), de número 483, 484, 485 e 486, dando origem ao novo marco regulatório para avaliação toxicológica de agrotóxicos. Após publicação no Diário Oficial da União (D.O.U) as empresas terão um ano para se adequar às novas regras.

Segundo a Anvisa, as mudanças propostas pelo novo marco regulatório para avaliação toxicológica de agrotóxicos foram com base nos padrões do GHS, consolidando a convergência regulatória internacional nessa área. Isso fará com que o Brasil passe a ter regras harmonizadas com as de países da União Europeia e da Ásia, entre outros, fortalecendo a comercialização de produtos nacionais no exterior.

A implementação pela Anvisa do novo marco regulatório para avaliação toxicológica de agrotóxicos, afins e preservativos de madeira tem como objetivos:

- Adotar padrões similares de classificação aos adotados por outros países, promovendo a convergência regulatória;

- Melhorar a comunicação do perigo dos produtos avaliados;

- Promover a utilização dos métodos alternativos ao uso de animais em experimentação;

- Tornar as atividades de avaliação dos estudos toxicológicos mais eficiente e priorizar os produtos de baixa toxicidade; e

- Padronizar a comparação da ação tóxica entre produtos.

A Anvisa partiu da premissa que, ao fornecer rótulos e bulas de agrotóxicos com informações toxicológicas mais claras, será possível comunicar melhor os perigos aos agricultores, tornando-os parceiros no controle e fiscalização desses produtos. Para o consumidor final de produtos da cadeia agroalimentar já existem programas que minimizam os riscos de intoxicação, como o Programa de Avaliação de Resíduos de Agrotóxicos em Alimentos (PARA). Este Programa foi criado em 2001 com o objetivo de avaliar, continuamente, os níveis de resíduos de agrotóxicos nos alimentos de origem vegetal que chegam à mesa do consumidor. Trata-se de uma iniciativa do Sistema Nacional de Vigilância Sanitária (SNVS), coordenado pela Anvisa em conjunto com órgãos estaduais e municipais de 
vigilância sanitária e laboratórios estaduais de saúde pública. Desde sua criação, foram analisadas mais de 35 mil amostras referentes a 28 tipos de alimentos de origem vegetal.

Mesmo com a implantação do novo marco regulatório, permanece o previsto na Lei $n^{\circ} 7802 / 1989$, que proíbe o registro de produtos, cuja ação tóxica seja maior do que aqueles já registrados. A pedido do requerente do registro, a Anvisa deve priorizar a análise da avaliação toxicológica dos produtos de baixa toxicidade. Será indeferido o pedido de avaliação toxicológica de registro ou pósregistro para os agrotóxicos ou afins quando o produto for enquadrado em categoria de maior perigo do que todos os outros já registrados.

\subsection{4.}

\section{Classificação do sistema GHS versus Classificação da Portaria MS 3/1992}

De acordo com Almeida (2019), a classificação toxicológica prevista pela Portaria $\mathrm{n}^{\circ}$ 03, de 16 de janeiro de 1992, do Ministério da Saúde, Secretaria de Vigilância Sanitária (Brasil, 1992) não está harmonizada com relação ao que é praticado no mundo.

A tabela 2.1 apresenta os critérios para a classificação toxicológica, de acordo com a Portaria $\mathrm{N}^{\circ}$ 03, de 16 de janeiro de 1992. Nesta classificação, são considerados os efeitos tóxicos agudos, via oral ou dérmica, dos agrotóxicos, diferenciando-se formulações sólidas ou liquidas e também, considerando a capacidade dos produtos provocarem corrosão, ulceração ou opacidade na córnea e provocarem ulceração ou corrosão na pele.

Segundo a Portaria n ${ }^{\circ}$ 03/1992, para a classificação em uma dessa classes toxicológicas, o agrotóxico não precisa apresentar todos os dados toxicológicos de uma mesma classe. É utilizado o dado mais agravante, bastando atender a um dos parâmetros. São quatro as classes toxicológicas determinadas pela Portaria $n^{\mathbf{o}}$ 03/1992:

- Classe I: Produto Extremamente Tóxico - faixa vermelha;

- Classe II: Produto Altamente Tóxico - faixa amarela;

- Classe III: Produto Moderadamente Tóxico - faixa azul; e

- Classe IV: Produto Pouco Tóxico - faixa verde. 
Tabela 2.1 - Critérios para a classificação toxicológica de acordo com a Portaria № 03, de 16 de janeiro de 1992

\begin{tabular}{|c|c|c|c|c|}
\hline & Classe I & Classe II & Classe III & Classe IV \\
\hline Categoria & Extremamente Tóxico & Altamente Tóxico & Medianamente Tóxico & Pouco Tóxico \\
\hline $\begin{array}{l}\text { Formulações líquidas que } \\
\text { apresentam DL50 oral, } \\
\text { para ratos }\end{array}$ & $£ 20 \mathrm{mg} / \mathrm{kg}$ & $>20 \mathrm{mg} / \mathrm{kg} £ 200 \mathrm{mg} / \mathrm{kg}$ & $>200 \mathrm{mg} / \mathrm{kg} £ 2.000 \mathrm{mg} / \mathrm{kg}$ & $>2000$ mg/kg \\
\hline $\begin{array}{l}\text { Formulações sólidas que } \\
\text { apresentam DL50 oral, } \\
\text { para ratos }\end{array}$ & $£ 5 \mathrm{mg} / \mathrm{kg}$ & $>5 \mathrm{mg} / \mathrm{kg} £ 50 \mathrm{mg} / \mathrm{kg}$ & $>50 \mathrm{mg} / \mathrm{kg} £ 500 \mathrm{mg} / \mathrm{kg}$ & $>500 \mathrm{mg} / \mathrm{kg}$ \\
\hline $\begin{array}{l}\text { Formulações líquidas que } \\
\text { apresentam DL50 dérmica, } \\
\text { para ratos }\end{array}$ & $£ 40 \mathrm{mg} / \mathrm{kg}$ & $>40 \mathrm{mg} / \mathrm{kg} £ 400 \mathrm{mg} / \mathrm{kg}$ & $>400 \mathrm{mg} / \mathrm{kg} £ 4.000 \mathrm{mg} / \mathrm{kg}$ & $>4000 \mathrm{mg} / \mathrm{kg}$ \\
\hline $\begin{array}{l}\text { Formulações sólidas que } \\
\text { apresentam DL50 dérmica, } \\
\text { para ratos }\end{array}$ & $£ 10 \mathrm{mg} / \mathrm{kg}$ & $>10 \mathrm{mg} / \mathrm{kg} £ 100 \mathrm{mg} / \mathrm{kg}$ & $>100 \mathrm{mg} / \mathrm{kg} £ 1.000 \mathrm{mg} / \mathrm{kg}$ & $>1.000 \mathrm{mg} / \mathrm{kg}$ \\
\hline $\begin{array}{l}\text { Formulações que possuam } \\
\text { CL50 inalatória para ratos }\end{array}$ & $\begin{array}{l}£ 0,2 \mathrm{mg} / \mathrm{I} \mathrm{de} \text { ar por uma } \\
\text { hora de exposição }\end{array}$ & $\begin{array}{l}>0,2 \mathrm{mg} / \text { I } £ 2 \mathrm{mg} / \mathrm{I} \mathrm{de} \text { ar por } \\
\text { uma hora de exposição }\end{array}$ & $\begin{array}{l}>2 \mathrm{mg} / \text { / £ } 20 \mathrm{mg} / \text { I de ar por } \\
\text { uma hora de exposição }\end{array}$ & $\begin{array}{l}>20 \mathrm{mg} / \mathrm{I} \text { de ar por hora } \\
\text { de exposição }\end{array}$ \\
\hline Formulações que... & $\begin{array}{l}\text { provocam opacidade na } \\
\text { córnea reversível ou não } \\
\text { dentro de sete dias ou } \\
\text { irritação persistente nas } \\
\text { mucosas oculares dos } \\
\text { animais testados }\end{array}$ & $\begin{array}{l}\text { não apresentam de modo algum, } \\
\text { opacidade na córnea, bem como } \\
\text { aquelas que apresentam irritação } \\
\text { reversível dentro de } 7 \text { (sete) dias } \\
\text { nas mucosas oculares de } \\
\text { animais testados; }\end{array}$ & $\begin{array}{l}\text { não apresentam, de modo } \\
\text { algum, opacidade na córnea } \\
\text { e aquelas que apresentam } \\
\text { irritação reversível dentro de } \\
72 \text { (setenta e duas) horas } \\
\text { nas mucosas oculares dos } \\
\text { animais testados }\end{array}$ & $\begin{array}{l}\text { não apresentam de modo } \\
\text { algum, opacidade na } \\
\text { córnea e aquelas que } \\
\text { apresentam irritação leve, } \\
\text { reversível dentro de } 24 \\
\text { (vinte e quatro) horas, nas } \\
\text { mucosas oculares dos } \\
\text { animais testados }\end{array}$ \\
\hline Formulações que... & $\begin{array}{l}\text { provocam ulceração ou } \\
\text { corrosão na pele dos } \\
\text { animais testados }\end{array}$ & $\begin{array}{l}\text { provocam irritação severa, ou } \\
\text { seja, obtenham um escore igual } \\
\text { ou superior a } 5 \text { (cinco) segundos } \\
\text { o método de Draize e Cols na } \\
\text { pele de animais testados }\end{array}$ & $\begin{array}{l}\text { provocam irritação moderada } \\
\text { ou um escore igual ou } \\
\text { superior a } 3 \text { (três) e até } 5 \\
\text { (cinco), segundo o método de } \\
\text { Draize e Cols, na pele dos } \\
\text { animais testados }\end{array}$ & $\begin{array}{l}\text { provocam irritação leve ou } \\
\text { um escore inferior a } 3 \\
\text { (três), segundo o método } \\
\text { de Draize e Cols, na pele } \\
\text { dos animais testados }\end{array}$ \\
\hline & $\begin{array}{l}\text { Produtos, ainda em fase de } \\
\text { desenvolvimento, a serem } \\
\text { pesquisados ou } \\
\text { experimentados no Brasil }\end{array}$ & & & \\
\hline
\end{tabular}

Fonte: Brasil, 1992

pesquisados ou 
Segundo Almeida (2019), com a adoção do GHS para classificar os agrotóxicos, os resultados dos estudos toxicológicos de irritação dérmica e ocular e de sensibilização dérmica e inalatória não serão utilizados para fins de classificação toxicológica e sim para estabelecer a comunicação do perigo dos produtos. Os critérios para classificação dos desfechos de irritação/corrosão também são distintos, e passam a valer seis tipos de classificação.

A classificação em função da toxicidade aguda deve ser determinada e identificada com os respectivos nomes das categorias e cores nas faixas do rótulo dos produtos, de acordo com o estabelecido abaixo:

- I - Categoria 1: Produto extremamente tóxico - faixa vermelha;

- II - Categoria 2: Produto altamente tóxico - faixa vermelha;

- III - Categoria 3: Produto moderadamente tóxico - faixa amarela;

- IV - Categoria 4: Produto pouco tóxico - faixa azul;

- V - Categoria 5: Produto improvável de causar dano agudo - faixa azul;

- VI- Não Classificado - Produto não classificado - faixa verde.

A tabela 2.2 mostra os critérios para a classificação toxicológica de agrotóxicos de acordo com a - RDC n 294/2019, aprovada pela Anvisa.

De acordo com a UNECE (2017), o GHS traz um Sistema de Classificação das substâncias químicas quanto aos perigos físicos (incêndio, explosão, reatividade); à saúde humana e ao meio ambiente. Após a classificação o GHS traz os critérios para comunicação de perigos e riscos genéricos (nos usos previstos) que inclui a Rotulagem (ou etiquetagem) preventiva e a elaboração de Ficha de Dados de Segurança (FDS).

Com relação aos perigos relacionados à saúde humana, o GHS traz em sua última versão disponível de 2017, critérios para toxicidade aguda; corrosão/irritação à pele; lesões oculares graves/irritação ocular; sensibilização respiratória; sensibilização à pele; mutagenicidade em células germinativas; carcinogenicidade; toxicidade à reprodução; toxicidade para órgãos-alvo específicos- exposição única; toxicidade para órgãos-alvo específicos - exposição repetida e perigo por aspiração.

A discussão internacional sobre a necessidade de se criar o GHS teve início especialmente a partir da convenção 170 e recomendação 174 da Organização internacional do Trabalho (OIT), em 1990, sobre Segurança na utilização de produtos químicos no trabalho. 
Tabela 2.2 - Critérios para a classificação toxicológica de agrotóxicos de acordo com a RDC no 294/2019 da Anvisa

\begin{tabular}{|c|c|c|c|c|c|c|c|}
\hline \multicolumn{2}{|l|}{ Categoria } & Categoria 1 & Categoria 2 & Categoria 3 & Categoria 4 & Categoria 5 & $\begin{array}{l}\text { Não } \\
\text { classificado }\end{array}$ \\
\hline \multicolumn{2}{|c|}{ Nome da categoria } & & tóvisi & t́́ & & & \\
\hline $\begin{array}{l}\text { Via de } \\
\text { exposição Oral } \\
\text { DL50 } \\
\text { (mg/kg p.c.) }\end{array}$ & & $£ 5$ & $>5 £ 50$ & $>50 £ 300$ & $>300 £ 2000$ & $>2000 £ 5000$ & $>5000$ \\
\hline $\begin{array}{l}\text { Via de } \\
\text { exposição } \\
\text { Cutânea DL50 } \\
\text { (mg/kg p.c.) }\end{array}$ & & $£ 50$ & $>50 £ 200$ & $>200 £ 1000$ & $>1000 £ 2000$ & $>2000 £ 5000$ & $>5000$ \\
\hline $\begin{array}{l}\text { Via de } \\
\text { exposição } \\
\text { Inalatória CL50 }\end{array}$ & $\begin{array}{l}\text { Gases } \\
(\mathrm{ppm} / \mathrm{V})\end{array}$ & $£ 100$ & $>100 £ 500$ & $>500 £ 2500$ & $>2500 £ 20000$ & $>20000 £ 50000$ & \\
\hline & $\begin{array}{l}\text { Vapores } \\
\text { (mg/L) }\end{array}$ & $£ 0,5$ & $>0,5 £ 2,0$ & $>2,0 £ 10$ & $>10 £ 20$ & $>20 £ 50$ & \\
\hline & $\begin{array}{l}\text { Produtos } \\
\text { sólidos e } \\
\text { líquidos } \\
\text { (mg/L) }\end{array}$ & $£ 0,05$ & $>0,05 £ 0,5$ & $>0,5 £ 1,0$ & $>1,0 £ 5,0$ & $>5,0 £ 12,5$ & \\
\hline
\end{tabular}

Fonte: Brasil, 2019. 
$\mathrm{Na}$ Conferência das Nações Unidas sobre o Meio Ambiente e Desenvolvimento - CNUMAD (UNCED), popularmente conhecida como Eco92 ou Rio92, aprovou-se um documento chamado Agenda 21, cujo capítulo 19 focaliza o manejo ecologicamente saudável das substâncias químicas tóxicas, incluindo a prevenção do tráfico internacional ilegal dos produtos tóxicos e perigosos'(Brasil, 1992). Este documento estabeleceu seis áreas programáticas, sendo uma delas praticamente decorrente da Convenção 170 da Organização Internacional do Trabalho (OIT), pois estabelecia a necessidade da harmonização da classificação e da rotulagem dos produtos químicos.

Para promover a cooperação internacional com a finalidade de alcançar as metas da Agenda 21, mais especificamente aquelas referentes ao capítulo 19 do referido documento, criou-se, em 1994, o Fórum Intergovernamental de Segurança Química. Em 2003, o Comitê Econômico e Social da Organização das Nações Unidas aprovou a proposta do novo sistema que passou a ser conhecido pela sigla GHS (UNECE, 2017).

No dia 24 de maio de 2011 foi aprovada a Portaria $n^{\circ} 229$, que alterou a Norma Regulamentadora 26 (NR 26) sobre sinalização de segurança nos ambientes de trabalho, do antigo Ministério do Trabalho e Emprego, e que foi publicada no dia 27 de maio pelo DOU (Diário Oficial da União), passando a adotar o GHS.

Segundo a Anvisa, a harmonização da classificação e rotulagem de produtos químicos é uma das seis áreas programáticas endossadas pela Assembleia Geral da Organização das Nações Unidas (ONU) para fortalecer os esforços internacionais relativos à gestão ambientalmente segura de produtos químicos. De acordo com dados de 2017 do Stockholm Environment Institute (SEI), da Suécia, atualmente 53 países adotam os padrões do GHS e 12 têm sua implementação parcial, como é o caso do Brasil, Austrália e México.

No Brasil, diretrizes e parâmetros do sistema GHS já são aplicados ao uso de produtos químicos e a normas de segurança do Ministério do Trabalho. O novo marco regulatório para avaliação toxicológica de agrotóxicos segue este sistema de classificação harmonizado e estabelece critérios científicos para comparar a toxicidade entre os produtos com base na mortalidade. A seguir, será abordada a aplicação dos pictogramas do sistema GHS na RDC 296/2019. 


\subsection{5.}

Comunicação do perigo: pictogramas do GHS utilizados em rótulos e bulas de agrotóxicos, afins e preservativos de madeira

Segundo a Anvisa, as novas regras para comunicação do perigo, com a adoção dos pictogramas do GHS em rótulos e bulas de agrotóxicos, afins e preservativos de madeira, trazem mais segurança para o mercado consumidor, porque facilitam a identificação do perigo do uso (Anvisa, 2021).

Conforme argumento de Pan (2012), a classificação é o ponto de partida para a comunicação de perigos. Ela envolve a identificação dos perigos de um produto químico, e é usada para indicar apenas as propriedades intrinsecamente perigosas das substâncias e misturas.

Além da classificação descrita no item anterior, o sistema GHS define os seguintes perigos:

- Perigos físicos: explosivos; gases inflamáveis; aerossóis inflamáveis; gases oxidantes; gases sob pressão; líquidos inflamáveis; sólidos inflamáveis; substâncias auto-reativas; líquidos pirofóricos; sólidos pirofóricos; substâncias auto-aquecíveis; substâncias que, em contato com a água, emitem gases inflamáveis; líquidos oxidantes; sólidos oxidantes; peróxidos orgânicos; corrosivo aos metais;

- Perigos à saúde: toxicidade aguda; corrosão/irritação da pele; danos / irritação séria nos olhos; sensibilização respiratória ou dérmica; mutagenicidade em células germinativas; carcinogenicidade; toxicidade à reprodução; toxicidade sistêmica em órgão alvo - exposição única; toxicidade sistêmica em órgão alvo - exposição múltipla; perigoso por aspiração;

- Perigos ao meio ambiente: perigoso para o ambiente aquático; toxicidade aquática aguda; toxicidade aquática crônica; potencial de bioacumulação; degradabilidade rápida.

Após a identificação dos perigos, devem-se transmitir as informações sobre esses perigos, por meio dos rótulos e as fichas com dados de segurança (FISPQ), sendo essas as principais ferramentas de comunicação. Os elementos dos rótulos estão diretamente associados ao nível de perigo. A seguir, descrevem-se os elementos dos rótulos:

- Símbolos/Pictogramas: transmitem informações sobre os perigos físicos, ambientais e à saúde, designados para uma classe e categoria de perigo do GHS. Pictogramas incluem os símbolos harmonizados de 
riscos e outros elementos gráficos, como bordas, padrões e cores de fundo, destinados a conter informações específicas.

- Palavras de advertência "Perigo" ou "Aviso": usadas para enfatizar os riscos e indicar o nível relativo de severidade; "Perigo" para os perigos mais severos; "Aviso" para os perigos menos severos;

- Declarações de perigo: frases padrão designadas para uma classe de perigo e categoria que descrevem a natureza do perigo. Uma declaração apropriada para cada perigo e deve ser incluída no rótulo para produtos que tenham mais de um perigo.

A figura 2.2 apresenta os pictogramas e classes de perigo, de acordo com o sistema GHS.

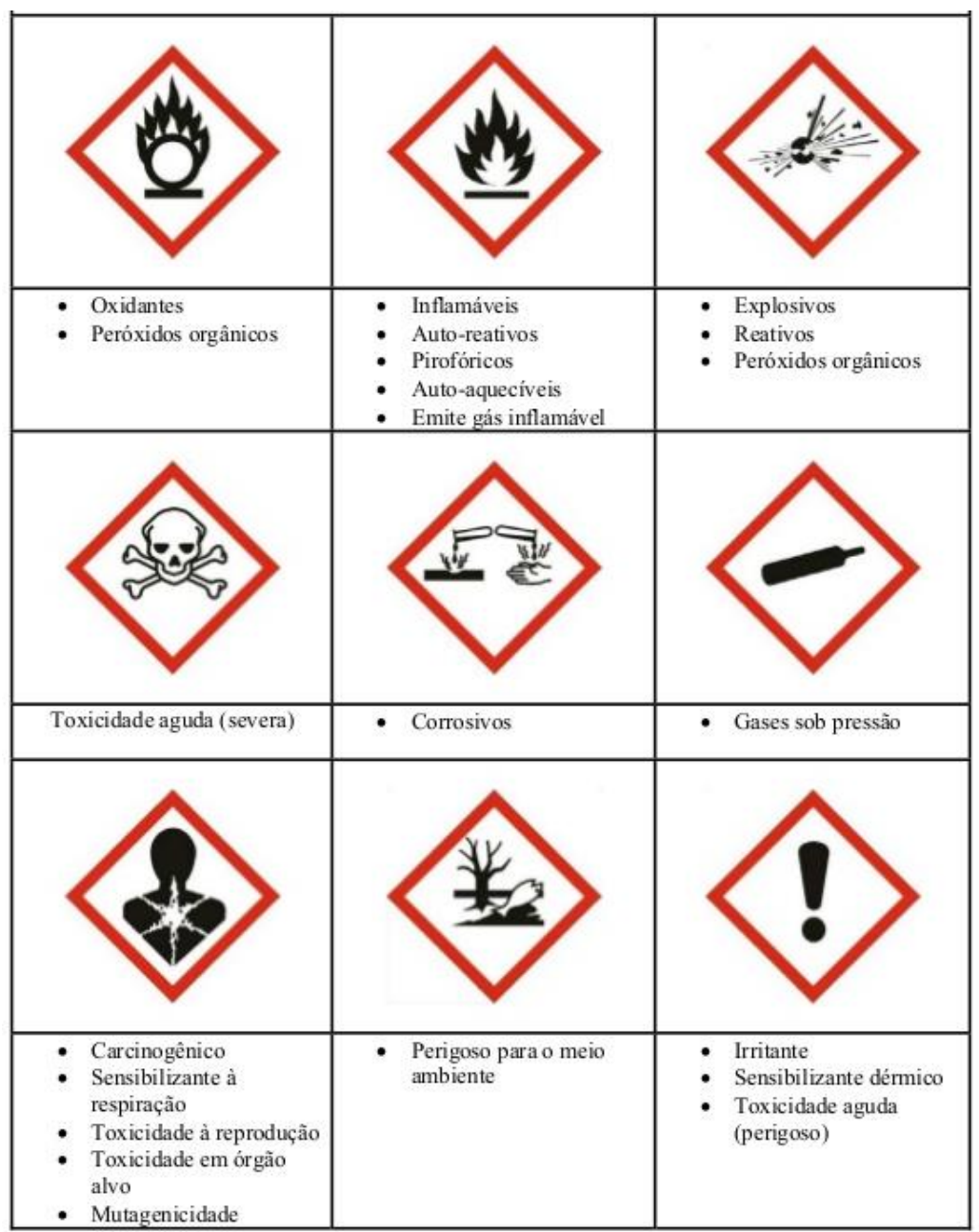

Figura 2.2 - Pictogramas e classes de perigo Fonte: Almeida (2019). 
Também são consideradas importantes a 'Ficha de Informações de Segurança de Produtos Químicos' (FISPQ), que seguem o modelo definido pela Norma Brasileira ABNT-NBR 14725/2019, publicada pela Associação Brasileira de Normas Técnicas (ABNT, 2019). Este é um documento capaz de comunicar informações essenciais sobre os perigos de um produto químico ao seu usuário, possibilitando-lhe agir de acordo com uma avaliação de riscos, tendo em vista as condições de uso do produto, e tomar as medidas necessárias para desenvolver um programa ativo de segurança, saúde e meio ambiente, incluindo treinamentos para manter as pessoas cientes quanto aos perigos no seu local de trabalho.

\section{4.}

\section{Estudos empíricos sobre a adoção do GHS}

O quadro 2.3, a seguir, sintetiza os objetivos, abrangência da aplicação, variáveis e métodos de análise adotados em 15 estudos empíricos sobre a adoção e implementação do GHS - Globally Harmonized System of Classification and Labeling of Chemicals.

Analisando-se o quando 2.3, pode-se constatar que os estudos empíricos apresentados foram desenvolvidos em diferentes continentes. Dentre eles, quatro artigos na Europa, quatro na Ásia, dois estudos empíricos na América do Norte e um estudo na África. Também foram identificados quatro estudos na América do Sul, sendo três no Brasil (estados de São Paulo, Goiás e Rio Grande do Sul) e um no Chile.

O estudo empírico conduzido por Farías (2020) descreve sobre a percepção dos consumidores ao avaliarem os rótulos de produtos, que comunicam a informação de ausência ou promoção de pesticidas em sua composição. E de como os rótulos contribuem consideravelmente para melhorar o valor percebido pelos consumidores e a intenção de compra desses produtos. A pesquisa foi realizada com um total de 195 discentes de um curso de graduação de uma universidade chilena, através da web e os resultados foram apresentados de forma estatística. 
Quadro 2.3 - Estudos empíricos sobre adoção do GHS

\begin{tabular}{|c|c|c|c|c|c|}
\hline Ref. & Autores (ano) & Objetivo do estudo empírico & $\begin{array}{l}\text { Abrangência de } \\
\text { aplicação }\end{array}$ & $\begin{array}{l}\text { Abordagem metodológica } \\
\text { e métodos adotados }\end{array}$ & Variáveis analisadas \\
\hline $\mathrm{R} 01$ & $\begin{array}{l}\text { Farías } \\
(2020)\end{array}$ & $\begin{array}{l}\text { Analisar como os rótulos influenciam a } \\
\text { percepção dos consumidores. }\end{array}$ & $\begin{array}{l}\text { País/região: } \\
\text { Chile/América Latina }\end{array}$ & $\begin{array}{l}\text { Pesquisa quantitativa } \\
\text { Coleta de dados }\end{array}$ & $\begin{array}{l}\text { - Interpretação dos rótulos } \\
\text { - valor percebido pelos } \\
\text { consumidores } \\
\text { - intenção de compra }\end{array}$ \\
\hline $\mathrm{R} 02$ & $\begin{array}{l}\text { Bagheri et al. } \\
(2021)\end{array}$ & $\begin{array}{l}\text { Estudo da interpretação dos agricultores } \\
\text { ao risco pela avaliação dos } \\
\text { pictogramas exibido nos rótulos dos } \\
\text { pesticida. }\end{array}$ & País/região: Irã/Ásia & $\begin{array}{l}\text { Estudo de caso } \\
\text { Pesquisa quantitativa } \\
\text { Coleta e análise dos dados }\end{array}$ & $\begin{array}{l}\text { - Interpretação dos rótulos } \\
\text { - Escala Likert } \\
\text { - Questionário como } \\
\text { instrumento de pesquisa }\end{array}$ \\
\hline R03 & $\begin{array}{l}\text { Bagheri et al. } \\
(2021)\end{array}$ & $\begin{array}{l}\text { Avaliar o comportamento dos } \\
\text { fazendeiros ao ler e usar informações } \\
\text { de risco exibidas em rótulos, usando a } \\
\text { teoria do comportamento planejado } \\
\text { (TPB). }\end{array}$ & $\begin{array}{l}\text { País/região: } \\
\text { Grécia/Europa }\end{array}$ & $\begin{array}{l}\text { Coleta de dados } \\
\text { Estrutura do TPB - Teoria } \\
\text { do Comportamento } \\
\text { Planejado } \\
\text { Pesquisa quantitativa }\end{array}$ & $\begin{array}{l}\text { - Interpretação dos rótulos } \\
\text { - Teoria do comportamento } \\
\text { planejado (TPB) }\end{array}$ \\
\hline R04 & $\begin{array}{l}\text { Silva et al. } \\
(2020)\end{array}$ & $\begin{array}{l}\text { Avalia a toxicidade agrícola } \\
\text { no Brasil, identificando avanços e } \\
\text { oportunidades no século XXI. }\end{array}$ & $\begin{array}{l}\text { País/região: } \\
\text { Brasil/América Latina }\end{array}$ & Pesquisa bibliográfica & $\begin{array}{l}\text { - Regulamentação } \\
\text { - Avanços e oportunidades no } \\
\text { século XXI } \\
\text { - Aspectos regulatórios para } \\
\text { registro }\end{array}$ \\
\hline R05 & $\begin{array}{l}\text { Como et al. } \\
(2019)\end{array}$ & $\begin{array}{l}\text { Estudo para compreender a adoção } \\
\text { do GHS para pesticidas na Malásia. }\end{array}$ & $\begin{array}{l}\text { País/região: } \\
\text { Malásia/Âsia }\end{array}$ & Pesquisa descritiva & $\begin{array}{l}\text { - Adoção e implantação do } \\
\text { GHS } \\
\text { - Aspectos regulatórios }\end{array}$ \\
\hline R06 & $\begin{array}{l}\text { Rother } \\
\text { (2018) }\end{array}$ & $\begin{array}{l}\text { Estuda a eficácia da comunicação de } \\
\text { riscos à saúde através dos rótulos dos } \\
\text { pesticidas. }\end{array}$ & $\begin{array}{l}\text { País/região: Cidade } \\
\text { do Cabo/África }\end{array}$ & Pesquisa descritiva & $\begin{array}{l}\text { - Eficácia de comunicação aos } \\
\text { riscos }\end{array}$ \\
\hline R07 & $\begin{array}{l}\text { Wallau } \\
(2013)\end{array}$ & Estuda a implantação do GHS no Brasil. & $\begin{array}{l}\text { País/região: } \\
\text { Brasil/América Latina }\end{array}$ & Pesquisa descritiva & - Implantação do GHS \\
\hline $\mathrm{R} 08$ & $\begin{array}{l}\text { Garcia } \\
(2008)\end{array}$ & $\begin{array}{l}\text { Estuda a classificação toxicológica e } \\
\text { prevê a implantação do GHS }\end{array}$ & $\begin{array}{l}\text { País/região: } \\
\text { Brasil/América Latina }\end{array}$ & Pesquisa descritiva & $\begin{array}{l}\text { - Classificação toxicológica em } \\
1991 \\
\text { - Previsão da implantação do } \\
\text { GHS para produtos químicos } \\
\text { no Brasil }\end{array}$ \\
\hline
\end{tabular}


Quadro 2.3 - Estudos empíricos sobre adoção do GHS (cont.)

\begin{tabular}{|c|c|c|c|c|c|}
\hline Ref. & Autores (ano) & Objetivo do estudo empírico & $\begin{array}{l}\text { Abrangência de } \\
\text { aplicação }\end{array}$ & $\begin{array}{l}\text { Abordagem metodológica } \\
\text { e métodos adotados }\end{array}$ & Variáveis analisadas \\
\hline R09 & $\begin{array}{l}\text { Emery et al. } \\
(2015)\end{array}$ & $\begin{array}{l}\text { Avaliar a compreensão } \\
\text { e interpretação de pictogramas usados } \\
\text { em rótulos de pesticida para comunicação } \\
\text { do risco no contexto regulatório da União } \\
\text { Europeia (UE) }\end{array}$ & $\begin{array}{l}\text { País/região: } \\
\text { Reino } \\
\text { Unido/Europa }\end{array}$ & Pesquisa quali-quantitativa & $\begin{array}{l}\text { - Interpretação de pictogramas } \\
\text { em rótulos de pesticidas }\end{array}$ \\
\hline R10 & $\begin{array}{l}\text { Persson et al. } \\
\text { (2017) }\end{array}$ & $\begin{array}{l}\text { Fornece uma visão global sobre a } \\
\text { implantação do GHS discutindo as } \\
\text { diferenças entre os países na capacidade } \\
\text { de implementar padrões internacionais. }\end{array}$ & $\begin{array}{l}\text { País/região: } \\
\text { Holanda/Europa }\end{array}$ & Pesquisa descritiva & $\begin{array}{l}\text { - Status da implementação do } \\
\text { GHS em } 2017 \\
\text { - Barreiras para implantação } \\
\text { do GHS }\end{array}$ \\
\hline R11 & $\begin{array}{l}\text { Yazid, M. et al } \\
\text { (2020) }\end{array}$ & $\begin{array}{l}\text { Comparação de classificação resultados } \\
\text { para carcinogenicidade, mutagenicidade de } \\
\text { células germinativas e toxicidade } \\
\text { reprodutiva para produtos químicos pela } \\
\text { União Europeia, Japão, Malásia e Nova } \\
\text { Zelândia }\end{array}$ & $\begin{array}{l}\text { País/região: } \\
\text { Malásia/Europa }\end{array}$ & Pesquisa descritiva & $\begin{array}{l}\text { - Inconsistência na } \\
\text { comparação química entre os } \\
\text { países que adotam o GHS }\end{array}$ \\
\hline $\mathrm{R} 12$ & $\begin{array}{l}\text { Choi et al. } \\
(2020)\end{array}$ & $\begin{array}{l}\text { Estudo para pontuar e classificar os perigos } \\
\text { dos biocidas para a saúde através da } \\
\text { metodologia CRS. }\end{array}$ & $\begin{array}{l}\text { País/região: } \\
\text { Coréíia do } \\
\text { Sul/Ásia }\end{array}$ & $\begin{array}{l}\text { Pesquisa descritiva } \\
\text { Método CRS }\end{array}$ & $\begin{array}{l}\text { - Toxicidade dos biocidas } \\
\text { - Método de pontuacãa CRS } \\
\text { para priorizar os riscos à } \\
\text { saúde }\end{array}$ \\
\hline R13 & $\begin{array}{l}\text { Saemi Shin et } \\
\text { al. (2014) }\end{array}$ & $\begin{array}{l}\text { Estudo utilizando o método CRIRS para } \\
\text { seleção de indicadores de perigo e } \\
\text { exposição; visando melhorar o custo do } \\
\text { gerenciamento de produtos químicos } \\
\text { utilizados em ambientes ocupacionais. }\end{array}$ & $\begin{array}{l}\text { País/região: } \\
\text { Suíça/Europa }\end{array}$ & $\begin{array}{l}\text { Pesquisa descritiva } \\
\text { Método CRIRS }\end{array}$ & $\begin{array}{l}\text { - Gerenciamento de produtos } \\
\text { químicos } \\
\text { - Método de pontuação, } \\
\text { CRIRS para seleção de } \\
\text { indicadores de perigo e } \\
\text { exposiçãa }\end{array}$ \\
\hline R14 & $\begin{array}{l}\text { Boelhouwer } \\
\text { et al. (2013) }\end{array}$ & $\begin{array}{l}\text { Estudo para avaliar a diferença na } \\
\text { compreensão das informações } \\
\text { apresentadas no rótulo do produto químico, } \\
\text { com pictogramas de perigo do GHS e os } \\
\text { pictogramas de precaução da União } \\
\text { Europeia. }\end{array}$ & $\begin{array}{l}\text { País/região: } \\
\text { Estados } \\
\text { Unidos/América } \\
\text { do Norte }\end{array}$ & $\begin{array}{l}\text { Pesquisa descritiva } \\
\text { Coleta e análise dos dados } \\
\text { através de questionário }\end{array}$ & $\begin{array}{l}\text { - Avaliar a compreensão dos } \\
\text { rótulos de produtos químicos, } \\
\text { com pictogramas de perigo } \\
\text { do GHS e os pictogramas de } \\
\text { precaução da União Europeia }\end{array}$ \\
\hline R15 & $\begin{array}{l}\text { Peterson et al. } \\
\text { (2010) }\end{array}$ & $\begin{array}{l}\text { Estudo sobre o progresso de implantação } \\
\text { do GHS nos países utilizando indicadores } \\
\text { como ferramenta de avaliação. }\end{array}$ & $\begin{array}{l}\text { País/região: } \\
\text { Suíça/Europa }\end{array}$ & Pesquisa descritiva & $\begin{array}{l}\text { - Indicadores como ferramenta } \\
\text { - Implementação do GHS } \\
\text { - Método de pontuação } \\
\text { simples aplicado aos } \\
\text { questionários OCDE e IFCS }\end{array}$ \\
\hline
\end{tabular}

Fonte: Elaboração própria. 
Bagheri et al. (2021a) relizaram uma pesquisa com o objetivo de avaliar o comportamento dos agricultores ao tomar conhecimento das informações de risco exibidas em rótulos, usando a teoria do comportamento planejado (TPB). Para os autores os rótulos e pictogramas de pesticidas são a primeira e mais importante fonte de informação para uso seguro e proteção à saúde, durante manuseio e aplicação. Sendo assim, o estudo explora os agricultores interpretam as informações presentes nos rótulos dos pesticidas. Utilizou-se um questionário como instrumento de pesquisa, verificado por um corpo de docentes e especialistas em extensão agrícola. Os resultados foram verificados em escala Likert.

Identificou-se outro artigo dos mesmos autores, com o mesmo objetivo; de avaliar o entendimento dos agricultores ao ler as informações de risco exibidas nos rótulos por pictogramas. No entanto, neste caso os autores utilizaram a teoria do comportamento planejado (TPB). Por fim, os autores concluem que os fabricantes de pesticidas devem considerar as condições especiais dos agricultores ao elaborarem os rótulos desses produtos químicos, pois muitos agricultores possuem baixa escolaridade e idade avançada. Orientam que treinamentos podem melhorar a interpretação e entendimento dos agricultores aos rótulos de pesticidas Bagheri et al. (2021b).

Silva et al. (2020), avaliaram a toxicidade agrícola no Brasil, identificando avanços e oportunidades no século XXI. Os autores exploram os aspectos regulatórios do registro de agrotóxicos no Brasil, os testes obrigatórios para avaliação da toxicidade de agrotóxicos, a adoção do Sistema Globalmente Harmonizado de Classificação e Rotulagem de Produtos Químicos e o progresso recente em direção a métodos não animais para avaliação de toxicidade. Os autores destacam que a nova legislação brasileira para a categorização dos perigos de agrotóxicos trouxe enormes avanços em termos de harmonização internacional, o que impulsiona o comércio e reduz processos burocráticos e morosos, custos e testes desnecessários em animais. Mas que ainda há investimentos a serem feitos para que o país consolide definitivamente sua conduta no contexto de uma Toxicologia Regulatória Moderna.

Rother (2018) propôs um estudo sobre a eficácia da comunicação de riscos à saúde através dos rótulos dos pesticidas. No estudo são apresentados cinco fatores 
que os usuários finais de pesticidas devem alcançar simultaneamente para compreender e aplicar as informações encontradas em um rótulo de pesticida. Argumenta-se que os usuários finais são muitas vezes incapazes de cumprir esses fatores por razões sociais, culturais, políticas e econômicas. Esses fatores são: acesso ao rótulo, linguagem apropriada, nível adequado de alfabetização (para leitura e compreensão) e acesso a equipamentos e instalações.

Wallau et al. (2013) estudaram a implantação do GHS no Brasil para produtos químicos. Os autores destacam que $\mathrm{O}$ conhecimento das regras de rotulagem e manuseio permite uma maior segurança ao manusear os produtos químicos e aceleram as tomadas de decisão em caso de acidentes. Os autores concluem que deve haver um esforço de toda a comunidade para que as regras unificadas sejam universalmente aplicadas.

Garcia et al. (2008) avaliaram a classificação toxicológica dos agrotóxicos antes da mudança promovida pela regulamentação da "Lei dos Agrotóxicos" e previam a implantação do GHS. Em 1992, o Brasil modificou seus critérios de classificação toxicológica de agrotóxicos adequando-os à recomendação de classificação de periculosidade da Organização Mundial da Saúde (OMS). Em 2002, o Sistema Globalmente Harmonizado de Classificação e Rotulagem de Produtos Químicos (GHS) foi adotado pela Organização das Nações Unidas. Os autores concluíram que seria relevante a adoção e implantação do GHS no caso do Brasil, sobretudo pelo que a harmonização internacional pode ajudar na classificação de substâncias ainda não classificadas e na comunicação de riscos relacionados com o uso de produtos químicos em geral.

Emery et al. (2015) reuniram resultados da literatura sobre a compreensão e interpretação de pictogramas em rótulos de pesticidas, no contexto regulatório da EU. Os autores concluíram que a compreensão eficaz dos pictogramas poderia ser facilitada através de treinamentos.

Persson et al. (2017) forneceram em seu estudo uma visão geral do status da implementação do GHS na legislação, usando dados primários e secundários, e explicam as diferenças entre os países com base na teoria sobre fatores motivacionais e relacionados à capacidade para a implementação de padrões internacionais. Os autores concluem que parece haver amplo apoio dos países para uma maior colaboração internacional no campo da boa gestão de produtos 
químicos. No entanto, vários impulsionadores e barreiras para a implementação do GHS coexistem e há uma correlação positiva clara entre as capacidades financeiras e regulatórias de um país e seu status de implementação do GHS. Ao mesmo tempo sugerem que é possível aumentar a cobertura global de implementação usando uma combinação de estratégias motivacionais e relacionadas à capacidade.

Choi et al. (2020) investigaram o estado dos biocidas usados na Coreia do Sul, selecionando 124 biocidas. Aplicaram o método CRS para priorizar os riscos à saúde humana e animal pelas características de exposição e toxicidade dos biocidas. Os autores concluíram que o método CRS é uma ferramenta prática para pontuação, classificação e triagem de riscos à saúde provenientes dos biocidas refletindo os níveis de exposição.

O estudo empírico realizado por Saemi Shin et al. (2014) também utilizou um método de pontuação, chamado de CRIRS para seleção de indicadores de perigo e exposição; visando melhorar o custo do gerenciamento de produtos químicos utilizados em ambientes ocupacionais.

Boelhouwer et al. (2013) desenvolveram um estudo para avaliar a diferença na compreensão das informações apresentadas no rótulo do produto químico, com pictogramas de perigo do GHS e os pictogramas de precaução da União Europeia. Utilizou-se um questionário como instrumento de pesquisa. Os resultados deste estudo concluíram que a presença de pictogramas pode melhorar a comunicação de informações de segurança.

O estudo conduzido por Peterson et al. (2010) discute a necessidade de desenvolvimento de ferramentas como indicadores, onde o objetivo geral é a medição do progresso da implementação do GHS em nível nacional. Os autores utilizaram o método de pontuação simples aplicado aos questionários OCDE e IFCS, e concluíram que a abordagem adotada permite a que implementação do GHS em âmbito nacional, regional e global seja avaliada. Como resultados os autores indicam quais países precisam de assistência adicional para a implementação do GHS.

Avaliando-se os 15 estudos empíricos apresentados, conclui-se que a maior parte deles aborda a necessidade de uma comunicação clara entre o rótulo do produto químicos e o usuário final. Sobre a temática de agrotóxicos e pesticidas, 
garantir uma boa interpretação por parte dos agricultores daquilo que é descrito nos rótulos e bulas dos agrotóxicos, garante segurança e consequentemente diminui os casos de intoxicação humana.

A adoção do GHS busca a harmonização internacional das informações contidas nos rótulos dos produtos químicos. Dentre os estudos analisados, diversos autores destacam que o sucesso da implementação do GHS depende de diversos fatores; como por exemplo, econômicos, educacionais e sociais. E varia de país para país. Três dos estudos abordados desenvolveram indicadores como ferramenta para avaliar o progresso da implementação do GHS em nível nacional.

Importante ressaltar que, dentre os 15 estudos empíricos, nenhum abordou a proposição de indicadores para avaliar a padronização das informações contidas nos rótulos e bulas dos agrotóxicos. Não obstante a importância dos resultados alcançados até o momento para o avanço do conhecimento na temática em foco, a análise desses estudos indicou ainda uma segunda lacuna na literatura referente ao emprego de métodos multicritério de apoio à decisão, como ferramenta de seleção e classificação de indicadores de monitoramento e avaliação. Na presente pesquisa, propõe-se o emprego da abordagem multicritério híbrida fuzzy AHP e fuzzy TOPSIS para suprir tal lacuna na fase da modelagem conceitual.

\section{5 .}

\section{Considerações finais sobre o capítulo}

O novo marco regulatório para avaliação toxicológica de agrotóxicos é um tema que vem sendo amplamente discutido e gerando grande polemica em esfera política, social, econômica e ambiental, com diversos atores envolvidos e tendo em vista o potencial agropecuário do país. Dado o contexto deste capítulo e referencias teóricas abordadas, entende-se que é de suma importância garantir a segurança química e avaliar corretamente os efeitos toxicológicos dos agrotóxicos sobre a saúde humana e meio ambiente.

A RDC no 296/2019 dispõe de uma serie de itens a serem seguidos pelas fabricantes ao elaborarem rótulos e bulas de agrotóxicos, afins e preservativos de madeira. Todos os padrões estabelecidos nesta resolução estão harmonizados com o GHS - Globally Harmonized System of Classification and Labeling of 
Chemicals - com intuito de alcançar a padronização dos rótulos e bulas dos agrotóxicos no Brasil, de acordo com o que é praticado internacionalmente.

Os agricultores são os mais impactados com a implementação da RDC $n^{\circ}$ 296/2019. A mudança nos rótulos visa comunicar com maior clareza os riscos aos quais os agricultores estão expostos ao manusearem e aplicarem tais produtos químicos. Esta Resolução estabelece informações sobre quais equipamentos de segurança utilizar e informações sobre o que fazer em caso de acidente. 


\section{3 \\ Monitoramento e avaliação como instrumentos de gestão pública}

Caracterizam-se as atividades e ferramentas de monitoramento e avaliação (MA) como instrumentos da gestão pública, abordando-se a inicialmente conceituação e a função básica dos indicadores nessas atividades. Descreve-se a metodologia para construção de indicadores de MA, proposta pelo Ministério do Planejamento, Orçamento e Gestão (Brasil, 2010; 2012), como abordagem de escolha para a fase aplicada da presente pesquisa. Destacam-se neste capítulo a metodologia para elaboração do modelo lógico, proposta pelo Instituto de Pesquisa Econômica Aplicada (IPEA) para organizar avaliações dos Programas que integram o Plano Plurianual (PPA). Na sequência, apresenta-se um quadro comparativo de métodos multicritério de apoio à decisão, para fins de escolha daqueles que serão adotados na fase de pesquisa aplicada.

\section{1. Marco conceitual de monitoramento e avaliação}

As ações do governo para o crescimento econômico e desenvolvimento social do país são extremamente importantes e, para acompanhá-las, é fundamental a construção e utilização de medidas de desempenho que retratem o alcance das metas e objetivos pré-estabelecidos. Assim, tendo em vista que o Estado tem responsabilidade na implementação de programas e regulamentações, há necessidade da quantificação e qualificação de parâmetros que permitam às outras partes interessadas ter conhecimento, dar opinião e decidir frente aos numerosos e complexos arranjos possíveis.

Isso faz com que os indicadores de monitoramento e avaliação sejam instrumentos cruciais para a gestão pública. $\mathrm{O}$ marco conceitual aqui apresentado constitui a base para o entendimento de várias questões ligadas ao desenho do modelo lógico da regulamentação sobre rotulagem e bilas de agrotóxicos, afins e 
preservativos de madeira e à proposição de indicadores de monitoramento e avaliação desta regulamentação, como será abordado no capítulo 4 .

\section{2.}

\section{Elaboração do modelo lógico}

A elaboração do modelo lógico de um programa busca configurar um desenho de seu funcionamento, que possa ser realizado em determinadas circunstâncias, para resolver os problemas identificados. Os elementos do modelo lógico incluem recursos, ações, produtos, resultados intermediários e finais, assim como as hipóteses que suportam essas relações e as influências das variáveis relevantes do contexto do programa ou regulamentação (Ferreira, Cassiolato e Gonzalez, 2009; Cassiolato e Gueresi, 2010).

A metodologia para elaboração do modelo lógico foi concebida pelo Instituto de Pesquisa Econômica Aplicada (IPEA), com o objetivo de organizar avaliações do Plano Plurianual (PPA) com foco em seus resultados. Para o desenho da metodologia, o IPEA baseou-se em trabalhos anteriores sobre modelo lógico (McLaughlin e Jordan, 2004; W. K. Kellogg Foundation, 2004), combinando ainda elementos básicos de 'Planejamento de Projeto Orientado por Objetivos", também conhecido como ZOPP e de Planejamento Estratégico Situacional.

Para a construção do modelo lógico, seus autores definem três componentes: (i) explicação do problema e referências básicas do programa (objetivos, públicoalvo e beneficiários); (ii) estruturação do programa para alcance de resultados (resultados finais e impactos); e (iii) identificação de fatores relevantes do contexto, que são variáveis relevantes que se encontram fora da governabilidade dos responsáveis pela implementação do programa. A descrição detalhada de cada um dos componentes pode ser consultada nos trabalhos de Ferreira, Cassiolato e Gonzalez, (2009) e Cassiolato e Gueresi (2010). Segundo esses autores, o modelo lógico deve orientar a estratégia de execução de um determinado programa e a definição dos indicadores para o monitoramento e avaliação de seus resultados.

O processo de formulação do modelo lógico do programa deverá contribuir para garantir as seguintes condições:

- Definição clara e plausível dos objetivos e resultados esperados do programa; 
- Identificação de indicadores relevantes de desempenho, que possam ser obtidos a um custo razoável;

- Comprometimento dos gestores do programa com o que está proposto no modelo lógico.

\section{3.}

\section{Conceituação e função básica dos indicadores}

São muitas as definições de indicadores encontradas na literatura sobre MA, porém, conceitualmente, todas estão bem próximas. Segundo Ferreira, Cassiolato e Gonzalez (2009, p.28):

"O indicador é uma medida, de ordem quantitativa ou qualitativa, dotada de significado particular e utilizada para organizar e captar as informações relevantes dos elementos que compõem o objeto da observação. É um recurso metodológico que informa empiricamente sobre a evolução do aspecto observado."

De acordo com o Instituto Brasileiro de Geografia e Estatística (IBGE, 2008), os indicadores são ferramentas construídas de variáveis que, relacionadas de formas distintas, podem expor e circundar significados mais completos sobre os elementos aos quais são referidos.

Para Tanaka e Melo (2001), um indicador é parte de uma variável, atributo ou característica de uma estrutura, processo ou resultado, que tem a capacidade de condensar, configurar ou dar significado às coisas que se desejam legitimar, e pode ser aceito em um contexto específico.

Bonnefoy e Armijo (2005) definem como sendo duas as funções básicas dos indicadores, a saber:

- Função descritiva, que aborda informações sobre uma realidade empírica, situação social ou ação pública;

- Função valorativa, ou avaliativa, que agrega informação de valor à situação para avaliar a importância relativa ou a adequação de desempenho.

Os indicadores podem ser ainda classificados de acordo com diferentes momentos do ciclo de gestão, a saber:

- Ex-ante: antes da situação, dando suporte à definição do problema, ao desenho de uma política e estabelecimento das referências que se quer alterar;

- In curso: para o monitoramento e avaliação da situação, enquanto ela ocorre, revisão do planejamento inicial e correção das falhas e desvios; 
- Ex-post: para avaliação do alcance de metas, resultados e impactos na sociedade.

Bonnefoy e Armijo (2005) ressaltam que os indicadores devem ser considerados nos diversos estágios da formulação e, principalmente, na implementação de políticas, planos e programas. Adicionalmente, devem ser capazes de refletir a realidade do que se pretende mensurar.

\section{4 .}

\section{Taxonomia de indicadores}

Uma das classificações de indicadores mais importantes para os gestores de uma iniciativa ou programa governamental é aquela referente à gestão do processo de implementação até a mensuração dos impactos para os diversos segmentos da sociedade, beneficiados com os resultados da referida iniciativa/programa.

A figura 3.1 mostra como se dá a gestão do processo de implementação de uma iniciativa/programa. Para cada etapa, definem-se indicadores de MA (de entrada, de processo, de saída, de resultado e de impacto), conforme mostra a figura abaixo.

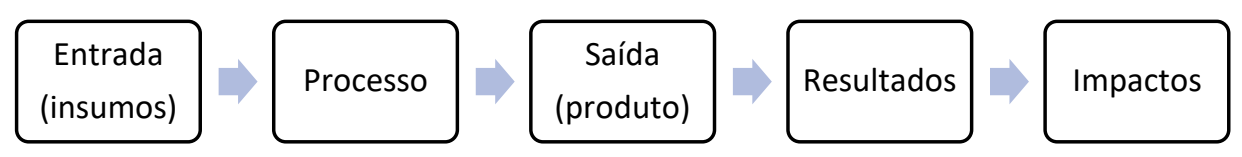

Figura 3.1- Gestão do processo de implementação de uma iniciativa/programa Fontes: Armijo, 2011; Brasil, 2012.

De acordo com Brasil (2012), Jannuzzi (2002), Bonnefoy e Armijo (2005), os indicadores podem ser categorizados em:

- Indicadores de entrada: relacionados à direita com os recursos de investimentos, sejam humanos, materiais, financeiros ou outros também chamados ex-ante facto;

- Indicadores de processo: tratam-se de medidas que transcorrem no processo e resultados intermediários, medindo níveis de utilização, traduzindo a obtenção de resultados pretendidos;

- Indicadores de saída: referem-se às medidas ex-post facto, medindo metas físicas que expressam entrega, produtos e serviços a um público em específico; 
- Indicadores de resultado: citam medidas que expressam o comportamento dos proveitos direcionados direta ou indiretamente a um público específico;

- Indicadores de impacto: são indicadores abrangentes que permitem aferir estratégias governamentais de médio e longo prazo, além de serem multidimensionais.

A figura 3.2 apresenta o ciclo de gestão de iniciativas e programas governamentais, compreendendo as seguintes etapas (i) diagnóstico do problema ou demanda, (ii) planejamento, (iii) execução e monitoramento; (iv) avaliação; e (v) revisão.

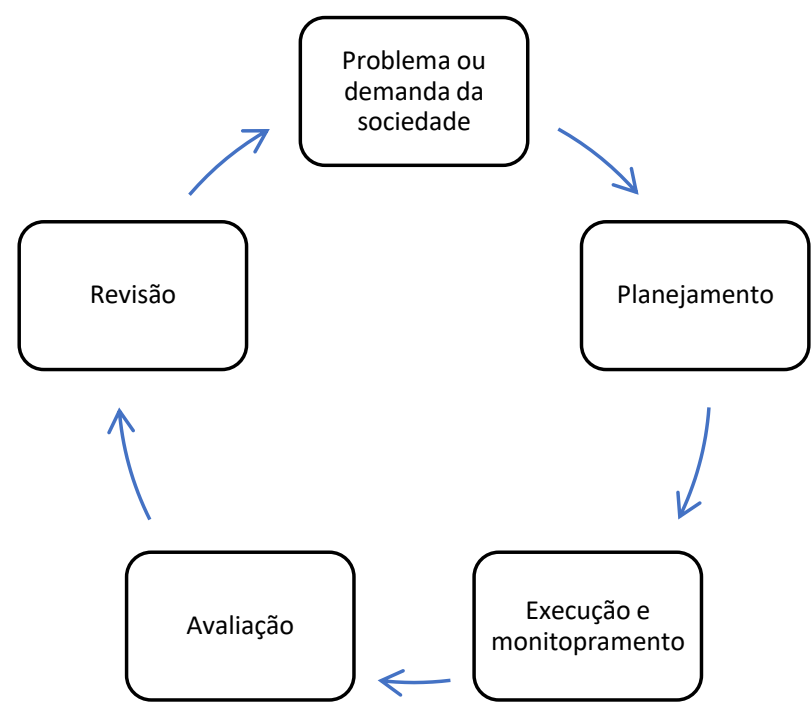

Figura 3.2 - Ciclo de gestão de programas governamentais.

Fonte: Brasil, 2010.

Cada etapa desse ciclo requer indicadores específicos, conforme descrito no Guia publicado pelo Ministério do Planejamento, Orçamento e Gestão, para construção de indicadores de MA voltados para a gestão pública (Brasil, 2010).

\section{5.}

\section{Construção de indicadores}

Apresenta-se nesta seção um método genérico, que visa orientar os gestores públicos na construção de indicadores de MA de programas, políticas e iniciativas governamentais em geral. O método foi concebido e divulgado pelo Ministério do Planejamento, Orçamento e Gestão, através do documento intitulado "Indicadores de Programas: Guia Metodológico" (Brasil, 2010).

Buscando-se incorporar conteúdos desse Guia Metodológico na construção de indicadores para monitorar e avaliar a regulamentação sobre rotulagem e bulas 
de agrotóxicos, afins e preservativos de madeira no Brasil, procedeu-se previamente a uma análise comparativa com outros trabalhos no campo de avaliação de programas.

Optou-se por adotar o método descrito no referido Guia como abordagem metodológica de base para a fase aplicada da presente pesquisa, devido a inúmeros aspectos, como: (i) confirmação da sua aplicabilidade em gestão pública; e (ii) viabilidade de construção no contexto da regulamentação em foco, com as devidas adaptações.

O fluxograma apresentado na figura 3.3 mostra esquematicamente o processo de construção de indicadores de um programa governamental genérico, conpreendendo oito passos, conforme Brasil (2010).

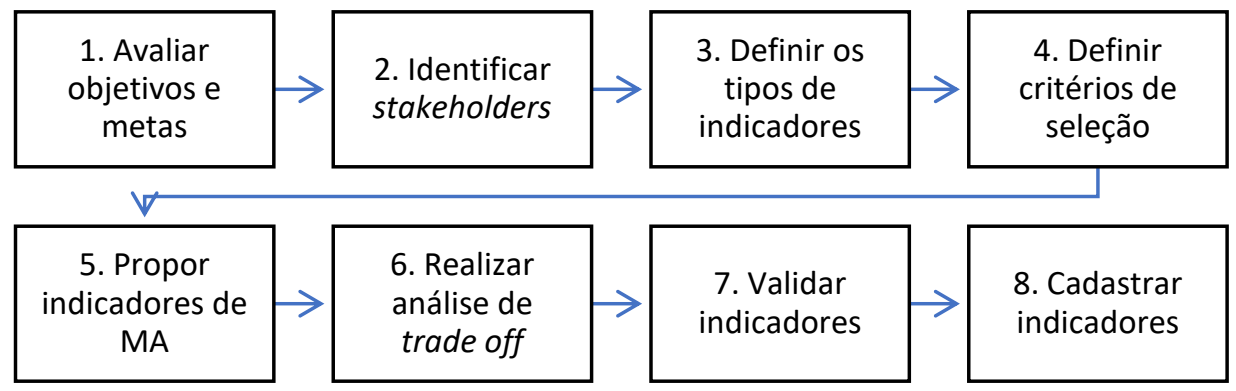

Figura 3.3 - Fluxograma de construção de indicadores de uma iniciativa/ programa governamental Fonte: Brasil, 2010, p. 54.

Descreve-se, a seguir, o processo de construção dos indicadores, visando sua execução na fase aplicada desta pesquisa.

Para a construção de indicadores de MA, é preciso, inicialmente, avaliar os objetivos e as metas do programa ou iniciativa governamental, que será alvo de monitoramento e avaliação. Visando garantir que os conceitos e as dimensões a serem abordados nas ações e subações sejam expressos por indicadores adequados, deve-se ter em mente um claro entendimento sobre os objetivos da iniciativa/programa, bem como as ações definidas para o cumprimento desses objetivos.

Uma vez adotado o método de construção do modelo lógico (Ferreira, Cassiolato e Gonzalez, 2009), é possível identificar as questões de monitoramento e avaliação que devem ser consideradas, mediante a análise do enunciado do problema e das ações consideradas mais importantes. 
O segundo passo refere-se à identificação das principais partes interessadas nos resultados da iniciativa/programa governamental. É fundamental notar a relevância do tema para a sociedade, de maneira geral, julgando a existência de temas transversais que podem envolver outros segmentos do governo. Da mesma maneira, é importante identificar a equipe gerencial responsável pela gestão da iniciativa/programa, para que as informações essenciais sejam direcionadas adequadamente.

Em seguida, o terceiro passo, consiste em definir os tipos de indicadores, quais serão obrigatórios para expressar os resultados esperados e também os que irão atender às necessidades de informação das partes interessadas. O Ministério do Planejamento, Orçamento e Gestão recomenda a seguinte tipologia para os indicadores:

- Indicadores-chave: expressam o conceito ou a dimensão mais importante e relevante do objetivo proposto. Os programas, sobretudo os que oferecem bens e/ou serviços para a sociedade, devem apresentar, pelo menos, um indicador do tipo chave;

- Indicadores complementares: apresentam a dimensão mais importante, assim como as demais, além das contempladas no escopo do Programa. Geralmente não devem ser interpretados isoladamente;

- Indicadores específicos: expõe as necessidades próprias de um ou outro público (identificados no passo dois) ou qualquer outra peculiaridade inerente ao conceito a ser aferido. São necessários, quando os outros dois tipos de indicadores anteriores não cumprem essa função.

O quarto passo depende da definição dos critérios de seleção, ou seja, aqueles que serão adotados para incluir ou descartar indicadores, conforme sua relevância para medir o alcance dos objetivos considerando a conjuntura da iniciativa/programa. De acordo com Villela et al. (2007), esses critérios podem ser de dois tipos:

- Critérios eliminatórios: devem ser obrigatoriamente atendidos pelo indicador candidato, tendo que ser descartado caso não atenda;

- Critérios classificatórios: usados para hierarquização dos indicadores, a partir de uma análise quantitativa ponderada.

Alguns dos critérios mais utilizados para a seleção de indicadores estão relacionados no quadro 3.1 . 
Ao se observar a lista de critérios do quadro 3.1, percebe-se que são critérios universais e aplicáveis a diversos contextos. Por esta razão, quando aplicável, deverão ser definidas outras normas específicas e úteis ao conceito a ser medido.

Para operacionalizar a aplicação dos critérios classificatórios, é fundamental definir: (i) o grau de atendimento dos indicadores candidatos aos critérios estabelecidos; e (ii) a atribuição de pesos aos critérios classificatórios, que podem variar de ação para ação, em conformidade com as especificidades de cada realidade e cada contexto.

Quadro 3.1 - Exemplos de critérios para seleção de indicadores

\begin{tabular}{|l|}
\hline Critérios para seleção de indicadores \\
\hline Atendimento às necessidades de informação dos interessados \\
\hline Confiabilidade da fonte \\
\hline Confiabilidade metodológica \\
\hline Desagregabilidade sociodemográfica \\
\hline Desagregabilidade espacial \\
\hline Disponibilidade quando necessário \\
\hline Economicidade de obtenção \\
\hline Estabilidade ao longo do tempo \\
\hline Existência de suporte técnico \\
\hline Facilidade de obtenção \\
\hline Mensurabilidade \\
\hline Objetividade \\
\hline Rastreabilidade ao longo do tempo \\
\hline Representatividade (em relação ao objetivo do programa) \\
\hline Sensibilidade à intervenção \\
\hline Simplicidade de construção e entendimento \\
\hline Tempestividade \\
\hline
\end{tabular}

Fonte: Brasil, 2010, p. 54.

O quinto passo consiste em mapear indicadores 'candidatos'. Nesta etapa deve-se pesquisar a temática em questão, indicadores e métricas prontas que apontem, com a maior proximidade possível, os conceitos postos nas intenções do programa/ação e que devem ser expressos na mensuração dos resultados aguardados.

Recomenda-se como boa prática a utilização do conhecimento e da experiência de especialistas nos temas abordados pelo programa/ação. Outras práticas, como o uso da técnica de brainstorming e grupos focais e análise de situações análogas, podem ser aplicados nesta etapa. Obtém-se, enquanto resultado, um repertório de indicadores 'candidatos', originários de várias fontes. A partir desse repertório realiza-se uma análise trade-off, que caracteriza o sexto 
passo. Para otimizar os resultados de uma análise desse tipo, realizam-se, em geral, duas análises encadeadas: uma quantitativa e em seguida uma qualitativa. Para tanto, é preciso escolher entre duas ou mais opções de indicadores. Ganha-se com a escolha de um indicador candidato, mas perde-se com a não escolha de outro.

A análise quantitativa baseia-se na adoção de critérios objetivos e na construção da 'Matriz de avaliação quantitativa de indicadores', conforme recomendado pelo Guia do Ministério do Planejamento, Orçamento e Gestão. A referida matriz é composta pelos seguintes elementos:

- Linhas: contemplam os indicadores que são candidatos à avaliação do comportamento do programa/ação;

- Colunas: contém informações sobre o tipo do indicador (se chave, complementar de resultado e/ou específico); a natureza do critério de seleção (se eliminatório ou classificatório); os julgamentos associados a cada indicador candidato quanto ao atendimento aos critérios eliminatórios e classificatórios; e o somatório dos pontos obtidos pelo indicador candidato, com sua posição na hierarquização final.

Para aplicação dos critérios eliminatórios, recomenda-se o preenchimento das células que representam a interseção da linha do indicador 'candidato' com a coluna do critério eliminatório, da seguinte forma: (i) não atende, indicado por 0; e (ii) atende, indicado por 1.

Em relação aos critérios classificatórios, situam-se em duas colunas que representam: (i) o grau de importância do critério (peso) no contexto da iniciativa/programa; e (ii) o grau de atendimento do indicador 'candidato' ao critério classificatório. Os autores do Guia do Ministério do Planejamento, Orçamento e Gestão recomendam ainda as seguintes escalas:

- Grau de importância do critério (peso): baixa (3); média (5); alta (7) e muito alta (9); e

- Grau de atendimento do indicador ao critério: não atende (0); atende parcialmente (1); e atende totalmente (2).

A ferramenta apresentada permite que os indicadores sejam organizados em forma de um ranking, em ordem decrescente de pontos obtidos, em conformidade com o atendimento aos critérios pré-definidos (de C1 a C5).

A fórmula proposta pelo Ministério do Planejamento, Orçamento e Gestão para cálculo do total de pontos alcançado pelo indicador é: 


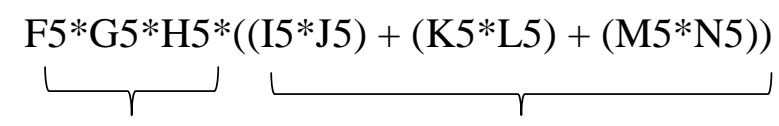

Critérios eliminatórios Critérios classificatórios (ponderados)

A segunda análise a ser realizada é a qualitativa. A partir da hierarquização estabelecida pela "Matriz de avaliação quantitativa de indicadores", o gestor deve optar entre os indicadores de maior classificação, ou seja, aqueles que melhor expressam os resultados esperados pelo programa/ação em questão.

No que tange à aplicabilidade da ferramenta "Matriz de avaliação quantitativa de indicadores" na presente pesquisa, alternativamente ao recomendado no Guia, optou-se pelo emprego de uma abordagem multicritério de apoio à decisão, que combina dois métodos (AHP e TOPSIS) com a lógica fuzzy, como será abordado adiante.

Os critérios utilizados geralmente são subjetivos, segundo experiências anteriores; opinião especializada; comparação com outros programas; indicações de instituições nacionais e internacionais; e quaisquer outras fontes consideradas relevantes.

Considerando-se ainda a perspectiva de melhoria contínua da gestão da iniciativa/programa, ressalta-se que a análise qualitativa permite: (i) verificar indicadores candidatos inicialmente ideais, mas que terminaram mal classificados ou mesmo eliminados pela análise quantitativa; (ii) checar as razões pelas quais esses indicadores foram reprovados e quais os critérios que não foram atendidos; (iii) realizar um plano de ação para excluir as restrições de uso desses indicadores; e (iv) comprometer-se na revisão dos indicadores do programa/ação, para que esses indicadores ideais possam ser aprovados e operacionalizados em um ciclo seguinte.

O sétimo passo refere-se à validação dos indicadores selecionados. Nesse passo, realiza-se uma verificação final da conformidade e pertinência dos indicadores, conforme o atendimento aos requisitos, adotando-se a seguinte ordem de verificação: (i) os indicadores escolhidos são válidos para expressar os resultados esperados?; (ii) eles têm relação direta com os objetivos da ação governamental?; (iii) são originários de fontes confiáveis?; (iv) são mensuráveis?; (v) são em quantidade suficiente para expressar as dimensões envolvidas?; (vi) consideram a dimensão territorial quando necessária?; (vii) expressam questões transversais quando existirem?; (viii) as limitações inerentes aos indicadores 
foram consideradas?; e (ix) atendem ao critério de completude dos atributos exigidos para o seu cadastramento?

Tal lista de verificação pode ser aplicada de forma total ou parcial, dependendo, portanto, da iniciativa/programa. Além disso, em concordância com as respostas, é necessário examinar a pertinência dos indicadores selecionados ou revisar o modelo lógico como inicialmente concebido.

O oitavo e último passo, resume-se em cadastrar os indicadores escolhidos e suas respectivas métricas no sistema de informações gerenciais do órgão responsável pela gestão do programa/ação.

\section{6.}

\section{Métodos multicritério de apoio à decisão}

$\mathrm{Na}$ atual conjuntura econômica, política e social, os processos decisórios em gestão pública vêm requerendo cada vez mais que os instrumentos de MA sejam eficientes e flexíveis. Tal desafio torna-se complexo, uma vez observada a existência de variáveis subjetivas e julgamentos de valor. Os métodos multicritério de apoio à decisão (MMAD) têm o objetivo de proporcionar a modelagem para a solução de problemas de gestão, caracterizando-se como um instrumental relevante e de uso crescente nos ambientes organizacionais (Costa, 2006).

\subsection{1.}

\section{Visão geral e quadro comparativo}

Segundo Sousa e Mendes (2014), os métodos multicritério de apoio à decisão referem-se a um conjunto de técnicas desenvolvidas para auxiliar os decisores a analisar um problema complexo, de resolução trabalhosa e com distintas alternativas de solução, em concordância com determinados critérios.

No quadro 3.2, a seguir, apresentam-se alguns métodos multicritério de apoio a decisão, qua auxiliam no processo de hierarquização. Cada método possui uma taxonomia, e no quadro 3.2 listam-se as principais vantagens e desvantagens de cada um deles. Dentre os métodos mais utilizados estão o "Analytical Hierarchy Process" - AHP; Elimination et Choix Traduisant la Realite ELECTRE, e "Technique for Order Preference by Similarity to Ideal Solution" TOPSIS. (Gomes e Freitas Junior, 2000). 
$\mathrm{Na}$ fase de pesquisa aplicada, cujos resultados serão apresentados no capítulo 4, foram utilizados dois desses métodos, combinados com a lógica fuzzy, a saber: (i) o método fuzzy AHP para definição dos pesos dos critérios para seleção dos indicadores, dentre os 'candidatos'; e (ii) o método fuzzy TOPSIS para hierarquização dos indicadores, por categoria de requisitos da regulamentação.

Quadro 3.2 - Quadro-resumo dos métodos multicritério de apoio à decisão

\begin{tabular}{|c|c|c|}
\hline Ferramenta AMD & Vantagens & Desvantagens \\
\hline $\begin{array}{l}\text { Processo Analítico } \\
\text { Hierárquico (Analytical } \\
\text { Hierarchy Process - } \\
\text { AHP) } \\
\text { (Saaty, 1977; 1990; } \\
\text { 1991;2000) }\end{array}$ & $\begin{array}{l}\text { - Modelo simples para construir; } \\
\text { - Processo lógico; } \\
\text { - Eficiente em lidar com atributos } \\
\text { qualitativos e quantitativos; } \\
\text { - Resultados de fácil entendimento. }\end{array}$ & $\begin{array}{l}\text { - Dúvidas têm sido } \\
\text { levantadas sobre a } \\
\text { fundamentação dessa } \\
\text { teoria. Existe uma forte } \\
\text { visão de que os axiomas em } \\
\text { que o AHP se baseia não } \\
\text { são suficientemente claros } \\
\text { para serem empiricamente } \\
\text { testados. }\end{array}$ \\
\hline $\begin{array}{l}\text { Técnica para avaliar o } \\
\text { desempenho de } \\
\text { alternativas através de } \\
\text { similaridade com a } \\
\text { solução ideal (Technique } \\
\text { for Order Preference by } \\
\text { Similarity to Ideal } \\
\text { Solution - TOPSIS) } \\
\text { (Hwang e Yoon, 1981) }\end{array}$ & $\begin{array}{l}\text { - A consistência interna e solidez } \\
\text { lógica; } \\
\text { - Fácil de seguir; } \\
\text { - Intuitivamente atraente; } \\
\text { - Não há cálculos complicados; } \\
\text { - Facilmente configurado em MS } \\
\text { Excel; } \\
\text { - Os resultados são de fácil } \\
\text { entendimento; } \\
\text { - Valor do índice simples dado; } \\
\text { - Os resultados podem ser facilmente } \\
\text { demonstrados graficamente. }\end{array}$ & $\begin{array}{l}\text { - Grande número de } \\
\text { procedimentos; } \\
\text { - Grande número de } \\
\text { cálculos; } \\
\text { - Fornece um resultado } \\
\text { geral. }\end{array}$ \\
\hline $\begin{array}{l}\text { Preference Ranking } \\
\text { Method for Enrichment } \\
\text { Evaluation- } \\
\text { PROMETHEE } \\
\text { (Brans e Vincke, 1984) }\end{array}$ & $\begin{array}{l}\text { - Incentiva mais interação entre o } \\
\text { decisor e o modelo, na procura de } \\
\text { boas opções; } \\
\text { - Os defensores argumentam que o } \\
\text { seu conceito outranking é mais } \\
\text { relevante para situações práticas do } \\
\text { que o conceito de dominação restritiva. }\end{array}$ & $\begin{array}{l}\text { - Muito conhecimento } \\
\text { necessário. }\end{array}$ \\
\hline $\begin{array}{l}\text { Métodos ELimination Et } \\
\text { Choix TRaduisant la } \\
\text { rEalité - ELECTRE } \\
\text { (Roy e Bouyssou, 1993) }\end{array}$ & $\begin{array}{l}\text { - Os defensores argumentam que o } \\
\text { seu conceito outranking é mais } \\
\text { relevante a situações práticas do que o } \\
\text { conceito de dominação restritiva; } \\
\text { - Pode ser usado para escolher, } \\
\text { classificar, e ordenar alternativas. }\end{array}$ & $\begin{array}{l}\text { - Muito conhecimento } \\
\text { necessário. } \\
\text { - Não é transparente; } \\
\text { - Muito provavelmente será } \\
\text { necessário um especialista } \\
\text { em AMD para ajudar e } \\
\text { realizar a análise. }\end{array}$ \\
\hline
\end{tabular}

Fonte: Adaptado de Saaty (1977; 1990; 1991; 2000); Hwang e Yoon (1981); Brans, Mareschal e Vincke (1984); Roy e Bouyssou (1993).

\section{7.}

\section{Descrição da abordagem multicritério fuzzy AHP-TOPSIS}

A validação dos indicadores propostos compreende os seguintes passos:

- Definição da estrutura hierárquica de decisão e critérios para seleção dos indicadores de MA da regulamentação em foco; 
- Atribuição de pesos aos critérios pelo método fuzzy AHP;

- Avaliação quantitativa do grau de atendimento dos indicadores aos critérios e hierarquização por categoria de requisitos legais, pelo método fuzzy TOPSIS; e

- Avaliação qualitativa dos resultados da avaliação quantitativa.

A definição da estrutura hierárquica de decisão para aplicação dos referidos métodos fuzzy multicritério deverá seguir o esquema genérico mostrado na figura 3.4, que teve como base as estruturas propostas por Saaty (1991) e Hwang e Yoon (1981), para aplicação dos métodos AHP e TOPSIS, respectivamente.

A partir da estrutura hierárquica de decisão representada na figura 3.4, definem-se os critérios, situados no nível da estrutura abaixo do objetivo de decisão, que neste modelo se refere à validação dos indicadores propostos para monitoramento e avaliação da regulamentação para rótulos e bulas de agrotóxicos, afins e preservativos de madeira aprovada pela Anvisa.

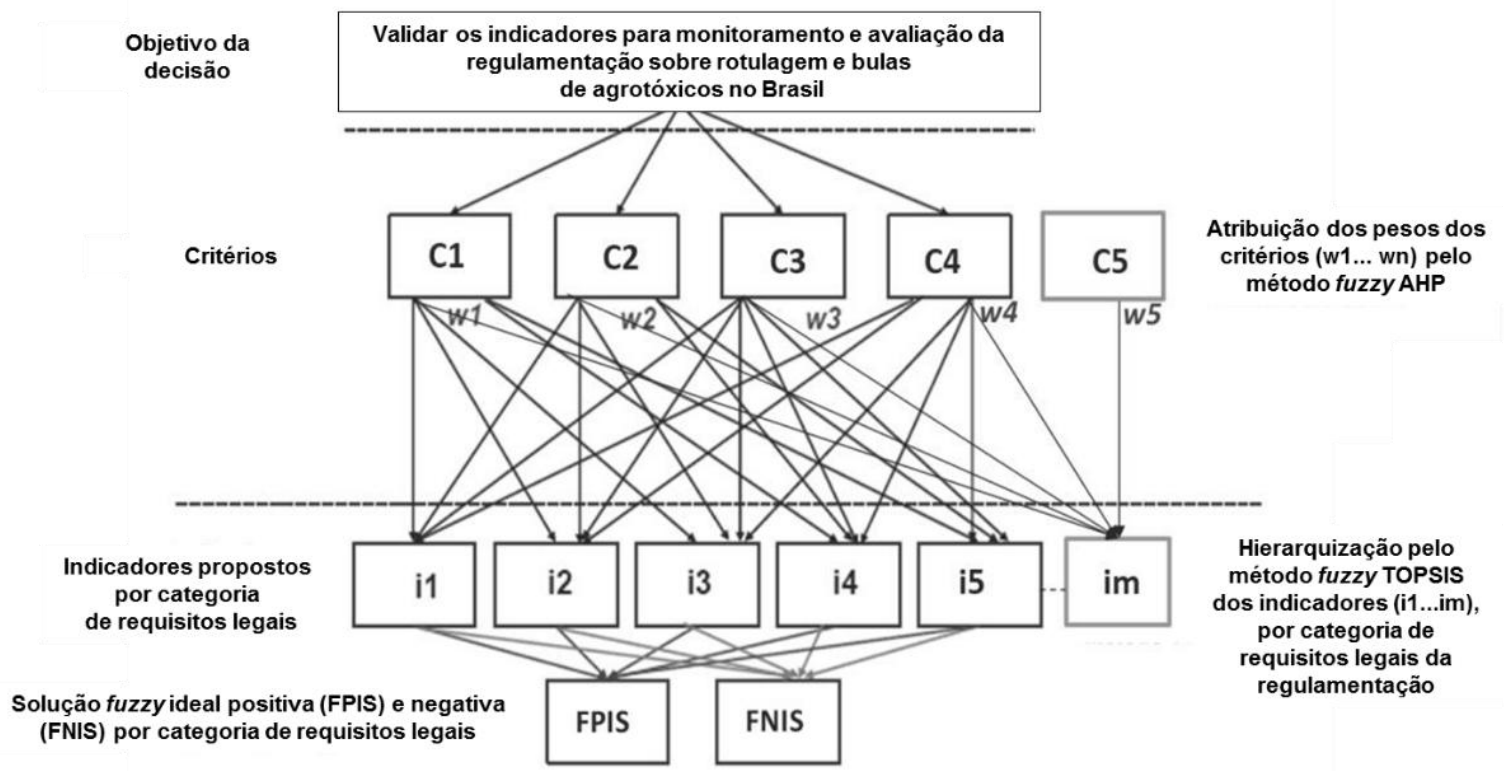

Figura 3.4 - Estrutura hierárquica de decisão referente à regulamentação de rotulagem e bulas de agrotóxicos, afins e preservativos de madeira no Brasil

Fonte: Adaptação de Sá (2018).

Com base nas diretrizes para construção de indicadores propostas pelo Ministério do Planejamento, Orçamento e Gestão (Brasil, 2010; 2012), recomendam-se para esta etapa o emprego dos critérios definidos no quadro 3.3. 
Quadro 3.3 - Proposição de critérios para validação dos indicadores

\begin{tabular}{|l|l|l|}
\hline Ref. & Critério & Descrição \\
\hline C1 & Relevância & $\begin{array}{l}\text { O indicador deve revelar o grau de relevância da mensuração em } \\
\text { relação à dimensão considerada e ao atendimento às necessidades } \\
\text { de informação dos interessados. }\end{array}$ \\
\hline C2 & Mensurabilidade & $\begin{array}{l}\text { O indicador deve contar com uma capacidade de mensuração, além } \\
\text { de uma ótima precisão sem ambiguidade. O custo da coleta dos } \\
\text { dados é compensado pelos benefícios que são gerados a partir das } \\
\text { informações resultantes do indicador. }\end{array}$ \\
\hline C3 & Tempestividade & $\begin{array}{l}\text { As informações que compõem o indicador devem ser atuais e } \\
\text { possíveis de serem obtidas em tempo hábil para seu uso. }\end{array}$ \\
\hline C5 & Ronfiabilidade & $\begin{array}{l}\text { Deve ser proveniente de fontes seguras, íntegras, sem a } \\
\text { possibilidade de manipulação de resultados. A mensuração deve ser } \\
\text { objetiva, verdadeira e verificável. }\end{array}$ \\
\hline
\end{tabular}

Fonte: Brasil (2010).

\subsection{1.}

\section{Atribuição dos pesos aos critérios pelo método fuzzy AHP}

A atribuição dos pesos aos critérios definidos no quadro 3.3 requer a participação de especialistas (respondentes) para atribuir a importância de cada critério em relação aos demais, de acordo com a preferência estabelecida entre eles. Nesta fase de aplicação da ferramenta, deverá ser adotada a escala apresentada por Chang (1996) para aplicação do método AHP em ambientes de incerteza. Nessa escala, definem-se números fuzzy triangulares correspondentes aos termos linguísticos da importância atribuída pelos respondentes a cada critério em relação aos demais.

A título de ilustração, se um especialista (respondente) julgar que o critério (C1) é moderadamente mais importante do que o critério (C2), significa que na escala fuzzy triangular o critério $\mathrm{C} 1$ em relação ao critério $\mathrm{C} 2$ será $(2,3,4)$, expresso por um número fuzzy triangular, ao invés do número crisp 3. Já a comparação pareada do critério $\mathrm{C} 2$ com $\mathrm{C} 1$, de acordo com a escala fuzzy triangular, deverá ser $(1 / 4,1 / 3,1 / 2)$. 
Quadro 3.4 - Termos linguísticos e correspondentes números fuzzy triangulares para comparação pareada dos critérios

\begin{tabular}{|c|c|c|c|}
\hline $\begin{array}{l}\text { Nível de } \\
\text { importância }\end{array}$ & Termo linguísitico & Conceituação & $\begin{array}{l}\text { Escala } \\
\text { fuzzy } \\
\text { triangular }\end{array}$ \\
\hline 1 & Mesma importância & $\begin{array}{l}\text { Os dois atributos contribuem } \\
\text { igualmente para o objetivo. }\end{array}$ & $(1,1,1)$ \\
\hline 3 & $\begin{array}{l}\text { Importância moderada } \\
\text { de uma sobre a outra }\end{array}$ & $\begin{array}{l}\text { A experiência e o julgamento } \\
\text { favorecem levemente um atributo } \\
\text { em relação ao outro. }\end{array}$ & $(2,3,4)$ \\
\hline 5 & $\begin{array}{l}\text { Importância grande ou } \\
\text { essencial }\end{array}$ & $\begin{array}{l}\text { A experiência e o julgamento } \\
\text { favorecem fortemente um atributo } \\
\text { em relação ao outro. }\end{array}$ & $(4,5,6)$ \\
\hline 7 & $\begin{array}{l}\text { Importância muito } \\
\text { grande ou demonstrada }\end{array}$ & $\begin{array}{l}\text { Um atributo é muito fortemente } \\
\text { favorecido em relação ao outro; sua } \\
\text { dominação de importância é } \\
\text { demonstrada na prática. }\end{array}$ & $(6,7,8)$ \\
\hline 9 & $\begin{array}{l}\text { Importância } \\
\text { absoluta }\end{array}$ & $\begin{array}{l}\text { A evidência favorece um atributo em } \\
\text { relação ao outro com o mais alto } \\
\text { grau de certeza }\end{array}$ & $(9,9,9)$ \\
\hline 2 & \multirow{4}{*}{$\begin{array}{l}\text { Valores intermediários } \\
\text { entre os valores } \\
\text { adjacentes. }\end{array}$} & \multirow{4}{*}{$\begin{array}{l}\text { Quando se procura uma condição } \\
\text { de compromisso entre as duas } \\
\text { definições }\end{array}$} & $(1,2,3)$ \\
\hline 4 & & & $(3,4,5)$ \\
\hline 6 & & & $(5,6,7)$ \\
\hline 8 & & & $(7,8,9)$ \\
\hline
\end{tabular}

Fonte: Sá (2018).

A matriz de comparação pareada é expressa pela equação (02) a seguir. Nessa equação, $\tilde{d}_{i j}^{k}$ indica a preferência do $k$-ésimo especialista sobre o i-ésimo critério em relação ao j-ésimo critério, via números fuzzy triangulares. Por exemplo, $\tilde{d}_{12}^{1}$ representa a preferência do primeiro especialista do primeiro critério sobre o segundo critério, ou seja $\tilde{\mathrm{d}}_{12}^{1}=(2,3,4)$.

$$
\tilde{\mathrm{A}}^{K}=\left[\begin{array}{lll}
\tilde{\mathrm{d}}_{11}^{k} & \cdots & \tilde{\mathrm{d}}_{1 n}^{k} \\
\tilde{\mathrm{d}}_{n 1}^{k} & \cdots & \tilde{\mathrm{d}}_{n n}^{k}
\end{array}\right]
$$

Se existirem vários $(K)$ especialistas e gestores no processo de tomada de decisão, então a média das preferências de todos os participantes $\tilde{\mathrm{d}}_{i j}^{k}$ deverá ser calculada, conforme equação 03.

$$
\tilde{\mathrm{d}}_{i j}^{1}=\frac{\sum_{k=1}^{k} \tilde{\mathrm{d}}_{i j}^{1}}{k}
$$

De acordo com a média das preferências, a matriz de comparação pareada deverá ser atualizada como na equação 04 .

$$
\tilde{\mathrm{A}}=\left[\begin{array}{lll}
\tilde{\mathrm{d}}_{11} & \cdots & \tilde{\mathrm{d}}_{1 n} \\
\tilde{\mathrm{d}}_{n 1} & \cdots & \tilde{\mathrm{d}}_{n n}
\end{array}\right]
$$


Segundo Buckcley (1985), a média geometrica dos valores fuzzy correspondentes a cada critério deverá ser calculada pela equação 05 .

$$
\tilde{\mathrm{r}}_{i}=\left(\prod_{j=1}^{n} \tilde{\mathrm{d}}_{i j}\right)^{\frac{1}{n}}, \mathrm{i}=1,2, \ldots, \mathrm{n}
$$

Os pesos fuzzy de cada critério poderão ser gerados conforme a equação 06, em três passos. O primeiro passo consiste em calcular a soma vetorial de cada $\tilde{r_{l}}$. No segundo passo, calcula-se a potência (-1) da soma vetorial resultante e substituise o número fuzzy triangular. Por fim, para achar o peso fuzzy dos critérios $i \tilde{\text { (W }}$ l), deve-se multiplicar cada $n_{\mathrm{b}}$ por seu vetor reverso.

$$
\tilde{\mathrm{W}}_{i}=\tilde{\mathrm{r}}_{i} \oplus\left(\tilde{\mathrm{r}}_{i} \oplus \tilde{\mathrm{r}}_{2} \oplus \ldots \oplus \tilde{\mathrm{r}}_{n}\right)^{-1}=\left(l m_{i}, m w_{i}, u w_{i}\right)
$$

Uma vez que os $\tilde{w}_{i}$ são números fuzzy triangulares, torna-se necessário defuzzificá-los pelo método proposto por Chou e Chang (2008), aplicando-se a equação 07.

$$
M_{i}=\frac{l m_{i}, m w_{i}, u w_{i}}{3}
$$

Onde: $l w_{i}, m w_{i}$ e $u w_{i}$ correspondem aos valores mínimo, intermediário e máximo dos números fuzzy triangulares correspondentes aos pesos dos critérios. O número não fuzzy resultante $M_{i}$ requer normalização, conforme equação 08, para se obter a hierarquização final pela ordem de importância.

$$
N_{i}=\frac{M_{i}}{\sum_{i=1}^{n} M i}
$$

A análise de consistência das matrizes de comparação pareadas fuzzy pelo índice de consistência (IC) pode ser realizada pelo método clássico AHP, pois quando a comparação da matriz crisp (valores reais fixos) $A$ for consistente, significa que a matriz de comparação fuzzy $\tilde{A}$ também será consistente. O índice randômico $(I R)$ é um valor tabelado de consistência aleatório, como indicado no quadro 11 (Saaty, 1991).

$$
\begin{aligned}
& R C=\frac{I C}{I R} \\
& I C=\frac{\lambda_{\max }-n}{n-1}
\end{aligned}
$$


A razão de consistência (RC) calculada pela equação 09 permite estimar a consistência das comparações pareadas. Se $R C \leq 0,10$, então a consistência das comparações será aceita (tabela 3.1). Caso contrário, torna-se necessária a revisão dos julgamentos pelos especialistas. Na equação 10, $\lambda$ max é o maior autovalor e $n$ o tamanho da matriz.

Tabela 3.1 - Índice de consistência aleatória (IR)

\begin{tabular}{ccccccccc}
\hline Tamanho $n$ & 1 & 2 & 3 & 4 & 5 & 6 & 7 & 8 \\
\hline IR & 0 & 0 & 0,52 & 0,89 & 1,11 & 1,25 & 1,35 & 1,40 \\
\hline
\end{tabular}

Fonte: Saaty (1991)

\subsection{2.}

\section{Avaliação quantitativa do grau de atendimento dos indicadores aos critérios pelo método fuzzy TOPSIS}

A exemplo da aplicação do método fuzzy AHP para definição dos pesos dos critérios, o emprego do método fuzzy TOPSIS também requer a participação de especialistas para julgar o grau de atendimento dos indicadores de cada categoria de requisitos da regulamentação em foco aos critérios de decisão previamente ponderados pelo método fuzzy AHP.

$\mathrm{Na}$ fase de aplicação do modelo, adotamos a escala concebida por Chen (2000) para emprego do método fuzzy TOPSIS em ambientes de incerteza, sem, porém, considerar valores nulos como em Chen (2000). Definem-se números fuzzy triangulares correspondentes aos termos linguísticos do grau de atendimento aos critérios, atribuídos pelos especialistas a cada indicador em análise.

A aplicação do método fuzzy TOPSIS inicia-se pela consulta a especialistas sobre o grau de atendimento de cada indicador de uma determinada categoria de requisitos (rótulo, bula ou informações médicas) aos critérios definidos e ponderados anteriormente. Aos termos linguísticos fornecidos pelos especialistas (DMr), agregam-se números fuzzy triangulares, conforme escala apresentada anteriormente.

A equação 11 deve ser usada para agregar as pontuações atribuídas aos indicadores, denominados como alternativas (Ai). Nesta equação, $X^{Y} i j$ refere-se ao grau de atendimento ao critério $\mathrm{Cj}(\mathrm{j}=1, \ldots, \mathrm{m})$, atribuído à alternativa $\mathrm{Ai}(\mathrm{i}=1$, ..., n), avaliado pelo decisor $\operatorname{DMr}(\mathrm{r}=1, \ldots, \mathrm{k})$. As avaliações dos pesos dos critérios são agregadas usando a equação 12 , na qual $\tilde{W} j$ corresponde ao peso do critério, dado por DMr. 


$$
\begin{aligned}
& \tilde{X} i j=1 K[\tilde{x} i j 1+\tilde{x} i j r+\cdots+\tilde{x} i j k] \\
& \tilde{w} i j=1 K[\tilde{w} j 1+\tilde{w} j 2+\cdots+\tilde{w} j k]
\end{aligned}
$$

Na sequência, deve-se construir uma matriz de decisão fuzzy $\tilde{D}$ para as pontuações das alternativas em um vetor fuzzy $\tilde{W}$ para o peso dos critérios, de acordo com as equações 13 e 14, respectivamente.

$$
\begin{aligned}
& C_{1} C_{2} \quad \ldots \quad C_{j} \ldots C_{m} \\
& D=\begin{array}{c}
A_{1} \\
\vdots \\
A_{i} \\
\vdots \\
A_{n}
\end{array}\left[\begin{array}{ccccccc}
\tilde{\mathrm{x}}_{11} & \tilde{\mathrm{x}}_{12} & & \tilde{\mathrm{x}}_{1 j} & & \tilde{\mathrm{x}}_{1 m} \\
\vdots & & \ldots & \vdots & \ldots & \vdots \\
\tilde{\mathrm{x}}_{i 1} & \tilde{\mathrm{x}}_{i 2} & \ldots & \tilde{\mathrm{x}}_{i j} & \ldots & \tilde{\mathrm{x}}_{i m} \\
\vdots & & & \vdots & & \vdots \\
\tilde{\mathrm{x}}_{n 1} & \tilde{\mathrm{x}}_{n 2} & \ldots & \tilde{\mathrm{x}}_{n j} & \ldots & \tilde{\mathrm{x}}_{n m}
\end{array}\right] \\
& \tilde{W}=\left[\tilde{w_{1}}, \tilde{w_{2}}, \ldots, \tilde{w_{m}}\right]
\end{aligned}
$$

Em seguida, a matriz $\tilde{D}$ deve ser normalizada, utilizando-se uma escala de transformação linear. A matriz normalizada $\tilde{R}$ é dada pela equação 15 , sendo $\tilde{r} i j$ obtido por meio das equações 16 ou 17 (correspondentes aos casos de critérios de benefício ou de custo).

$$
\begin{aligned}
& \tilde{R}=[\tilde{r} i j] m x n \\
& \tilde{r} i j=(l i j u j+, m i j u j+, u i j u j+)
\end{aligned}
$$

Sendo, $u_{j}^{+}=\max _{i} u_{i j} \quad$ (critérios de benefício)

$$
\tilde{r} i j=\left(\frac{l j}{u i j}, \frac{l j}{m i j}, \frac{l j-}{l i j}\right)
$$

Sendo, $l_{j}^{+}=m_{i} n_{i} l_{i j} \quad$ (critérios de benefício)

Para a obtenção da matriz normalizada e ponderada $\tilde{V}$, utiliza-se a equação 18, por meio da multiplicação dos pesos $\tilde{w} j$ pelos elementos $\tilde{r} i j$ da matriz normalizada, de acordo com a equação 19.

$$
\tilde{V}=[\tilde{v} i j] m \times n
$$




$$
\tilde{v} i j=\tilde{r} i j * \tilde{w} j
$$

O próximo passo da aplicação do método fuzzy TOPSIS é calcular a solução ideal positiva fuzzy (Fuzzy Positive Ideal Solution, FPIS, A+) e a solução ideal negativa (Fuzzy Negative Ideal Solution, FNIS, $A_{-}$), conforme as equações $20 \mathrm{e}$ 21 , nas quais $\tilde{v} j+=(1,1,1)$ e $\tilde{v} j-=(0,0,0)$.

$$
\begin{aligned}
& A+=\{\tilde{v} 1+, \tilde{v} j+, \ldots, \tilde{v} m+\} \\
& A^{-}=\left\{\tilde{v} 1-, \tilde{v} j^{-}, \ldots, \tilde{v} m-\right\}
\end{aligned}
$$

Para o cálculo da distância $D i+$ entre os valores de FPIS e as pontuações das alternativas da matriz $\tilde{V}$, deve-se usar a equação 21. Analogamente, o cálculo da distância $D i-$ entre os valores FNIS e as pontuações das alternativas deve ser realizado conforme equação 22 .

Nas equações 22 e 23 , d $(\tilde{x}, \tilde{z})$ representa a distância entre dois números fuzzy, que pode ser obtida utilizando-se a equação 24 (para o caso de números fuzzy triangulares).

$$
\begin{aligned}
& D i+=\Sigma d v(\tilde{v} i j, \tilde{v} j+) n j=1 \\
& D i-=\Sigma d v(\tilde{v} i j, \tilde{v} j-) n j=1 \\
& d(\tilde{x}, \tilde{z})=\sqrt{ } 13[(l x-l z) 2+(m x-m z) 2+(u x-u z) 2]
\end{aligned}
$$

Para cada um dos indicadores avaliados, deve-se calcular o coeficiente de aproximação $C C i$ com a FPSIS e a FNIS, de acordo com a equação 25.

$$
C C i=D i-\left(D i++D i^{-}\right)
$$

Finalmente, obtém-se a hierarquização dos indicadores propostos para cada uma das categorias de requisitos legais da regulamentação em foco, pela ordem decrescente dos valores de CCi. Quão mais próximo a 1,0 for este valor, melhor é o grau de atendimento do indicador aos critérios de decisão. 


\subsection{3. \\ Avaliação qualitativa dos indicadores propostos aos critérios previamente estabelecidos}

De posse dos resultados da avaliação quantitativa do grau de atendimento dos indicadores de cada categoria de requisitos legais aos critérios de decisão, deve-se realizar uma avaliação qualitativa da hierarquização dos indicadores (em cada categoria), com o objetivo de viabilizar a mensuração e aumentar o grau de confiabilidade e de rastreabilidade daqueles indicadores posicionados nos níveis inferiores.

\section{8.}

\section{Considerações finais sobre o capítulo}

Como abordado neste capítulo, os indicadores são formas quantificáveis de se representar características de produtos e processos. Os efeitos das iniciativas/programas na esfera pública devem ser aferidos de alguma forma, de modo que o gerenciamento de um dado iniciativa/programa governamental seja realizado de forma eficaz. Os indicadores permitem avaliar resultados positivos e negativos, servem de base para uma decisão, melhoram processos, medem desempenho, entre diversas outras funções. Para uma boa utilização, os indicadores devem ser bem definidos, acompanhados sistematicamente para tomada de decisão e aplicáveis ao que de fato for relevante.

Destacaram-se neste capítulo a incorporação de uma abordagem fuzzy multicritério ao método de construção de indicadores de MA, divulgado pelo Ministério do Planejamento, Orçamento e Gestão. Cabe ressaltar que o método para construção da matriz de indicadores de MA foi concebido para dar suporte à definição de indicadores e métricas para avaliar o desempenho de Programas do PPA do Governo Federal. Para aplicação no contexto da regulamentação em foco, sofreu adaptações na fase de construção do modelo lógico.

A parte final do capítulo abordou métodos multicritério de apoio à decisão, para fins de opção daqueles a serem adotados na fase de pesquisa aplicada, sobretudo na definição de pesos dos critérios para classificar indicadores candidatos e na etapa final de hierarquização dos indicadores selecionados para monitorar e avaliar a regulamentação sobre rotulagem e bulas de agrotóxicos, afins e preservativos de madeira no Brasil. 
Os métodos quantitativos multicritério de apoio à decisão têm sido empregados em uma série de aplicações. Propõe-se, então, como ferramenta de seleção e classificação de indicadores de monitoramento e avaliação, a adoção de uma abordagem multicritério, integrando os métodos Fuzzy Analytical Hierarchy Process (Fuzzy AHP) (Buckley, 1985; Chang, 1996; Ayhan, 2013) e Fuzzy Technique for Order Preference by Similarity to Ideal Solution (Fuzzy TOPSIS) (Chen, 2000).

Por fim, considera-se que a integração dos métodos fuzzy AHP e fuzzy TOPSIS à metodologia que vem sendo adotada pelo Ministério do Planejamento, Orçamento e Gestão possam cooperar para o aperfeiçoamento da prática atual, que consiste na construção de indicadores de MA em diversos contextos da gestão pública. 

rotulagem e bulas de agrotóxicos, afins e preservativos de madeira no Brasil: proposição de indicadores e métricas

Apresentam-se e discutem-se os resultados da fase aplicada da pesquisa até a proposição de um conjunto consistente de indicadores para monitorar e avaliar a regulamentação em foco, respondendo a questão principal da dissertação. Descreve-se o processo de construção da matriz quantitativa de indicadores de MA, com suporte dos referidos métodos multicritério de apoio à decisão. Apresentam-se os seguintes resultados: (i) modelo lógico para proposição de indicadores para o monitoramento e avaliação da implementação da regulamentação em foco; (ii) abordagem metodológica fuzzy multicritério para hierarquização dos indicadores inicialmente propostos; e (iii) um conjunto de indicadores hierarquizados por categoria de requisitos legais da RDC no 296/2019 a serem selecionados posteriormente pela Anvisa.

\section{1. Desenho do modelo lógico da regulamentação para rotulagem e bulas de agrotóxicos, afins e preservativos de madeira no Brasil}

Para fins do desenho do modelo lógico da regulamentação para rotulagem e bulas de agrotóxicos, afins e preservativos de madeira, adaptou-se a metodologia proposta pelo Instituto de Pesquisa Econômica Aplicada (IPEA), voltada para a organização de avaliações dos Programas que integram o Plano Plurianual (PPA). O modelo lógico elaborado compõe-se de três partes: (i) explicação do problema e referências básicas da regulamentação; (ii) estruturação da regulamentação para o alcance de resultados; e (iii) identificação dos fatores de contexto.

Considera-se que o modelo lógico da regulamentação para rotulagem e bulas de agrotóxicos, afins e preservativos de madeira foi essencial para orientar a proposição dos indicadores para o monitoramento e avaliação de seus resultados. A elaboração do modelo lógico da regulamentação em foco contribuiu para 
garantir as seguintes condições: (i) definição clara dos objetivos e resultados esperados com a implementação da regulamentação sobre rotulagem e bulas de agrotóxicos, afins e preservativos de madeira no Brasil; (ii) identificação de indicadores, que possam ser obtidos e gerenciados pela Anisa; e (iii) comprometimento dos gestores do órgão regulador e dos fabricantes de produtos agrotóxicos.

O modelo lógico representado através do fluxograma no item 4.1.4, serviu como base para o mapeamento dos indicadores candidatos, focalizando-se as categorias de requisitos legais da regulamentação em foco. Os indicadores candidatos são os indicadores inicialmente propostos, desenvolvidos a partir do modelo lógico, que serão avaliados de acordo com a ferramenta de avaliação quantitativa. Apresentam-se, a seguir, o processo de construção e o modelo lógico da regulamentação para rotulagem e bulas de agrotóxicos, afins e preservativos de madeira no Brasil.

\subsection{1.}

\section{Explicação do problema e referências básicas da regulamentação}

Conforme reportado no capítulo 2, uma das dificuldades da Anvisa durante a análise de registro e pós registro de agrotóxicos, afins e preservativos de madeira consiste na avaliação das informações encontradas nos rótulos e bulas. Como a responsabilidade sobre as informações nos rótulos e bulas é das empresas não ocorre uma padronização e harmonização nesses documentos entre os diferentes produtos comercializados. Muitas das informações veiculadas não advertem corretamente para os perigos e riscos de utilização desses produtos. Além disso, as informações médicas presentes nos rótulos e bulas não refletem as reias condutas a serem tomadas em casos de emergência.

Para superar estas dificuldades a Anvisa pubicou a RDC n 296 em julho de 2019, que dispõe sobre as informações toxicológicas para rótulos e bulas de agrotóxicos, afins e preservativos de madeira, alinhando as exigências de rótulos e bulas as diretrizes utilizadas internacionalmente através da adoção do GHS. Com isso a Agência espera comunicar com maior clareza os riscos aos quais os agricultores estão expostos ao manusearem e aplicarem esses produtos químicos. 
Após publicação a resolução prevê prazo de um ano para que as fabricantes possam se adequar as novas diretrizes para elaboração dos rótulos e bulas dos agrotóxicos, afins e preservativos de madeira, incorporando pictogramas estabelecidos pelo GHS para a comunicação do perigo, juntamente com as palavras de advertência e frases de perigo. Como objetivos estratégicos a Anvisa pretende garantir o acesso seguro aos produtos, aprimorar a qualidade regulatória em vigilância sanitária e fortalecer a atuação internacional e o relacionamento com atores e parceiros estratégicos.

Busca-se com este trabalho de pesquisa, propor um conjunto de indicadores e métricas para monitorar e avaliar a regulamentação sobre rotulagem e bulas de agrotóxicos, afins e preservativos de madeira no Brasil.

\subsection{2.}

\section{Estruturação da regulamentação para o alcance de resultados}

A regulamentação foi estruturada distinguindo-se as três categorias de requisitos legais, para modelo de rótulo, modelo de bula e instruções para preenchimento do quadro de informações médicas. A categoria para modelo de rótulo conta com dezenove itens, desesseis itens para modelo de bula e doze itens para o quadro de informações médicas.

Os indicadores serão mapeados para cada categoria de requisitos legais. Esses deverão ser propostos mediante análise de conteúdo de cada requisito, pois não existem na literatura.

\subsection{3.}

\section{Identificação dos fatores de contexto}

A última etapa da construção do modelo lógico foi a identificação dos fatores relevantes de contexto, para uma reflexão das possíveis influências, tanto positivas quanto negativas, relacionadas às ações de implementação da regulamentação representada na Figura 4.1. Trata-se de um exercício importante, que permite confrontar aspectos bons e ruins da implementação e analisar previamente as hipóteses assumidas na estruturação do problema, realizada na primeira etapa (item 4.1.1). 
Cabe ressaltar que esses fatores devem ser atualizados continuamente, pois mudanças sempre acontecem, gerando novos fatos, que podem representar oportunidades a serem aproveitadas ou problemas a serem superados.
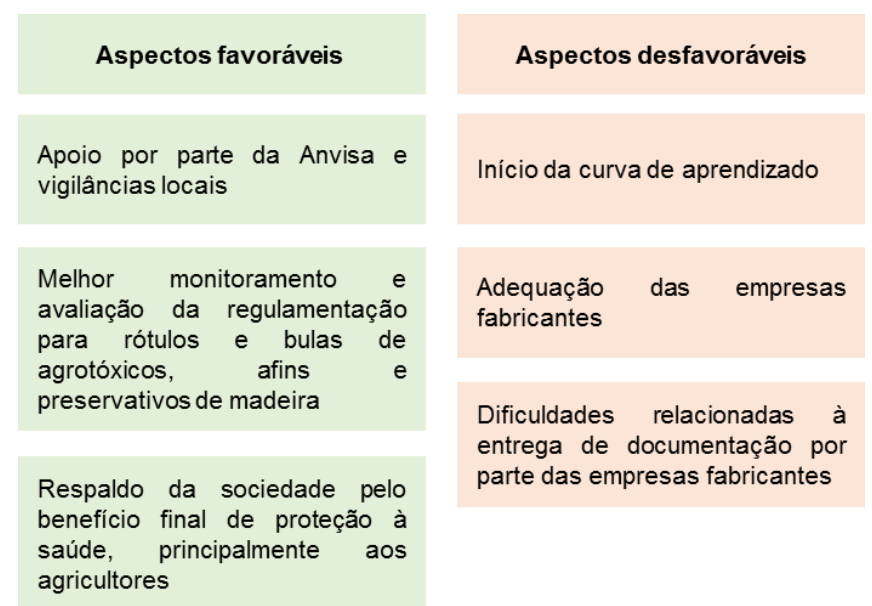

Figura 4.1 - Fatores relevantes de contexto para implementação da regulamentação para rotulagem e bulas de agrotóxicos, afins e preservativos de madeira no Brasil

Fonte: Elaboração própria.

\subsection{4.}

Modelo lógico da regulamentação para rotulagem e bulas de agrotóxicos, afins e preservativos de madeira

A construção do modelo lógico é uma proposta para organizar as ações componentes de um programa de forma articulada aos resultados esperados, apresentando também as hipóteses e as ideias que dão sentido à intervenção. Neste caso a intervenção se deu através da implantação da RDC n 296/19 elaborada pela Anvisa.

Conhecer o problema regulatório e os objetivos da intervenção permite determinar melhor os indicadores. Para fins do desenho do modelo lógico da regulamentação para rotulagem e bulas de agrotóxicos, afins e preservativos de madeira foi necessário adaptar a metodologia proposta pelo Instituto de Pesquisa Econômica Aplicada (IPEA), voltada para a organização de avaliações dos Programas que integram o Plano Plurianual (PPA). A figura 4.2 apresenta o modelo lógico da regulamentação para rotulagem e bulas de agrotóxicos, afins e preservativos de madeira no Brasil. 


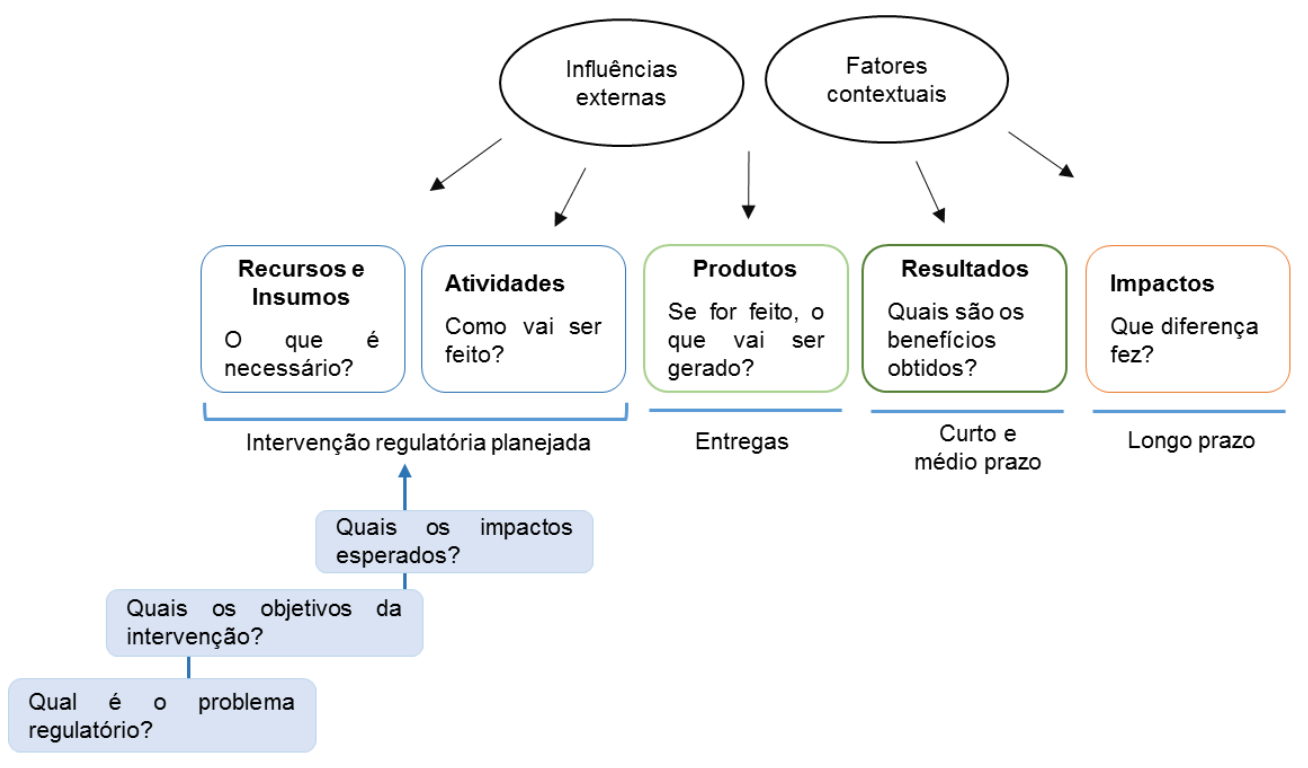

Figura 4.2 - Modelo lógico da regulamentação para rotulagem e bulas de agrotóxicos, afins e preservativos de madeira no Brasil Fonte: Elaboração própria

O modelo lógico serviu de base para a construção da matriz inicial de avaliação quantitativa de indicadores candidatos, focalizando-se as categorias de requisitos legais da regulamentação em foco. Os esforços deverão se concentrar no monitoramento e avaliação para os fabricantes, Anvisa, órgãos de vigilância sanitária e principalmente para os agricultores.

\section{2.}

\section{Fluxograma do modelo conceitual}

A figura 4.3 apresenta o fluxograma da regulamentação para rotulagem e bulas de agrotóxicos, afins e preservativos de madeira, desde a construção do modelo lógico, aplicação das ferramentas multicritério de apoio a decisão, análise trade off proposta para Anvisa e cadastro dos indicadores pelo órgão regulador. Desta forma, torna-se mais fácil identificar as fases do modelo e a aplicação das ferramentas. 

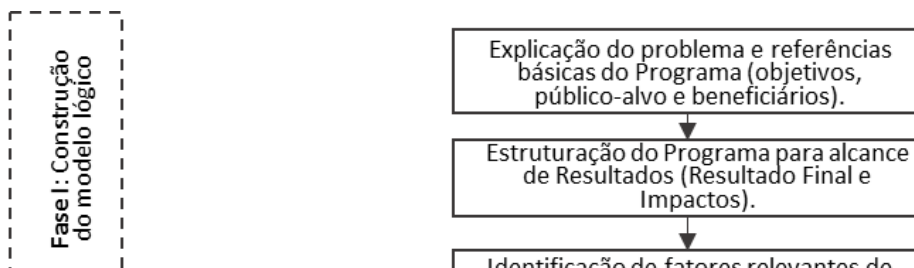

básicas do Programa (objetivos,

público-alvo e beneficiários).

Estruturação do Programa para alcance
de Resultados (Resultado Final e

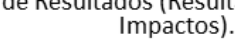

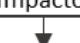

Identificação de fatores relevantes de Contexto.

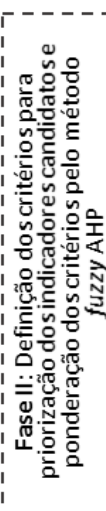

\section{Definir os critérios e a escala linguística}

Análise da RDC no 296/2019

Comparação pareada por especialistas dos critérios "números fuzzy triangulares"

Verificação de consistệncia da matriz pareada "Sistema IPE versão 1.0"

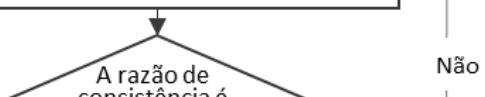

consistência é
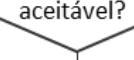

$\checkmark \quad \operatorname{sim}$

Resultado dos pesos de cada critério usando a ferramenta Fuzzy AHP Software
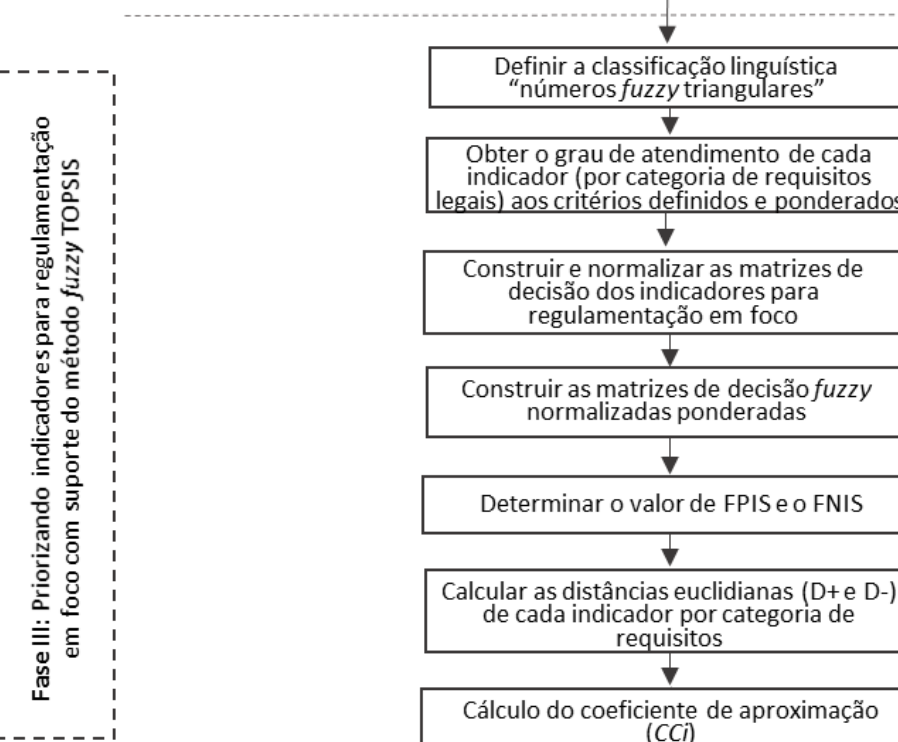

Obter o grau de atendimento de cada egais) aos critérios definidos e ponderados

$\boldsymbol{\nabla}$ decisão dos indicadores para regulamentação em foco

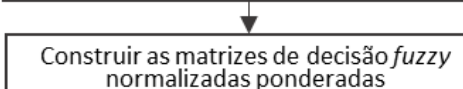
normalizadas ponderadas

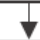

Determinar o valor de FPIS e o FNIS

Calcular as distâncias euclidianas ( $D+$ e D-) de cada indicador por categoria de requisitos$$
\checkmark
$$

Cálculo do coeficiente de aproximação $(C C i)$

\section{$\nabla$}

Hierarquização dos indicadores propostos para cada uma das categorias de requisitos legais da regulamentação em foco

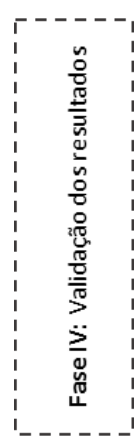

Avaliação dos indicadores hierarquizados por parte dos especialistas em metrologia

$$
\downarrow
$$

Avaliação dos indicadores por parte da Anvisa, para escolha daqueles que mais expressem os resultados esperados

Cadastro dos indicadores pelo órgão regulador, neste caso a Anvisa

Figura 4.3 - Fluxograma do modelo para regulamentação em foco Fonte: Elaboração própria 


\section{3.}

Construção da matriz de indicadores de MA para a nova regulamentação de rotulagem e bulas de agrotóxicos

A construção da matriz de avaliação quantitativa de indicadores de Monitoramento e Avaliação - MA - teve como ponto de partida a caracterização das categorias de requisitos legais de rótulos, bulas e instruções para preenchimento do quadro de informações médicas; identificando assim as questões relevantes a serem avaliadas em cada categoria. Os indicadores inicialmente propostos para cada categoria serão posteriormente selecionados e hierarquizados com suporte de métodos multicritério de apoio à decisão, utilizando os métodos fuzzy AHP e fuzzy TOPSIS.

O quadro 4.1, apresentado a seguir, reúne as bases para a construção da matriz de indicadores de MA da regulamentação sobre rotulagem e bulas de agrotóxicos no Brasil. 
Quadro 4.1 - Base para a construção da matriz de indicadores de MA da regulamentação sobre rotulagem e bulas de agrotóxicos, afins e preservativos de madeira no Brasil

\begin{tabular}{|c|c|c|}
\hline Objetivo da regulamentação & Categoria de requisitos legais & $\begin{array}{l}\text { Informação a ser apresentada no rótulo do } \\
\text { agrotóxico }\end{array}$ \\
\hline \multirow[t]{2}{*}{$\begin{array}{l}\text { Estabelecer as informações obrigatórias } \\
\text { relativas à proteção da saúde humana } \\
\text { que devem constar em rótulos e bulas de } \\
\text { agrotóxicos, afins e preservativos de } \\
\text { madeira. } \\
\text { Implantar a adoção das diretrizes de } \\
\text { rotulagem do Sistema Globalmente } \\
\text { Harmonizado de Classificação e } \\
\text { Rotulagem de Produtos Químicos } \\
\text { (GHS) }\end{array}$} & \multirow[t]{2}{*}{ Modelo de rótulo } & $\begin{array}{l}\text { COLUNA CENTRAL } \\
\text { Marca comercial do produto; } \\
\text { Composição do produto; } \\
\text { Conteúdo; } \\
\text { Classe; } \\
\text { Grupo Químico; } \\
\text { Tipo de Formulação; } \\
\text { Titular do Registro; } \\
\text { Fabricantes do Produto Técnico ou Produto Técnico; } \\
\text { Formulador/Manipulador; } \\
\text { Quadro sobre Informações Relativas ao Lote do } \\
\text { Produto; } \\
\text { Frases e Outras Informações; } \\
\text { Classificação Toxicológica }\end{array}$ \\
\hline & & $\begin{array}{l}\text { COLUNA DA DIREITA } \\
\text { Frases Relativas à Proteção da Saúde Humana; } \\
\text { Quadro de Primeiros Socorros; } \\
\text { Quadro de Antídoto e Tratamento; } \\
\text { Quadro de "TELEFONES DE EMERGÊNCIA PARA } \\
\text { INFORMAÇÕES MÉDICAS" } \\
\text { Faixa do Rótulo. }\end{array}$ \\
\hline
\end{tabular}


Quadro 4.1- Base para a construção da matriz de indicadores de MA da regulamentação sobre rotulagem e rótulos de agrotóxicos no Brasil (cont.)

\begin{tabular}{|c|c|c|}
\hline Objetivo da regulamentação & Categoria de requisitos legais & Informação a ser apresentada no rótulo do agrotóxico \\
\hline \multirow[t]{2}{*}{$\begin{array}{l}\text { Estabelecer as informações obrigatórias relativas à } \\
\text { proteção da saúde humana que devem constar em } \\
\text { rótulos e bulas de agrotóxicos, afins e preservativos } \\
\text { de madeira. } \\
\text { Implantar a adoção das diretrizes de rotulagem do } \\
\text { Sistema Globalmente Harmonizado de } \\
\text { Classificação e Rotulagem de Produtos Químicos } \\
\text { (GHS). }\end{array}$} & Modelo de bula & $\begin{array}{l}\text { Composição; } \\
\text { Conteúdo; } \\
\text { Classe; } \\
\text { Grupo Químico; } \\
\text { Tipo de Formulação; } \\
\text { Titular do Registro; } \\
\text { Fabricantes do Produto; Técnico ou Produto Técnico; } \\
\text { Formulador/Manipulador; } \\
\text { Quadro de Informações de Fabricação; } \\
\text { Frases e Outras Informações; } \\
\text { Classificação Toxicológica; } \\
\text { Classificação do Potencial de Periculosidade Ambiental; } \\
\text { Faixa de Classificação Toxicológica; } \\
\text { Instruções de Uso; } \\
\text { Frases Relativas à Proteção da Saúde Humana; } \\
\text { Quadro de Primeiros Socorros. }\end{array}$ \\
\hline & $\begin{array}{l}\text { Instruções para preenchimento do } \\
\text { quadro de informações médicas }\end{array}$ & $\begin{array}{l}\text { Grupo Químico; } \\
\text { Classe Toxicológica; } \\
\text { Vias de Exposição; } \\
\text { Toxicocinética; } \\
\text { Toxicodinâmica; } \\
\text { Sintomas e Sinais Clínicos; } \\
\text { Diagnóstico; } \\
\text { Tratamento; } \\
\text { Contraindicações; } \\
\text { Efeitos das Interações Químicas (Efeitos Sinérgicos); } \\
\text { Mecanismos de Ação; } \\
\text { Absorção, Excreção Efeitos Agudos e Crônicos para } \\
\text { Animais de Laboratório. }\end{array}$ \\
\hline
\end{tabular}

Fonte: Elaboração própria. 


\subsection{1.}

\section{Avaliação do objetivo da regulamentação e resultados esperados}

Identificam-se neste item os aspectos da regulamentação que deveriam ser alvo de monitoramento e avaliação, a partir da análise de conteúdo da RDC 296/19, associando-os às três categorias de requisitos legais apresentados no quadro 4.1.

O quadro 4.2, a seguir, sintetiza os resultados desta análise, que contemplou as evidências da existência do problema a ser monitorado e avaliado; os objetivos da regulamentação como estabelecido na RDC no 296/209 pela Anvisa; os principais resultados esperados e os aspectos da regulamentação que devem ser considerados para fins de monitoramento e avaliação.

\subsection{2.}

\section{Identificação das partes interessadas}

Faz-se necessário identificar os stakeholders, ou seja, quais são os principais interessados da nova regulamentação para avaliação toxicológica de agrotóxicos no Brasil. São eles:

- Anvisa: orgão federal responsável pela avaliação toxicológica dos produtos agrotóxicos, pela formulação da RDC296/19 e monitoramento e avaliação dos resultados durante sua implementação;

- Órgãos de Vigilância Sanitária Estaduais e Municipais: responsáveis pela fiscalização e avaliação da conformidade das embalagens dos agrotóxicos, afins e preservativos de madeira;

- Fabricantes e comercializadores de agrotóxicos, afins e preservativos de madeira;

- Agricultores: realizam o preparo e aplicação dos agrotóxicos, afins e preservativos de madeira em campo;

- População: consumidores de produtos da cadeia agroalimentar. 
Quadro 4.2 - Síntese da avaliação dos objetivos da regulamentação e resultados esperados

\begin{tabular}{|c|c|}
\hline Componentes & Descrição \\
\hline Casos de evidências da existência do problema & $\begin{array}{l}\text { - Não ocorre uma padronização e harmonização das informações } \\
\text { presentes nos rótulos e bulas das embalagens dos agrotóxicos; } \\
\text { - Muitas das informações veiculadas não advertem corretamente } \\
\text { para os perigos e riscos da utilização desses produtos; } \\
\text { - As informações médicas presentes nos rótulos e bulas não } \\
\text { refletem as reais condutas a serem tomadas em casos de } \\
\text { emergência; }\end{array}$ \\
\hline Objetivos da regulamentação & $\begin{array}{l}\text { - Estabelecer as informaçães obrigatórias relativas à proteção da } \\
\text { saúde humana que devem constar em rótulos e bulas de } \\
\text { agrotóxicos, afins e preservativos de madeira; } \\
\text { - Adoção das diretrizes de rotulagem do Sistema Globalmente } \\
\text { Harmonizado de Classificação e Rotulagem de Produtos } \\
\text { Químicos (GHS). }\end{array}$ \\
\hline Resultados esperados & $\begin{array}{l}\text { - Alinhar as informações toxicológicas dos rótulos e bulas de } \\
\text { agrotóxicos com as diretrizes utilizadas internacionalmente; } \\
\text { - Possibilitar melhor entendimento dos riscos desses produtos ao } \\
\text { agricultor, minimizando os possíveis efeitos prejudiciais sobre a } \\
\text { saúde do homem; } \\
\text { - Informar com maior clareza as precauções para evitar danos às } \\
\text { pessoas que aplicam e manipulam agrotóxicos e afins; } \\
\text { - Manter os símbolos de advertências e frases padronizados; } \\
\text { - Padronizar as instruções para o caso de acidente, incluindo } \\
\text { sintomas de alarme, primeiros socorros, antídotos e informações } \\
\text { para os médicos. } \\
\text { - Garantir o acesso seguro da população a produtos e serviços } \\
\text { sujeitos a vigilância sanitária; } \\
\text { - Aprimorar a qualidade regulatória em vigilância sanitária; } \\
\text { - Fortalecer a atuação internacional e o relacionamento com atores } \\
\text { e parceiros estratégicos. }\end{array}$ \\
\hline $\begin{array}{l}\text { Categorias de requisitos legais que deverão ser objeto de } \\
\text { monitoramento e avaliação. }\end{array}$ & $\begin{array}{l}\text { - Modelo de rótulo; } \\
\text { - Modelo de bula; } \\
\text { Instruções para preenchimento do quadro de informações } \\
\text { médicas. }\end{array}$ \\
\hline
\end{tabular}

Fonte: Elaboração própria. 


\subsection{3. \\ Definição dos tipos de indicadores}

Considera-se esta, uma fase importante da pesquisa, a partir de então serão definidos os tipos de indicadores que serão obrigatórios para atender os diferentes interesses identificados pelos stakeholders. Seguindo-se a recomendação do Ministério de Planejamento, Orçamento e Gestão (Brasil, 2010), os indicadores podem ser classificados em três tipos:

- Indicadores-chave: refletem o conceito mais importante de um ou mais requisitos legais que deverão ser objeto de monitoramento e avaliação da rotulagem de alimentos que causam alergia;

- Indicadores complementares: complementam os indicadores- chave, proporcionando confiabilidade da mensuração e rastreabilidade da informação;

- Indicadores específicos: além de expressar necessidades próprias de determinados interessados específicos do tema em contexto, questões especificamente ao MA da regulamentação em foco.

\subsection{4.}

\section{Definição dos critérios de seleção dos indicadores}

Os critérios podem ser classificados em:

- Critérios eliminatórios: devem ser obrigatoriamente atendidos pelo indicador proposto (caso não atenda, o indicador deve ser descartado);

- Critérios classificatórios: permitem a hierarquização dos indicadores, com suporte da técnica TOPSIS.

O quadro 4.3 apresenta a proposição dos critérios para validação dos indicadores, que deverão compor a matriz de avaliação quantitativa de indicadores de MA da regulamentação sobre rotulagem e bulas de agrotóxicos. Essa proposta foi validada durante o pré-teste com o grupo de mestrandos do Programa de Pósgraduação em Metrologia da PUC-Rio. 
Quadro 4.3 - Proposição de critérios para validação dos indicadores

\begin{tabular}{|l|l|l|}
\hline Ref. & Critério & Descrição \\
\hline C1 & Relevância & $\begin{array}{l}\text { O indicador deve revelar o grau de relevância da mensuração em } \\
\text { relação à dimensão considerada e ao atendimento às necessidades } \\
\text { de informação dos interessados. }\end{array}$ \\
\hline C2 & Mensurabilidade & $\begin{array}{l}\text { O indicador deve contar com uma capacidade de mensuração, além } \\
\text { de uma ótima precisão sem ambiguidade. O custo da coleta dos } \\
\text { dados é compensado pelos benefícios que são gerados a partir das } \\
\text { informações resultantes do indicador. }\end{array}$ \\
\hline C3 & Tempestividade & $\begin{array}{l}\text { As informações que compõem o indicador devem ser atuais e } \\
\text { possíveis de serem obtidas em tempo hábil para seu uso. }\end{array}$ \\
\hline C5 & Confiabilidade & $\begin{array}{l}\text { Deve ser proveniente de fontes seguras, íntegras, sem a } \\
\text { possibilidade de manipulação de resultados. A mensuração deve ser } \\
\text { objetiva, verdadeira e verificável. }\end{array}$ \\
\hline $\begin{array}{l}\text { Reve ser rastreável e conter informações necessárias de fontes } \\
\text { confiáveis, que possam ser acessadas em qualquer momento que se } \\
\text { fizer necessário. }\end{array}$ \\
\hline
\end{tabular}

Fonte: Elaboração própria.

\subsection{5.}

\section{Proposição de indicadores candidatos}

Elaborou-se a lista de indicadores candidatos, com base na análise de conteúdo da Resolução RDC n 296/2019 sobre rótulos e bulas de agrotóxicos, Guia para Elaboração de Rótulos e Bulas de Agrotóxicos, Afins e Preservativos de Madeira; ambos elaborados pela Anvisa, Lei no 7.802, de 11 de julho de 1989 e o Decreto $n^{\circ} 4.074$, de 4 de janeiro de 2002.

De acordo com o Guia para elaboração de rótulo e bula de agrotóxicos, afins e preservativos de madeira, elaborado e revisado pela Anvisa (2019), os rótulos de agrotóxicos estão divididos em coluna central e coluna da direita. As informações da saúde constantes nos rótulos de agrotóxicos são importantes ferramentas de comunicação para os usuários. Desta forma, a Anvisa deve avaliar as informações relativas à saúde humana, submetidas pelas empresas registrantes na apresentação dos rótulos quanto à adequabilidade do conteúdo.

Os rótulos dos agrotóxicos devem ser fixados de forma a não permitir que ele seja removido ou alterado durante o transporte, armazenamento e uso do produto. Deve conter as precauções relativas à saúde humana.

No apêndice 1, apresentam-se os 'indicadores candidatos' e suas métricas para todas as categorias de requisitos legais, a saber: (i) imodelos de rótulos (colunas central e da direita); (ii) modelos de bulas; e (iii) instruções para preenchimento do quadro de informações médicas. 
As informações na bula de agrotóxicos devem ser dispostas conforme estabelecido no Decreto $\mathrm{n}^{\mathrm{o}}$ 4.074, de 04 de janeiro de 2002, acrescidas das informações do rótulo e das estabelecidas na RDC 296/2019 da Anvisa e no Guia para elaboração de rótulo e bula de agrotóxicos, afins e preservativos de madeira.

As informações médicas devem ser dispostas de forma crítica e concisa, sustentadas pela literatura técnico-científica e pelos estudos toxicológicos realizados com o produto formulado. Deve-se avaliar a composição qualiquantitativa do produto, bem como a toxicologia dos ingredientes ativos e dos componentes toxicologicamente relevantes presentes na formulação.

\section{4. Pré-teste da matriz de avaliação quantitativa de indicadores de Monitoramento e Avaliação - MA}

Antes da definição dos pesos dos critérios classificatórios, realizou-se o préteste da "Matriz de Avaliação Quantitativa de Indicadores de MA" junto a cinco mestrandos do Programa de Pós-graduação em Metrologia da PUC-Rio (PósMQI), que haviam cursado as disciplinas 'Fundamentos da Tecnologia Industrial Básica' e 'Sistemas de Avaliação da Sustentabilidade'.

Antecedendo a fase do pré-teste, realizou-se uma reunião pela plataforma Zoom, com todos os especialistas, ocasião em que foram apresetnados os objetivos do novo marco regulatório e o foco da presente pesquisa. Os objetivos do pré-teste foram dimensionar o tempo necessário para preenchimento da matriz e melhorar a ferramenta com relação aos seguintes aspectos:

- Objetividade da mensagem introdutória;

- Clareza e precisão dos termos e das orientações;

- Estrutura da matriz e quantidade de itens a serem respondidos;

- Formato dos indicadores e métricas apresentadas.

Todos os participantes do pré-teste consideraram o formato das matrizes adequado para aplicação posterior. Mencionaram um tempo médio de preenchimento de 120 minutos.

A definição dos pesos dos critérios classificatórios foi realizada com suporte do método fuzzy AHP e com a participação de outros cinco mestrandos do PósMQI, que haviam cursado as referidas disciplinas junto com a autora. 


\section{5.}

\section{Resultados da atribuição dos pesos aos critérios pelo método fuzzy AHP}

Propõe-se uma matriz inicial dos indicadores 'candidatos', considerando as categorias de requisitos legais descritos no quadro 4.1. Tendo em vista os tipos de indicadores necessários para atender aos diferentes interesses dos stakeholders, determinam-se quais os critérios eliminatórios e classificatórios devem ser atendidos para selecionar e classificar os indicadores.

Utilizou-se a ferramenta computacional Fuzzy AHP Software ${ }^{\circledR}$ para cálculo dos pesos dos cinco critérios: (i) relevância; (ii) mensurabilidade; (iii) tempestividade; (iv) confiabilidade; e (v) rastreabilidade. O julgamento dos critérios consiste no reflexo de duas perguntas: qual dos dois elementos é o mais importante, tendo em vista a nova regulamentação para rótulos e bulas dos agrotóxicos, e com qual intensidade ele é mais importante.

Apresentam-se nas tabelas 4.1 a 4.4 os resultados da atribuição dos pesos aos critérios definidos por comparações pareadas dos critérios. Os julgamentos foram realizados por cinco especialistas (respondentes) em metrologia.

Tabela 4.1 - Comparação pareada dos critérios de decisão

\begin{tabular}{|c|c|c|c|c|c|c|}
\hline \multirow{2}{*}{\multicolumn{2}{|c|}{ Comparação pareada dos critérios }} & \multicolumn{5}{|c|}{$\begin{array}{c}\text { Julgamento crispy sobre intensidade } \\
\text { da importância do critério* }\end{array}$} \\
\hline & & R1 & R2 & R3 & R4 & R5 \\
\hline (x ) C1 - Relevância & ( ) C2 - Mensurabilidade & 1 & 1 & 1 & 1 & 1 \\
\hline (x ) C1 - Relevância & ( ) C3 - Tempestividade & 3 & 2 & 3 & 3 & 3 \\
\hline (x ) C1 - Relevância & ( ) C4 - Confiabilidade & 1 & 2 & 2 & 3 & 2 \\
\hline (x ) C1 - Relevância & ( ) C5 - Rastreabilidade & 2 & 3 & 2 & 2 & 2 \\
\hline ( x ) C2 - Mensurabilidade & ( ) C3 - Tempestividade & 2 & 3 & 2 & 2 & 2 \\
\hline ( x ) C2 - Mensurabilidade & ( ) C4 - Confiabilidade & 1 & 1 & 1 & 1 & 1 \\
\hline ( x ) C2 - Mensurabilidade & ( ) C5 - Rastreabilidade & 2 & 1 & 2 & 3 & 3 \\
\hline ( ) C3 - Tempestividade & ( x ) C4 - Confiabilidade & 3 & 2 & 2 & 3 & 3 \\
\hline (x ) C3 - Tempestividade & ( ) C5 - Rastreabilidade & 1 & 1 & 1 & 1 & 1 \\
\hline (x) C4 - Confiabilidade & ( ) C5 - Rastreabilidade & 2 & 2 & 3 & 2 & 3 \\
\hline
\end{tabular}

Fonte: Elaboração própria.

Nota: ${ }^{*} \mathrm{R}=$ Respondente. 
Tabela 4.2 - Pesos dos critérios e razões de consistência (RC) das matrizes com os julgamentos respondentes (R1 a R5)

\begin{tabular}{lccccc}
\hline Critérios & $\mathbf{R 1}$ & $\mathbf{R 2}$ & $\mathbf{R 3}$ & $\mathbf{R 4}$ & $\mathbf{R 5}$ \\
\hline C1 - Relevância & 0,264 & 0,306 & 0,304 & 0,323 & 0,298 \\
\hline $\mathbf{C 2}$ - Mensurabilidade & 0,244 & 0,238 & 0,240 & 0,256 & 0,255 \\
\hline C3 - Tempestividade & 0,105 & 0,113 & 0,110 & 0,101 & 0,100 \\
\hline C4 - Confiabilidade & 0,264 & 0,211 & 0,232 & 0,212 & 0,245 \\
\hline C5 - Rastreabilidade & 0,006 & 0,133 & 0,113 & 0,108 & 0,102 \\
\hline RC & $\mathbf{0 , 0 0 6}$ & $\mathbf{0 , 0 4 0}$ & $\mathbf{0 , 0 2 2}$ & $\mathbf{0 , 0 4 4}$ & $\mathbf{0 , 0 2 7}$ \\
\hline
\end{tabular}

Fonte: Elaboração própria, a partir das respostas dos mestrandos do PósMQI/PUC-Rio.

Apresenta-se, a seguir, a matriz de comparação pareada dos critérios de decisão com números fuzzy triangulares (NFT), calculados através da média dos julgamentos dos especialistas (tabela 4.3).

Tabela 4.3 - Matriz de comparação pareada dos critérios de decisão com números fuzzy triangulares (NFT)

\begin{tabular}{lccccc}
\hline Critérios & C1 & C2 & C3 & C4 & C5 \\
\hline C1 & $(1,00 ; 1,00 ; 1,00)$ & $(1,00 ; 1.00,1.00)$ & $(1,00 ; 2,76 ; 4,00)$ & $(1,00 ; 1,88 ; 4,00)$ & $(1,00 ; 2,16 ; 4,00)$ \\
\hline C2 & $(1,00 ; 1,00 ; 1,00)$ & $(1,00 ; 1,00 ; 1,00)$ & $(1,00 ; 2,16 ; 4,00)$ & $(1,00 ; 1,00 ; 1,00)$ & $(1,00 ; 2,04 ; 4,00)$ \\
\hline C3 & $(0,25 ; 0,36 ; 1,00)$ & $(0,25 ; 0,46 ; 1,00)$ & $(1,00 ; 1,00 ; 1,00)$ & $(0,25 ; 0,39 ; 1,00)$ & $(1,00 ; 1,00 ; 1,00)$ \\
\hline C4 & $(0,25 ; 0,53 ; 1,00)$ & $(1,00 ; 1,00 ; 1,00)$ & $(1,00 ; 2,54 ; 4,00)$ & $(1,00 ; 1,00 ; 1,00)$ & $(1,00 ; 2,35 ; 4,00)$ \\
\hline C5 & $(0,25 ; 0,46 ; 1,00)$ & $(0,25 ; 0,48 ; 1,00)$ & $(1,00 ; 1,00 ; 1,00)$ & $(0,25 ; 0,42 ; 1,00)$ & $(1,00 ; 1,00 ; 1,00)$ \\
\hline
\end{tabular}

Fonte: Elaboração própria.

Como apresentado na tabela 4.4, foram calculados os pesos dos critérios, com suporte do Fuzzy AHP Software®.

Tabela 4.4 - Pesos atribuídos aos critérios de decisão

\begin{tabular}{clc}
\hline Rank & \multicolumn{1}{c}{ Critério } & Peso \\
\hline $\mathbf{1}$ & C1 - Relevância & 0,272 \\
\hline $\mathbf{3}$ & C2 - Mensurabilidade & 0,243 \\
\hline $\mathbf{5}$ & C3 - Tempestividade & 0,119 \\
\hline $\mathbf{2}$ & C4 - Confiabilidade & 0,246 \\
\hline $\mathbf{4}$ & C5 - Rastreabilidade & 0,121 \\
\hline
\end{tabular}

Fonte: Elaboração própria.

Na tabela 4.4, pode-se observar o ranking com os critérios de decisão de maior peso. Os resultados foram submetidos à avaliação dos cinco respondentes, sendo considerados satisfatórios. Os pesos apresentados serão considerados na fase fuzzy TOPSIS para hierarquização dos indicadores propostos, por categoria 
de requisitos da regulamentação para rótulos e bulas de agrotóxicos, afins e preservativos de madeira.

\section{6. \\ Resultados da avaliação quantitativa do grau de atendimento dos indicadores aos critérios pelo método fuzzy TOPSIS}

Após a atribuição dos pesos aos critérios de decisão pelo método fuzzy AHP, iniciou-se a avaliação quantitativa do grau de atendimento dos indicadores propostos a tais critérios pelo método fuzzy TOPSIS. Esta avaliação compreendeu os seguintes passos: (i) constituição das matrizes de avaliação quantitativa dos indicadores por categoria de requisitos legais da regulamentação em foco, preenchendo-as com termos linguísticos fornecidos por especialistas em metrologia referente ao grau de atendimento dos indicadores aos critérios de decisão. Os termos linguísticos foram representados por números fuzzy triangulares; (ii) definição da solução ideal positiva fuzzy e solução ideal negativa fuzzy (FPIS e FNIS) e definição da distância para FPIS (D+) e para FNIS (D-); e (iii) determinação da proximidade relativa do valor ideal e hierarquização dos indicadores por categoria de requisitos legais da regulamentação em foco.

\subsection{1. \\ Indicadores para Modelo de rótulo - colunas central e da direita}

Conforme as categorias de requisitos legais identificadas como objeto de monitoramento e avaliação da RDC n 296/2019, apresenta-se, inicialmente, na tabela 4.5 a matriz de decisão dos indicadores para modelo de rótulo, coluna central. Complementa esta Resolução, um guia para elaboração de rótulo e bula de agrotóxicos, afins e preservativos de madeira, revisado e publicado em 30 de setembro de 2019 (Anvisa, 2019b). Posteriormente, os valores foram normalizados e ponderados. Geraram-se as matrizes de distância total positiva D+ e distância total negativa D- conforme equações 20 e 21. Para o cálculo das distâncias entre os valores de FPIS e FNIS, utilizaram-se, respectivamente, as equações 22 e 23. Calcularam-se ainda os valores do coeficiente de proximidade (CCi). Todos os cálculos foram realizados com o apoio de planilha Excel®. Apresentam-se os resultados nas tabelas 4.6 a 4.8, referentes a todos os indicadores propostos para categoria de rótulos (colunas central e da direita). 
Tabela 4.5 - Matriz de decisão dos Indicadores para 'Modelo de Rótulo (Coluna Central)' avaliados à luz dos critérios C1 a C5

\begin{tabular}{|c|c|c|c|c|c|c|c|c|c|c|c|c|c|c|c|}
\hline Indicadores Candidatos & & C1 & & & C2 & & & C3 & & & C4 & & & C5 & \\
\hline $\begin{array}{l}\text { IMR1- Inadequação do rótulo por ausência da marca } \\
\text { comercial do produto. }\end{array}$ & 7,0 & 9,0 & 9,0 & 7,0 & 9,0 & 9,0 & 4,2 & 6,2 & 8,2 & 3,8 & 5,8 & 7,8 & 3,0 & 5,0 & 7,0 \\
\hline $\begin{array}{l}\text { IMR2- Inadequação do rótulo por ausência da } \\
\text { composição do produto. }\end{array}$ & 7,0 & 9,0 & 9,0 & 5,8 & 7,8 & 9,0 & 4,2 & 6,2 & 8,2 & 3,4 & 5,4 & 7,4 & 3,8 & 5,8 & 7,8 \\
\hline $\begin{array}{l}\text { IMR3- Inadequação do rótulo por ausência de informação do conteúdo, } \\
\text { em unidade de massa ou volume. }\end{array}$ & 7,0 & 9,0 & 9,0 & 4,6 & 6,6 & 8,6 & 4,2 & 6,2 & 8,2 & 3,8 & 5,8 & 7,8 & 4,2 & 6,2 & 8,2 \\
\hline $\begin{array}{l}\text { IMR4- Inadequação do rótulo por ausência da especificação da classe } \\
\text { do agrotóxico. }\end{array}$ & 7,0 & 9,0 & 9,0 & 5,0 & 7,0 & 9,0 & 3,8 & 5,8 & 7,8 & 4,2 & 6,2 & 8,2 & 3,4 & 5,4 & 7,4 \\
\hline $\begin{array}{l}\text { IMR5- Inadequação do rótulo por ausência da identificação do grupo } \\
\text { químico. }\end{array}$ & 7,0 & 9,0 & 9,0 & 5,4 & 7,4 & 9,0 & 4,6 & 6,6 & 8,6 & 4,2 & 6,2 & 8,2 & 3,4 & 5,4 & 7,4 \\
\hline IMR6- Inadequação do rótulo por ausência do tipode formulação. & 7,0 & 9,0 & 9,0 & 5,4 & 7,4 & 9,0 & 4,2 & 6,2 & 8,2 & 3,4 & 5,4 & 7,4 & 3,8 & 5,8 & 7,8 \\
\hline IMR7- Inadequação do rótulo por ausência do titular do registro & 7,0 & 9,0 & 9,0 & 5,0 & 7,0 & 9,0 & 5,0 & 7,0 & 9,0 & 3,8 & 5,8 & 7,8 & 3,8 & 5,8 & 7,8 \\
\hline $\begin{array}{l}\text { IMR8- Inadequação do rótulo por ausência do fabricante do produto técnico } \\
\text { ou produto }\end{array}$ & 7,0 & 9,0 & 9,0 & 5,0 & 7,0 & 8,6 & 4,2 & 6,2 & 8,2 & 3,8 & 5,8 & 7,8 & 3,8 & 5,8 & 7,8 \\
\hline IMR9- Inadequação do rótulo por ausência do formulador e/ou manipulador. & 7,0 & 9,0 & 9,0 & 5,0 & 7,0 & 8,6 & 4,6 & 6,6 & 8,6 & 3,4 & 5,4 & 7,4 & 3,8 & 5,8 & 7,8 \\
\hline $\begin{array}{l}\text { IMR10- Inadequação do rótulo por ausência da identificação do lote do } \\
\text { produto. }\end{array}$ & 7,0 & 9,0 & 9,0 & 6,6 & 8,6 & 9,0 & 4,6 & 6,6 & 8,2 & 4,2 & 6,2 & 8,2 & 3,8 & 5,8 & 7,8 \\
\hline $\begin{array}{l}\text { IMR11- Inadequação do rótulo por ausência da declaração "ANTES DE } \\
\text { USAR O PRODUTO LEIA O RÓTULO, A BULA E A RECEITA } \\
\text { AGRONÔMMICA E CONSERVE-OS EM SEU PODER". }\end{array}$ & 7,0 & 9,0 & 9,0 & 5,8 & 7,8 & 8,6 & 4,2 & 6,2 & 8,2 & 3,8 & 5,8 & 7,8 & 3,8 & 5,8 & 7,8 \\
\hline $\begin{array}{l}\text { IMR12- Inadequação do rótulo por ausência da declaração “É } \\
\text { OBRIGATÓRIO O USO DE EQUIPAMENTOS DE PROTEÇÃO } \\
\text { INDIVIDUAL". PROTEJA-SE." }\end{array}$ & 7,0 & 9,0 & 9,0 & 5,0 & 7,0 & 8,6 & 4,6 & 6,6 & 8,6 & 4,2 & 6,2 & 8,2 & 3,4 & 5,4 & 7,4 \\
\hline $\begin{array}{l}\text { IMR13- Inadequação do rótulo por ausência da declaração "E } \\
\text { OBRIGATÓRIA A DEVOLUÇÂO DA EMBALAGEM VAZIA". }\end{array}$ & 7,0 & 9,0 & 9,0 & 5,0 & 7,0 & 8,6 & 4,2 & 6,2 & 8,2 & 3,4 & 5,4 & 7,4 & 3,8 & 5,8 & 7,8 \\
\hline $\begin{array}{l}\text { IMR14- Inadequação do rótulo por ausência da declaração "Indicações e } \\
\text { restrições de uso: vide bula e receita agronômica". }\end{array}$ & 7,0 & 9,0 & 9,0 & 5,4 & 7,4 & 8,6 & 5,0 & 7,0 & 9,0 & 3,4 & 5,4 & 7,4 & 3,4 & 5,4 & 7,4 \\
\hline $\begin{array}{l}\text { IMR15- Inadequação do rótulo por ausência de Restrições Estaduais, do } \\
\text { Distrito Federal e Municipais. }\end{array}$ & 7,0 & 9,0 & 9,0 & 4,6 & 6,6 & 8,6 & 4,2 & 6,2 & 8,2 & 3,8 & 5,8 & 7,8 & 3,0 & 5,0 & 7,0 \\
\hline $\begin{array}{l}\text { IMR16- Inadequação do rótulo por ausência da declaração "Produto } \\
\text { registrado para cultura de: inserir as culturas solicitadas no pleito de } \\
\text { registro". }\end{array}$ & 7,0 & 9,0 & 9,0 & 4,6 & 6,6 & 8,6 & 4,2 & 6,2 & 8,2 & 3,8 & 5,8 & 7,8 & 3,8 & 5,8 & 7,8 \\
\hline $\begin{array}{l}\text { IMR17- Inadequação do rótulo por ausência da declaração "Indústria } \\
\text { Brasileira, quando aplicável". }\end{array}$ & 3,0 & 5,0 & 7,0 & 6,2 & 8,2 & 9,0 & 4,6 & 6,6 & 8,6 & 4,2 & 6,2 & 8,2 & 3,8 & 5,8 & 7,8 \\
\hline $\begin{array}{l}\text { IMR18- Inadequação do rótulo por ausência de Indicação se a formulação é } \\
\text { explosiva, inflamável, comburente, corrosiva, irritante ou sujeita à venda } \\
\text { aplicada. }\end{array}$ & 7,0 & 9,0 & 9,0 & 5,4 & 7,4 & 8,6 & 4,2 & 6,2 & 8,2 & 4,2 & 6,2 & 8,2 & 4,2 & 6,2 & 8,2 \\
\hline IMR19- Inadequação do rótulo por ausência da classificação toxicológica. & 7,0 & 9,0 & 9,0 & 5,0 & 7,0 & 9,0 & 4,6 & 6,6 & 8,6 & 4,2 & 6,2 & 8,2 & 4,2 & 6,2 & 8,2 \\
\hline IMR20- Inadequação do rótulo por ausência da Periculosidade Ambiental. & 7,0 & 9,0 & 9,0 & 4,6 & 6,6 & 8,6 & 3,8 & 5,8 & 7,8 & 3,4 & 5,4 & 7,4 & 4,2 & 6,2 & 8,2 \\
\hline Peso fuzzy & 0,27 & 0,27 & 0,27 & 0,24 & 0,24 & $\mid 0,24$ & 0,12 & 0,12 & 0,12 & 0,25 & $|0,25|$ & 0,25 & 0,12 & 0,12 & 0,12 \\
\hline
\end{tabular}


Tabela 4.6 - Hierarquização dos Indicadores para 'Modelo de Rótulo (Coluna Central)' pelo coeficiente de proximidade

\section{Indicadores para Modelo de Rótulo - coluna central - IMR}

IMR1- Inadequação do rótulo por ausência da marca comercial do produto.

IMR2- Inadequação do rótulo por ausência da composição do produto.

IMR3- Inadequação do rótulo por ausência de informação do conteúdo, em unidade de massa ou volume.

IMR4- Inadequação do rótulo por ausência da especificação da classe do agrotóxico.

IMR5- Inadequação do rótulo por ausência da identificação do grupo químico.

IMR6- Inadequação do rótulo por ausência do tipo de formulação.

IMR7- Inadequação do rótulo por ausência do titular do registro

IMR8- Inadequação do rótulo por ausência do fabricante do produto técnico ou produto

IMR9- Inadequação do rótulo por ausência do formulador e/ou manipulador.

IMR10- Inadequação do rótulo por ausência da identificação do lote do produto.

IMR11- Inadequação do rótulo por ausência da declaração "ANTES DE USAR O PRODUTO LEIA O RÓTULO, A BULA E A RECEITA AGRONÔMICA E CONSERVE-OS EM SEU PODER".

IMR12- Inadequação do rótulo por ausência da declaração "É OBRIGATÓRIO O USO DE EQUIPAMENTOS DE

PROTEÇÃO INDIVIDUAL". PROTEJA-SE."

IMR13- Inadequação do rótulo por ausência da declaração "É OBRIGATÓRIA A DEVOLUÇÃO DA EMBALAGEM

VAZIA".

IMR14- Inadequação do rótulo por ausência da declaração "Indicações e restrições de uso: vide bula e receita

agronômica".

IMR15- Inadequação do rótulo por ausência de Restrições Estaduais, do Distrito Federal e Municipais.

IMR16- Inadequação do rótulo por ausência da declaração "Produto registrado para cultura de: inserir as culturas

solicitadas no pleito de registro".

IMR17- Inadequação do rótulo por ausência da declaração "Indústria Brasileira, quando aplicável".

IMR18- Inadequação do rótulo por ausência de Indicação se a formulação é explosiva, inflamável, comburente,

corrosiva, irritante ou sujeita à venda aplicada.

IMR19- Inadequação do rótulo por ausência da classificação toxicológica.

IMR20- Inadequação do rótulo por ausência da Periculosidade Ambiental.

Fonte: Elaboração própria.

\begin{tabular}{|c|c|c|c|}
\hline $\mathbf{D +}$ & $\mathbf{D}-$ & $\mathbf{C C i}$ & Hierarquização \\
\hline 409 & 3,952 & 0,737 & 6 \\
\hline 457 & 3,917 & 0,729 & 9 \\
\hline, 525 & 3,916 & 0,726 & 10 \\
\hline 414 & 3,870 & 0,717 & 13 \\
\hline 490 & 3,981 & 0,738 & 5 \\
\hline 410 & 3,999 & 0,723 & 12 \\
\hline 485 & 3,894 & 0,724 & 4 \\
\hline 488 & 3,890 & 0,723 & 11 \\
\hline 479 & 4,089 & 0,762 & 1 \\
\hline 447 & 3,946 & 0,736 & 7 \\
\hline 526 & 3,937 & 0,731 & 8 \\
\hline 460 & 3,913 & 0,728 & 15 \\
\hline 603 & 3,776 & 0,702 & 9 \\
\hline 519 & 3,869 & 0,718 & 17 \\
\hline 658 & 3,733 & 0,692 & 18 \\
\hline 372 & 4,014 & 0,745 & 3 \\
\hline 367 & 4,050 & 0,748 & 2 \\
\hline 560 & 3,827 & 0,710 & 16 \\
\hline
\end{tabular}


Tabela 4.7 - Matriz de decisão dos Indicadores para 'Modelo de Rótulo (Coluna da Direita)' avaliados à luz dos critérios C1 a C5

\begin{tabular}{|c|c|c|c|c|c|c|c|c|c|c|c|c|c|c|c|}
\hline \multirow{2}{*}{$\begin{array}{l}\text { Indicadores para Modelo de Rótulo - IMR } \\
\text { IMR1- Inadequação do rótulo por ausência da declaração "ANTES } \\
\text { DE USAR O PRODUTO, LEIA COM ATENÇÃO AS INSTRUÇÕES } \\
\text { DA BULA". }\end{array}$} & \multicolumn{3}{|c|}{ C1 } & \multicolumn{3}{|c|}{ C2 } & \multicolumn{3}{|c|}{ C3 } & \multicolumn{3}{|c|}{ C4 } & \multicolumn{3}{|c|}{ C5 } \\
\hline & 7,0 & 9,0 & 9,0 & 4,2 & 6,2 & 8,2 & 3,0 & 5,0 & 7,0 & 3,4 & 5,4 & 7,4 & 2,2 & 4,2 & 6,2 \\
\hline $\begin{array}{l}\text { IMR2- Inadequação do rótulo por ausência de frases relacionadas } \\
\text { a precauções gerais. }\end{array}$ & 7,0 & 9,0 & 9,0 & 4,2 & 6,2 & 8,2 & 2,6 & 4,6 & 6,6 & 3,0 & 5,0 & 7,0 & 2,2 & 4,2 & 6,2 \\
\hline $\begin{array}{l}\text { IMR3- Inadequação do rótulo por ausência de frases relacionadas } \\
\text { a precauções durante a preparação da calda. }\end{array}$ & 7,0 & 9,0 & 9,0 & 4,2 & 6,2 & 8,2 & 2,6 & 4,6 & 6,6 & 3,4 & 5,4 & 7,4 & 1,8 & 3,8 & 5,8 \\
\hline $\begin{array}{l}\text { IMR4- Inadequação do rótulo por ausência de frases relacionadas } \\
\text { a precauções durante o manuseio. }\end{array}$ & 7,0 & 9,0 & 9,0 & 4,2 & 6,2 & 8,2 & 3,4 & 5,4 & 7,4 & 3,4 & 5,4 & 7,4 & 1,4 & 3,4 & 5,4 \\
\hline $\begin{array}{l}\text { IMR5- Inadequação do rótulo por ausência de frases relacionadas } \\
\text { a precauções para o tratamento de sementes. }\end{array}$ & 7,0 & 9,0 & 9,0 & 4,2 & 6,2 & 8,2 & 3,0 & 5,0 & 7,0 & 3,8 & 5,8 & 7,8 & 1,8 & 3,8 & 5,8 \\
\hline $\begin{array}{l}\text { IMR6- Inadequação do rótulo por ausência de frases relacionadas } \\
\text { a precauções durante a aplicação do produto. }\end{array}$ & 7,0 & 9,0 & 9,0 & 4,2 & 6,2 & 8,2 & 3,4 & 5,4 & 7,4 & 3,4 & 5,4 & 7,4 & 1,8 & 3,8 & 5,8 \\
\hline $\begin{array}{l}\text { IMR7- Inadequação do rótulo por ausência de frases relacionadas } \\
\text { a precauções após a aplicação do produto. }\end{array}$ & 7,0 & 9,0 & 9,0 & 3,8 & 5,8 & 7,8 & 2,6 & 4,6 & 6,6 & 3,8 & 5,8 & 7,8 & 2,2 & 4,2 & 6,2 \\
\hline $\begin{array}{l}\text { IMR8- Inadequação do rótulo por ausência de quadro de primeiros } \\
\text { socorros }\end{array}$ & 7,0 & 9,0 & 9,0 & 4,6 & 6,6 & 8,6 & 3,4 & 5,4 & 7,4 & 4,2 & 6,2 & 8,2 & 3,0 & 5,0 & 7,0 \\
\hline $\begin{array}{l}\text { IMR9- Inadequação do rótulo por ausência de quadro de antídotos } \\
\text { e tratamento. }\end{array}$ & 7,0 & 9,0 & 9,0 & 4,2 & 6,2 & 8,2 & 3,8 & 5,8 & 7,8 & 4,2 & 6,2 & 7,8 & 2,2 & 4,2 & 6,2 \\
\hline $\begin{array}{l}\text { IMR10- Inadequação do rótulo por ausência de quadro de } \\
\text { telefones em caso de emergência. }\end{array}$ & 7,0 & 9,0 & 9,0 & 5,0 & 7,0 & 9,0 & 3,4 & 5,4 & 7,4 & 4,2 & 6,2 & 8,2 & 3,0 & 5,0 & 7,0 \\
\hline $\begin{array}{l}\text { IMR11- Inadequação do rótulo por ausência de faixa do rótulo de } \\
\text { acordo com o guia da Anvisa. }\end{array}$ & 7,0 & 9,0 & 9,0 & 4,6 & 6,6 & 8,6 & 4,2 & 6,2 & 8,2 & 4,6 & 6,6 & 8,6 & 2,6 & 4,6 & 6,6 \\
\hline Peso fuzzy & 0,27 & 0,27 & 0,27 & 0,24 & 0,24 & 0,24 & 0,12 & 0,12 & 0,12 & 0,25 & 0,25 & 0,25 & 0,12 & 0,12 & 0,12 \\
\hline
\end{tabular}

Fonte: Elaboração própria. 
Tabela 4.8 - Hierarquização dos Indicadores para 'Modelo de Rótulo (Coluna da Direita)' pelo coeficiente de proximidade

\begin{tabular}{|c|c|c|c|c|}
\hline Indicadores para Modelo de Rótulo - IMR & D+ & D- & $\mathbf{C C i}$ & Hierarquização \\
\hline $\begin{array}{l}\text { IMR1- Inadequação do rótulo por ausência da declaração "ANTES DE USAR O PRODUTO, LEIA COM ATENÇÃO } \\
\text { AS INSTRUÇÕES DA BULA". }\end{array}$ & 1,81 & 3,59 & 0,665 & 5 \\
\hline IMR2- Inadequação do rótulo por ausência de frases relacionadas a precauções gerais. & 1,89 & 3,49 & 0,649 & 10 \\
\hline IMR3- Inadequação do rótulo por ausência de frases relacionadas a precauções durante a preparação da calda. & 1,90 & 3,49 & 0,647 & 11 \\
\hline IMR4- Inadequação do rótulo por ausência de frases relacionadas a precauções durante o manuseio. & 1,87 & 3,53 & 0,654 & 9 \\
\hline IMR5- Inadequação do rótulo por ausência de frases relacionadas a precauções para o tratamento de sementes. & 1,82 & 3,58 & 0,663 & 7 \\
\hline IMR6- Inadequação do rótulo por ausência de frases relacionadas a precauções durante a aplicação do produto. & 1,81 & 3,58 & 0,664 & 6 \\
\hline IMR7- Inadequação do rótulo por ausência de frases relacionadas a precauções após a aplicação do produto. & 1,85 & 3,54 & 0,657 & 8 \\
\hline IMR8- Inadequação do rótulo por ausência de quadro de primeiros socorros & 1,55 & 3,87 & 0,714 & 3 \\
\hline IMR9- Inadequação do rótulo por ausência de quadro de antídotos e tratamento. & 1,65 & 3,75 & 0,695 & 4 \\
\hline IMR10- Inadequação do rótulo por ausência de quadro de telefones em caso de emergência. & 1,52 & 3,92 & 0,721 & 2 \\
\hline IMR11- Inadequação do rótulo por ausência de faixa do rótulo de acordo com o guia da Anvisa. & 1,48 & 3,96 & 0,728 & 1 \\
\hline
\end{tabular}

Fonte: Elaboração própria. 


\subsection{2.}

\section{Indicadores para 'Modelo de bula'}

Apresenta-se na tabela 4.9 a matriz de decisão dos indicadores para modelo de bula. Conforme as categorias de requisitos legais identificadas na Resolução da Diretoria Colegiada - RDC no 296/2019 (Anvisa, 2019a). Na tabela 4.10, apresenta-se o ranking dos indicadores para 'Modelo de Bula', pelo coeficiente de proximidade.

Tabela 4.9 - Matriz de decisão dos indicadores para 'Modelo de Bula' avaliados à luz dos critérios $\mathrm{C} 1$ a $\mathrm{C} 5$

\begin{tabular}{|c|c|c|c|c|c|c|c|c|c|c|c|c|c|c|c|}
\hline $\begin{array}{l}\text { Indicadores para } \\
\text { Modelo de Bula - IMB }\end{array}$ & & C1 & & & C2 & & & C3 & & & C4 & & & C5 & \\
\hline $\begin{array}{l}\text { IMB1- Inadequação da } \\
\text { bula por ausência da } \\
\text { composição do produto. }\end{array}$ & 7,0 & 9,0 & 9,0 & 4,6 & 6,6 & 8,6 & 3,4 & 5,4 & 7,4 & 4,6 & 6,6 & 8,6 & 3,0 & 5,0 & 7,0 \\
\hline $\begin{array}{l}\text { IMB2- Inadequação da } \\
\text { bula por ausência de } \\
\text { informação do } \\
\text { conteúdo, em unidade } \\
\text { de massa ou volume. }\end{array}$ & 7,0 & 9,0 & 9,0 & 4,6 & 6,6 & 8,2 & 5,0 & 7,0 & 9,0 & 4,6 & 6,6 & 8,6 & 3,8 & 5,8 & 7,8 \\
\hline $\begin{array}{l}\text { IMB3- Inadequação da } \\
\text { bula por ausência da } \\
\text { especificação da classe } \\
\text { do agrotóxico. }\end{array}$ & 7,0 & 9,0 & 9,0 & 3,8 & 5,8 & 7,8 & 4,6 & 6,6 & 8,6 & 4,2 & 6,2 & 8,2 & 3,8 & 5,8 & 7,8 \\
\hline $\begin{array}{l}\text { IMB4- Inadequação } \\
\text { da bula por ausência } \\
\text { da identificação do } \\
\text { grupo químico. }\end{array}$ & 7,0 & 9,0 & 9,0 & 4,2 & 6,2 & 8,2 & 4,6 & 6,6 & 8,6 & 4,6 & 6,6 & 8,6 & 3,8 & 5,8 & 7,8 \\
\hline $\begin{array}{l}\text { IMB5- Inadequação da } \\
\text { bula por ausência do } \\
\text { tipo de formulação. }\end{array}$ & 7,0 & 9,0 & 9,0 & 4,6 & 6,6 & 8,6 & 4,2 & 6,2 & 8,2 & 4,6 & 6,6 & 8,6 & 3,8 & 5,8 & 7,8 \\
\hline $\begin{array}{l}\text { IMB6- Inadequação } \\
\text { da bula por ausência } \\
\text { do titular do registro. }\end{array}$ & 7,0 & 9,0 & 9,0 & 5,0 & 7,0 & 8,6 & 4,6 & 6,6 & 8,6 & 3,8 & 5,8 & 7,8 & 3,4 & 5,4 & 7,4 \\
\hline $\begin{array}{l}\text { IMB7- Inadequação } \\
\text { da bula por ausência } \\
\text { do fabricante do } \\
\text { produto técnico ou } \\
\text { produto. }\end{array}$ & 7,0 & 9,0 & 9,0 & 5,0 & 7,0 & 8,6 & 4,2 & 6,2 & 8,2 & 4,6 & 6,6 & 8,6 & 3,8 & 5,8 & 7,8 \\
\hline $\begin{array}{l}\text { IMB8- Inadequação da } \\
\text { bula por ausência do } \\
\text { formulador e/ou } \\
\text { manipulador. }\end{array}$ & 7,0 & 9,0 & 9,0 & 4,6 & 6,6 & 8,2 & 4,6 & 6,6 & 8,6 & 4,6 & 6,6 & 8,6 & 3,8 & 5,8 & 7,8 \\
\hline $\begin{array}{l}\text { IMB9- Inadequação da } \\
\text { bula por ausência de } \\
\text { informações de } \\
\text { fabricação. }\end{array}$ & 7,0 & 9,0 & 9,0 & 5,0 & 7,0 & 8,6 & 4,2 & 6,2 & 8,2 & 5,0 & 7,0 & 9,0 & 4,2 & 6,2 & 8,2 \\
\hline $\begin{array}{l}\text { IMB10- Inadequação } \\
\text { da bula por ausência } \\
\text { da declaração "ANTES } \\
\text { DE USAR O RODUTO } \\
\text { LEIA O RÓTULO, A } \\
\text { BULA E A RECEITA } \\
\text { AGRONÔMICA } \\
\text { CONSERVE-OS } \\
\text { SEU POM } \\
\text { SEORE". }\end{array}$ & 6,6 & 8,6 & 9,0 & 5,8 & 7,8 & 8,6 & 4,6 & 6,6 & 8,2 & 4,6 & 6,6 & 8,6 & 3,4 & 5,4 & 7,4 \\
\hline
\end{tabular}




\begin{tabular}{|c|c|c|c|c|c|c|c|c|c|c|c|c|c|c|c|}
\hline $\begin{array}{l}\text { IMB11- Inadequação } \\
\text { da bula por ausência da } \\
\text { declaração, “É } \\
\text { OBRIGATORIO O USO } \\
\text { DE EQUIPAMENTOS } \\
\text { DE PROTEÇÃO } \\
\text { INDIVIDUA". } \\
\text { PROTEJA-SE." }\end{array}$ & 6,6 & 8,6 & 9,0 & 5,4 & 7,4 & 8,6 & 4,2 & 6,2 & 8,2 & 4,6 & 6,6 & 8,6 & 3,4 & 5,4 & 7,4 \\
\hline $\begin{array}{l}\text { IMB12- Inadequação } \\
\text { da bula por ausência } \\
\text { da declaração "É } \\
\text { OBRIGATÓRIA A } \\
\text { DEVOLUÇÃO DA } \\
\text { EMBALAGEM VAZIA". }\end{array}$ & 6,6 & 8,6 & 9,0 & 5,8 & 7,8 & 8,6 & 4,2 & 6,2 & 8,2 & 4,6 & 6,6 & 8,6 & 3,0 & 5,0 & 7,0 \\
\hline $\begin{array}{l}\text { IMB13- Inadequação } \\
\text { da bula por ausência } \\
\text { da declaração } \\
\text { "Indicações e restrições } \\
\text { de uso: vide bula e } \\
\text { receita agronômica". }\end{array}$ & 6,6 & 8,6 & 9,0 & 5,4 & 7,4 & 8,6 & 4,6 & 6,6 & 8,6 & 4,2 & 6,2 & 8,2 & 3,4 & 5,4 & 7,4 \\
\hline $\begin{array}{l}\text { IMB14- Inadequação da } \\
\text { bula por ausência de } \\
\text { Restrições Estaduais, } \\
\text { do Distrito Federal e } \\
\text { Municipais. }\end{array}$ & 7,0 & 9,0 & 9,0 & 4,6 & 6,6 & 8,2 & 4,6 & 6,6 & 8,6 & 3,8 & 5,8 & 7,8 & 3,4 & 5,4 & 7,4 \\
\hline $\begin{array}{l}\text { IMB15- Inadequação da } \\
\text { bula por ausência da } \\
\text { declaração "Produto } \\
\text { registrado para cultura } \\
\text { de: inserir as culturas } \\
\text { solicitadas no pleito de } \\
\text { registro". }\end{array}$ & 7,0 & 9,0 & 9,0 & 4,2 & 6,2 & 7,8 & 4,2 & 6,2 & 8,2 & 4,2 & 6,2 & 8,2 & 3,0 & 5,0 & 7,0 \\
\hline $\begin{array}{l}\text { IMB16- Inadequação } \\
\text { da bula por ausência } \\
\text { da declaração } \\
\text { "Indústria Brasileira, } \\
\text { quando aplicável". }\end{array}$ & 7,0 & 9,0 & 9,0 & 4,6 & 6,6 & 8,2 & 4,6 & 6,6 & 8,6 & 4,2 & 6,2 & 8,2 & 3,4 & 5,4 & 7,4 \\
\hline $\begin{array}{l}\text { IMB17- Inadequação } \\
\text { da bula por ausência } \\
\text { de Indicação se a } \\
\text { formulação é explosiva, } \\
\text { inflamável, comburente, } \\
\text { corrosiva, irritante ou } \\
\text { sujeita à venda } \\
\text { aplicada. }\end{array}$ & 7,0 & 9,0 & 9,0 & 4,2 & 6,2 & 7,8 & 5,0 & 7,0 & 8,6 & 4,2 & 6,2 & 8,2 & 4,2 & 6,2 & 8,2 \\
\hline $\begin{array}{l}\text { IMB18- Inadequação da } \\
\text { bula por ausência da } \\
\text { classificação } \\
\text { toxicológica. }\end{array}$ & 7,0 & 9,0 & 9,0 & 4,2 & 6,2 & 8,2 & 4,2 & 6,2 & 8,2 & 4,6 & 6,6 & 8,6 & 3,8 & 5,8 & 7,8 \\
\hline $\begin{array}{l}\text { IMB19- Inadequação } \\
\text { da bula por ausência } \\
\text { da Periculosidade } \\
\text { Ambiental. }\end{array}$ & 7,0 & 9,0 & 9,0 & 4,2 & 6,2 & 8,2 & 4,2 & 6,2 & 8,2 & 4,6 & 6,6 & 8,6 & 3,8 & 5,8 & 7,8 \\
\hline $\begin{array}{l}\text { IMB20- Inadequação da } \\
\text { bula por ausência da } \\
\text { faixa de classificação } \\
\text { toxicológica. }\end{array}$ & 7,0 & 9,0 & 9,0 & 5,0 & 7,0 & 8,6 & 4,2 & 6,2 & 8,2 & 4,2 & 6,2 & 8,2 & 3,4 & 5,4 & 7,4 \\
\hline $\begin{array}{l}\text { IMB21- Inadequação da } \\
\text { bula por ausência de } \\
\text { instruções de uso. }\end{array}$ & 7,0 & 9,0 & 9,0 & 4,6 & 6,6 & 8,6 & 3,8 & 5,8 & 7,8 & 4,6 & 6,6 & 8,6 & 3,4 & 5,4 & 7,4 \\
\hline $\begin{array}{l}\text { IMB22- Inadequação } \\
\text { da bula por ausência } \\
\text { de frases relacionadas } \\
\text { a precauções gerais. }\end{array}$ & 7,0 & 9,0 & 9,0 & 17,6 & 19,6 & 21,6 & 3,8 & 5,8 & 7,8 & 4,2 & 6,2 & 8,2 & 3,0 & 5,0 & 7,0 \\
\hline
\end{tabular}

Fonte: Elaboração própria. 
Tabela 4.10 - Hierarquização dos indicadores para 'Modelo de Bula', pelo coeficiente de proximidade

\begin{tabular}{|c|c|c|c|c|}
\hline Indicadores para Modelo de Bula - IMB & D+ & D- & $\mathbf{C C i}$ & $\begin{array}{l}\text { Hierarquiz } \\
\text { ação }\end{array}$ \\
\hline $\begin{array}{l}\text { IMB1- Inadequação da bula por ausência da composição do } \\
\text { produto. }\end{array}$ & 1,628 & 3,746 & 0,697 & 15 \\
\hline $\begin{array}{l}\text { IMB2- Inadequação da bula por ausência de informação do } \\
\text { conteúdo, em unidade de massa ou volume. }\end{array}$ & 1,393 & 3,992 & 0,741 & 2 \\
\hline $\begin{array}{l}\text { IMB3- Inadequação da bula por ausência da especificação da } \\
\text { classe do agrotóxico. }\end{array}$ & 1,542 & 3,835 & 0,713 & 12 \\
\hline $\begin{array}{l}\text { IMB4- Inadequação da bula por ausência da identificação do grupo } \\
\text { químico. }\end{array}$ & 1,465 & 3,923 & 0,728 & 7 \\
\hline IMB5- Inadequação da bula por ausência do tipo de formulação. & 1,465 & 3,925 & 0,728 & 7 \\
\hline IMB6- Inadequação da bula por ausência do titular do registro. & 1,510 & 3,861 & 0,719 & 11 \\
\hline $\begin{array}{l}\text { IMB7- Inadequação da bula por ausência do fabricante do produto } \\
\text { técnico ou produto. }\end{array}$ & 1,429 & 3,951 & 0,734 & 5 \\
\hline $\begin{array}{l}\text { IMB8- Inadequação da bula por ausência do formulador e/ou } \\
\text { manipulador. }\end{array}$ & 1,429 & 3,949 & 0,734 & 5 \\
\hline $\begin{array}{l}\text { IMB9- Inadequação da bula por ausência de informações de } \\
\text { fabricação. }\end{array}$ & 1,355 & 4,041 & 0,749 & 1 \\
\hline $\begin{array}{l}\text { IMB10- Inadequação da bula por ausência da declaração "ANTES } \\
\text { DE USAR O PRODUTO LEIA O RÓTULO, A BULA E A RECEITA } \\
\text { AGRONÔMICA E CONSERVE-OS EM SEU PODER". }\end{array}$ & 1,395 & 3,955 & 0,739 & 4 \\
\hline $\begin{array}{l}\text { IMB11- Inadequação da bula por ausência da declaração "É } \\
\text { OBRIGATÓRIO O USO DE EQUIPAMENTOS DE PROTEÇÃO } \\
\text { INDIVIDUAL". PROTEJA-SE." }\end{array}$ & 1,464 & 3,903 & 0,727 & 8 \\
\hline $\begin{array}{l}\text { IMB12- Inadequação da bula por ausência da declaração "É } \\
\text { OBRIGATÓRIA A DEVOLUÇÃO DA EMBALAGEM VAZIA". }\end{array}$ & 1,472 & 3,884 & 0,725 & 9 \\
\hline $\begin{array}{l}\text { IMB13- Inadequação da bula por ausência da declaração } \\
\text { "Indicações e restrições de uso: vide bula e receita agronômica". }\end{array}$ & 1,464 & 3,903 & 0,727 & 8 \\
\hline $\begin{array}{l}\text { IMB14- Inadequação da bula por ausência de Restrições Estaduais, } \\
\text { do Distrito Federal e Municipais. }\end{array}$ & 1,547 & 3,816 & 0,712 & 13 \\
\hline $\begin{array}{l}\text { IMB15- Inadequação da bula por ausência da declaração "Produto } \\
\text { registrado para cultura de: inserir as culturas solicitadas no pleito de } \\
\text { registro". }\end{array}$ & 1,627 & 3,724 & 0,696 & 16 \\
\hline $\begin{array}{l}\text { IMB16- Inadequação da bula por ausência da declaração "Indústria } \\
\text { Brasileira, quando aplicável". }\end{array}$ & $\begin{array}{c}1,50 \\
8\end{array}$ & $\begin{array}{c}3,85 \\
9\end{array}$ & 0,719 & 11 \\
\hline $\begin{array}{l}\text { IMB17- Inadequação da bula por ausência de Indicação se a } \\
\text { formulação é explosiva, inflamável, comburente, corrosiva, irritante } \\
\text { ou sujeita à venda aplicada. }\end{array}$ & $\begin{array}{c}1,43 \\
2\end{array}$ & $\begin{array}{c}3,93 \\
2\end{array}$ & 0,733 & 6 \\
\hline $\begin{array}{l}\text { IMB18- Inadequação da bula por ausência da classificação } \\
\text { toxicológica. }\end{array}$ & $\begin{array}{c}1,50 \\
3\end{array}$ & $\begin{array}{c}3,88 \\
0\end{array}$ & 0,721 & 10 \\
\hline $\begin{array}{l}\text { IMB19- Inadequação da bula por ausência da Periculosidade } \\
\text { Ambiental. }\end{array}$ & $\begin{array}{c}1,50 \\
3\end{array}$ & $\begin{array}{c}3,88 \\
0\end{array}$ & 0,721 & 10 \\
\hline $\begin{array}{l}\text { IMB20- Inadequação da bula por ausência da faixa de classificação } \\
\text { toxicológica. }\end{array}$ & $\begin{array}{c}1,50 \\
8\end{array}$ & $\begin{array}{c}3,86 \\
1\end{array}$ & 0,719 & 11 \\
\hline IMB21- Inadequação da bula por ausência de instruções de uso. & $\begin{array}{c}1,54 \\
6\end{array}$ & $\begin{array}{c}3,83 \\
5\end{array}$ & 0,713 & 12 \\
\hline $\begin{array}{l}\text { IMB22- Inadequação da bula por ausência de frases relacionadas a } \\
\text { precauções gerais. }\end{array}$ & $\begin{array}{c}2,61 \\
9\end{array}$ & $\begin{array}{c}5,24 \\
2\end{array}$ & 0,667 & 19 \\
\hline $\begin{array}{l}\text { IMB23- Inadequação da bula por ausência de frases relacionadas a } \\
\text { precauções durante a preparação da calda. }\end{array}$ & $\begin{array}{c}1,70 \\
4\end{array}$ & $\begin{array}{c}3,65 \\
4\end{array}$ & 0,682 & 17 \\
\hline $\begin{array}{l}\text { IMB24- Inadequação da bula por ausência de frases relacionadas a } \\
\text { precaucões durante o manuseio. }\end{array}$ & $\begin{array}{c}1,74 \\
3\end{array}$ & $\begin{array}{c}3,61 \\
1\end{array}$ & 0,674 & 18 \\
\hline $\begin{array}{l}\text { IMB25- Inadequação da bula por ausência de frases relacionadas a } \\
\text { precauções para o tratamento de sementes. }\end{array}$ & $\begin{array}{c}1,70 \\
4\end{array}$ & $\begin{array}{c}3,65 \\
4\end{array}$ & 0,682 & 17 \\
\hline $\begin{array}{l}\text { IMB26- Inadequação da bula por ausência de frases relacionadas a } \\
\text { precauções durante a aplicação do produto. }\end{array}$ & $\begin{array}{c}1,58 \\
2\end{array}$ & $\begin{array}{c}3,77 \\
4\end{array}$ & 0,705 & 13 \\
\hline $\begin{array}{l}\text { IMB27- Inadequação da bula por ausência de frases relacionadas a } \\
\text { precaucões após a aplicação do produto. }\end{array}$ & $\begin{array}{c}1,61 \\
9\end{array}$ & $\begin{array}{c}3,74 \\
9\end{array}$ & 0,698 & 14 \\
\hline $\begin{array}{l}\text { IMB28- Inadequação da bula por ausência de quadro de primeiros } \\
\text { socorros }\end{array}$ & $\begin{array}{c}1,39 \\
8\end{array}$ & $\begin{array}{c}3,97 \\
2\end{array}$ & 0,740 & 3 \\
\hline
\end{tabular}

Fonte: Elaboração própria. 


\subsubsection{Indicadores de 'Instruções para preenchimento do quadro de informações médicas'}

Por fim, completando as três categorias de requisitos legais identificadas como objeto de monitoramento e avaliação da Resolução da Diretoria Colegiada RDC n 296/2019 (Anvisa, 2019a), apresentam-se nas tabelas 4.11 e 4.12 os resultados referentes a indicadores para instruções de preenchimento do quadro de informações médicas.

Tabela 4.11 - Matriz de decisão dos indicadores de 'Instruções médicas' avaliados à luz dos critérios $\mathrm{C} 1$ a C5

\begin{tabular}{|c|c|c|c|c|c|c|c|c|c|c|c|c|c|c|c|}
\hline \multirow{2}{*}{$\begin{array}{l}\text { Indicadores de } \\
\text { Instruções Médicas - IIM } \\
\text { IIM1- Inadequação da } \\
\text { bula por ausência/erro/ } \\
\text { incompletude da } \\
\text { informação sobre o grupo } \\
\text { químico de cada } \\
\text { ingrediente ativo. }\end{array}$} & \multicolumn{3}{|c|}{$\begin{array}{l}\text { C } \\
1\end{array}$} & \multicolumn{3}{|c|}{$\begin{array}{l}C \\
2\end{array}$} & \multicolumn{3}{|c|}{$\begin{array}{l}C \\
3\end{array}$} & \multicolumn{3}{|c|}{$\begin{array}{l}C \\
4\end{array}$} & \multicolumn{3}{|c|}{$\begin{array}{l}C \\
5\end{array}$} \\
\hline & 5,5 & 7,5 & 7,8 & 3,2 & 5,2 & 7,2 & 2,2 & 4,2 & 6,2 & 2,2 & 4,2 & 6,2 & 2,2 & 4,2 & 6,2 \\
\hline $\begin{array}{l}\text { IIM2- Inadequação da bula } \\
\text { por ausência da } \\
\text { informação sobre a classe } \\
\text { toxicológica. }\end{array}$ & 5,5 & 7,5 & 7,8 & 3,8 & 5,8 & 7,8 & 2,5 & 4,5 & 6,5 & 2,5 & 4,5 & 6,5 & 2,5 & 4,5 & 6,5 \\
\hline $\begin{array}{l}\text { IIM3- Inadequação da } \\
\text { bula por ausência da } \\
\text { informação sobre as } \\
\text { potenciais vias de } \\
\text { exposiçãoconsiderando a } \\
\text { indicação de uso. }\end{array}$ & 5,2 & 7,2 & 7,8 & 3,2 & 5,2 & 7,2 & 2,5 & 4,5 & 6,5 & 2,5 & 4,5 & 6,5 & 2,5 & 4,5 & 6,5 \\
\hline $\begin{array}{l}\text { IIM4- Inadequação da } \\
\text { bula por ausência da } \\
\text { informação sobre a } \\
\text { toxicocinética de cada } \\
\text { ingrediente ativo com } \\
\text { potencial tóxico, e } \\
\text { também dos } \\
\text { componentes } \\
\text { toxicologicamente } \\
\text { relevantes. }\end{array}$ & 5,2 & 7,2 & 7,8 & 3,2 & 5,2 & 7,2 & 2,5 & 4,5 & 6,5 & 2,2 & 4,2 & 6,2 & 2,5 & 4,5 & 6,5 \\
\hline $\begin{array}{l}\text { IIM5- Inadequação } \text { da } \\
\text { bula por ausência da } \\
\text { informação sobre a } \\
\text { toxicodinâmica de cada } \\
\text { ingrediente com potencial } \\
\text { tóxico. }\end{array}$ & 5,2 & 7,2 & 7,8 & 3,2 & 5,2 & 7,2 & 2,8 & 4,8 & 6,8 & 2,2 & 4,2 & 6,2 & 2,5 & 4,5 & 6,5 \\
\hline 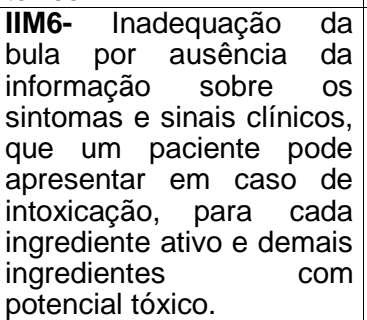 & 5,2 & 7,2 & 7,8 & 2,8 & 4,8 & 6,8 & 2,5 & 4,5 & 6,5 & 2,2 & 4,2 & 6,2 & 2,5 & 4,5 & 6,5 \\
\hline $\begin{array}{l}\text { IIM7- Inadequação da } \\
\text { bula por ausência da } \\
\text { descrição dos exames } \\
\text { que permitem } \\
\text { diagnosticar a } \\
\text { intoxicação pelo produto. }\end{array}$ & 5,2 & 7,2 & 7,8 & 2,8 & 4,8 & 6,8 & 2,5 & 4,5 & 6,5 & 2,2 & 4,2 & 6,2 & 2,2 & 4,2 & 6,2 \\
\hline
\end{tabular}




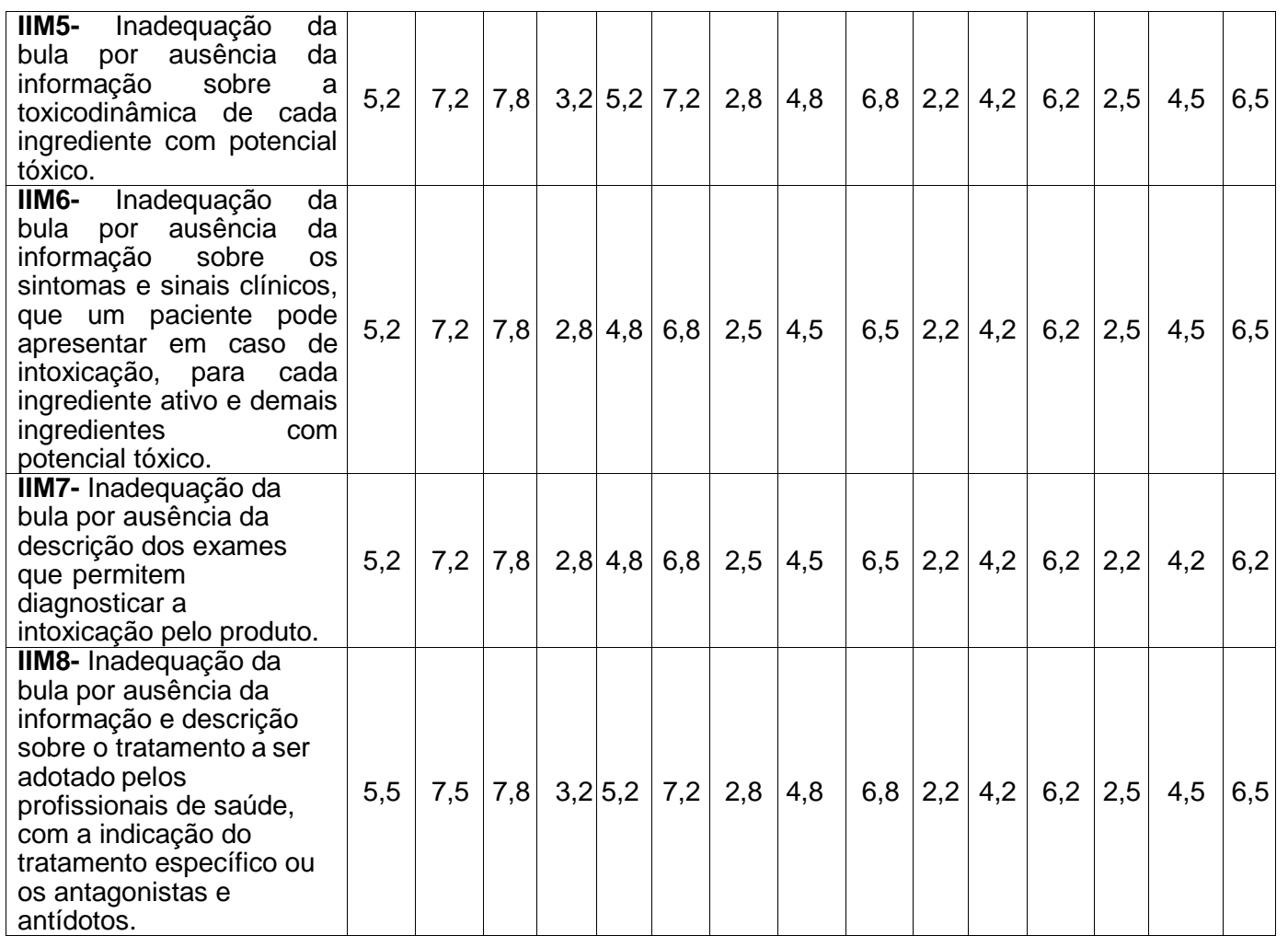

Fonte: Elaboração própria.

Tabela 4.12 - Hierarquização dos indicadores de 'Instruções Médicas' pelo coeficiente de proximidade

\begin{tabular}{|c|c|c|c|c|}
\hline Indicadores de Instruções Médicas - IIM & D+ & D- & $\mathbf{C C i}$ & Rank \\
\hline $\begin{array}{l}\text { IIM1- Inadequação da bula por ausência/erro/incompletude da informação } \\
\text { sobre o grupo químico de cada ingrediente ativo. }\end{array}$ & 1,926 & 3,586 & 0,651 & 8 \\
\hline $\begin{array}{l}\text { IIM2- Inadequação da bula por ausência da informação sobre a classe } \\
\text { toxicológica. }\end{array}$ & 1,734 & 3,807 & 0,687 & 1 \\
\hline $\begin{array}{l}\text { IIM3- Inadequação da bula por ausência da informação sobre as potenciais } \\
\text { vias de exposição (oral, inalatória, ocular e dérmica) considerando a } \\
\text { indicação de uso. }\end{array}$ & 1,833 & 3,700 & 0,669 & 4 \\
\hline $\begin{array}{l}\text { IIM4- Inadequação da bula por ausência da informação sobre a } \\
\text { toxicocinética de cada ingrediente ativo com potencial tóxico, e também } \\
\text { dos componentes toxicologicamente relevantes. }\end{array}$ & 1,873 & 3,652 & 0,661 & 6 \\
\hline $\begin{array}{l}\text { IIM5- Inadequação da bula por ausência da informação sobre a } \\
\text { toxicodinâmica de cada ingrediente com potencial tóxico. }\end{array}$ & 1,835 & 3,698 & 0,668 & 5 \\
\hline $\begin{array}{l}\text { IIM6- Inadequação da bula por ausência da informação sobre os sintomas } \\
\text { e sinais clínicos, que um paciente pode apresentar em caso de } \\
\text { intoxicação, para cada ingrediente ativo e demais ingredientes com } \\
\text { potencial tóxico. }\end{array}$ & 1,910 & 3,611 & 0,654 & 7 \\
\hline $\begin{array}{l}\text { IIM7- Inadequação da bula por ausência da descrição dos exames que } \\
\text { permitem diagnosticar a intoxicação pelo produto. }\end{array}$ & 1,951 & 3,566 & 0,646 & 9 \\
\hline $\begin{array}{l}\text { IIM8- Inadequação da bula por ausência da informação e descrição sobre } \\
\text { o tratamento a ser adotado pelos profissionais de saúde, com a indicação } \\
\text { do tratamento específico ou os antagonistas e antídotos, quando existirem, } \\
\text { ou tratamento sintomático e de suporte: descontaminação e manutenção } \\
\text { das funções vitais. }\end{array}$ & 1,806 & 3,724 & 0,673 & 3 \\
\hline $\begin{array}{l}\text { IIM9- Inadequação da bula por ausência da informação sobre as } \\
\text { contraindicações, abordando os procedimentos a serem adotados, os } \\
\text { tratamentos propostos e informando as possíveis interações químicas } \\
\text { medicamentosas. }\end{array}$ & 1,770 & 3,764 & 0,680 & 2 \\
\hline $\begin{array}{l}\text { IIM10- Inadequação da bula por ausência da informação sobre os efeitos } \\
\text { das interações químicas, tais como os efeitos aditivos, sinérgicos ou } \\
\text { potencializadores relacionados aos diferentes componentes. }\end{array}$ & 1,806 & 3,724 & 0,673 & 3 \\
\hline
\end{tabular}




\section{7.}

\section{Considerações finais sobre o capítulo}

O modelo lógico mostrou-se uma ferramenta muito útil para verificar a qualidade da teoria da regulamentação em foco, ou seja, verificar se está bem estruturada para que seja implementada com sucesso e seus resultados possam ser avaliados efetivamente. Mediante uma adaptação da proposta inicial do IPEA para construção do modelo lógico de programas governamentais, desenvolveu-se na fase de pesquisa aplicada, cujos resultados são apresentados neste capítulo, o modelo lógico da regulamentação para rotulagem e bulas de agrotóxicos, afins e preservativos de madeira no Brasil. A partir do modelo lógico desta regulamentação, foi possível delimitar o escopo do monitoramento e avaliação pretendido no âmbito da presente pesquisa, refletindo-se diretamente na definição posterior de indicadores 'candidatos' e respectivas métricas.

Com suporte do guia para construção de indicadores de programas do Ministério do Planejamento, Orçamento e Gestão, foi possível desenvolver uma matriz inicial de avaliação quantitativa de indicadores candidatos, que, por sua vez, foi submetida a um pré-teste com a participação dos cinco mestrandos do Programa de Pós-Graduação em Metrologia da PUC-Rio (PósMQI). O formato das matrizes foi considerado adequado à versão final da matriz de avaliação quantitativa de indicadores candidatos.

Buscando contribuir para o refinamento e melhoria contínua da abordagem metodológica proposta pelo Ministério do Planejamento, Orçamento e Gestão, optou-se pelo emprego de dois métodos multicritério de apoio à decisão, com apoio da lógica fuzzy, a saber: método fuzzy AHP para definição dos pesos dos critérios classificatórios (por categoria de requisitos legais da regulamentação) e a técnica fuzzy TOPSIS para a hierarquização final dos indicadores selecionados (também por categoria de requisitos legais). Assim, o resultado final consiste de uma lista 69 indicadores, hierarquizados pelo grau de atendimento aos critérios classificatórios.

Conclui-se que a hierarquização dos indicadores propostos foi considerada satisfatória indo ao encontro das diretrizes propostas pela RDC n 296/2019, para elaboração das informações toxicológicas para rótulos e bulas de agrotóxicos, afins e preservativos de madeira. 


\section{5 \\ Conclusões}

A presente pesquisa contribuiu para o avanço do conhecimento sobre ferramentas de monitoramento e avaliação (MA) como instrumentos de gestão pública, focalizando uma aplicação referente à regulamentação no Brasil sobre rotulagem e bulas de agrotóxicos. Nesse sentido, uma ferramenta de avaliação quantitativa de indicadores de MA foi desenvolvida especificamente para propor a Anvisa indicadores de MA para o novo marco regulatório para rótulos e bulas de agrotóxicos, afins e preservativos de madeira com foco na RDC 296/2019.

Os resultados obtidos ao longo da pesquisa aqui relatada permitiram que o objetivo geral da dissertação fosse alcançado. Foi possível, com uso da matriz quantitativa de indicadores e de dois métodos multicritério de apoio à decisão, combinados com a lógica fuzzy, propor indicadores e respectivas métricas para o monitoramento e avaliação da regulamentação abordada.

Os marcos conceituais e metodológicos descritos e discutidos no capítulo 2 fundamentaram a proposição e hierarquização de indicadores de MA para a regulamentação em foco, contribuindo de forma significativa para que os objetivos específicos da dissertação fossem alcançados.

Pelos aspectos descritos e resultados gerados na fase aplicada da pesquisa, considera-se que eles propiciarão ao órgão regulador, bem como aos diversos atores envolvidos na implementação dessa regulamentação, o ferramental adequado para o monitoramento dos procedimentos e avaliação de seus resultados. Quando aplicados pela Anvisa em toda sua abrangência, poderá ser considerada como uma inovação organizacional.

Com relação ao primeiro objetivo específico - "Discutir a importância da regulamentação para rotulagem e bulas de agrotóxicos, afins e preservativos de madeira no contexto do novo marco regulatório da avaliação toxicológica de agrotóxicos no Brasil, aprovado pela Anvisa em 2019”, foi possível contextualizar a experiência recente do Brasil desde os antecedentes até a proposta de Resolução 
$n^{\circ} 296 / 2019$, que estabeleceu as regras para as declarações de rótulos, bulas e instruções para preenchimento do quadro de informações médicas.

O segundo e o terceiro objetivos - "Identificar os aspectos da regulamentação sobre rotulagem e bulas de agrotóxicos, afins e preservativos de madeira no Brasil que necessitam de monitoramento e avaliação durante sua implementação" e "Elaborar o modelo lógico para fins de construção da matriz de indicadores de monitoramento e avaliação da regulamentação em foco" - foram plenamente atingidos, mediante a construção do modelo lógico da regulamentação baseada na metodologia desenvolvida pelo Ministério de Planejamento, Orçamento e Gestão (Brasil, 2010). A análise do objetivo e dos resultados esperados da regulamentação propiciou a identificação objetiva das categorias de requisitos legais que devem ser objeto de MA pela Anvisa.

Com suporte de métodos multicritério de apoio à decisão, combinados com a lógica fuzzy, particularmente do método fuzzy AHP e da técnica fuzzy TOPSIS, foi possível desenvolver e demonstrar a ferramenta para avaliação quantitativa dos indicadores propostos inicialmente, por simulação que contou com a participação de cinco especialistas do Programa Pós-MQI da PUC-Rio. Atingiu-se, assim, o quarto objetivo específico - "Desenvolver a ferramenta de seleção e classificação de indicadores e métricas de MA, com suporte de métodos fuzzy de apoio à decisão multicritério".

Finalmente, como resultado da simulação da avaliação quantitativa e qualitativa dos indicadores candidatos, chegou-se a um conjunto de 69 indicadores de MA, hierarquizados pelo método fuzzy TOPSIS por categoria de requisitos legais aplicáveis (Seção 4.5 do capítulo 4). Assim, o quinto objetivo específico - "Propor indicadores e métricas para o monitoramento e avaliação da regulamentação sobre rotulagem e bulas de agrotóxicos no Brasil, após sua implementação".

Para fins de integração dos indicadores aqui propostos a uma sistemática de monitoramento e avaliação da regulamentação em foco, pela Anvisa, recomendase:

- Validar os resultados da etapa 6 com especialistas na área de toxicologia ou representantes da Anvisa;

- Realizar as etapas 7 e 8 da metodologia de construção de indicadores, que vem sendo adotada pelo Ministério do Planejamento, Orçamento e 
Gestão, ou seja validar no âmbito da Anvisa e cadastrar os indicadores em sistemas de informações gerenciais da Agência.

Para trabalhos futuros de desdobramento da pesquisa e aprofundamento dos resultados, propõem-se:

- Desenvolver e aplicar ferramentas de avaliação de impacto regulatório (AIR) para avaliação ex-post dos impactos da regulamentação sobre rotulagem e bulas de agrotóxicos;

- Aplicar as ferramentas de modelo lógico e de seleção e hierarquização de indicadores de MA em outros contextos regulatórios.

No último Relatório de Gestão publicado pela Anvisa, no ano de 2020, cumpre-se ressaltar como atualizações após a publicação da RDC nº 296/19, a NT $n^{0}$ 11/20. Esta Norma Técnica foi editada pela Anvisa com orientações para a construção de rótulos e bulas de produtos de origem biológica.

Também foi elaborado pela Agência, o Procedimento Operacional Padrão ${ }^{\circ}$ 01, que trata dos entendimentos técnicos sobre a classificação e comunicação do perigo dos agrotóxicos e afins diante da publicação da RDC no 296/19. Ademais, 2.142 produtos obtiveram mudança de rótulo e bula implementada em conformidade com a RDC n $296 / 19$.

Finalmente, acredita-se que a ferramenta de seleção e hierarquização de indicadores de MA, com suporte dos métodos fuzzy AHP e fuzzy TOPSIS, bem como os indicadores e métricas resultantes de sua aplicação, poderão beneficiar as partes interessadas no processo da regulamentação sobre rotulagem e bulas de agrotóxicos no país. Principalmente, poderão contribuir para o monitoramento e avaliação do cumprimento do novo marco regulatório, publicado em julho de 2019. Busca-se com essa proposta de MA, minimizar a exposição do produtor rural/agricultor a produtos que possam representar um risco para sua saúde ou que estejam em desacordo com a legislação sanitária vigente. 


\section{6 \\ Referências bibliográficas}

ABIQUIM. Associação Brasileira da Indústria Química. Departamento de Assuntos Técnicos. O que é GHS? Sistema globalmente harmonizado para a classificação e rotulagem de produtos químicos. São Paulo, p.69, 2005.

ABNT. Associação Brasileira de Normas Técnicas. ABNT-NBR 14725: Produtos químicos - Informações sobre segurança, saúde e meio ambiente $\mathbf{E}$ Sistema de classificação de perigo. Rio de Janeiro, 2019.

ALMEIDA, C. A. Novo marco regulatório para a avaliação toxicológica de agrotóxicos. Gerência Geral de Toxicologia - GGTOX. 2019. Disponível em:< http://antigo.anvisa.gov.br/documents/219201/4340788/Apresenta\%C3\%A7\%C3

$\%$ A3o+agrot\%C3\%B3xicos+Dicol/3e2ee4c0-0179-485b-a30b-

27d9eaff696b?version=1.0\&previewFileIndex= >. Acesso em: 11 set. 2019.

ANVISA. Agência Nacional de Vigilância Sanitária. Consulta Pública no 483, de 16 de março de 2018. Disponível em: 〈http://portal.anvisa.gov.br〉. Acesso em: 07 set. 2020.

ANVISA. Agência Nacional de Vigilância Sanitária. Consulta Pública no 484, de 16 de março de 2018. Disponível em: 〈http://portal.anvisa.gov.br>. Acesso em: 07 set. 2020.

ANVISA. Agência Nacional de Vigilância Sanitária. Consulta Pública no 485, de 16 de março de 2018. Disponível em: 〈http://portal.anvisa.gov.br〉. Acesso em: 07 set. 2020.

ANVISA. Agência Nacional de Vigilância Sanitária. Consulta Pública no 483, de 16 de março de 2018. Disponível em: 〈http://portal.anvisa.gov.br〉. Acesso em: 07 set. 2020.

ANVISA. Agência Nacional de Vigilância Sanitária. Critérios para avaliação e classificação toxicológica, priorização da análise e comparação da ação toxicológica de agrotóxicos, componentes, afins e preservativos de madeira, e dá outras providências, Resolução RDC n 294 de julho de 2019. Brasília, DF, 2019. Disponível em: < http://portal.anvisa.gov.br>. Acesso em: 02 dez. 2019.

ANVISA. Agência Nacional de Vigilância Sanitária. Critérios para avaliação do risco dietético decorrente da exposição humana a resíduos de agrotóxicos, no âmbito da Anvisa, e dá outras providências, Resolução RDC n ${ }^{\circ} 295$ de julho de 2019. Brasília, DF, 2019. Disponível em: < http://portal.anvisa.gov.br>. Acesso em: 02 dez. 2019. 
ANVISA. Agência Nacional de Vigilância Sanitária. Dispõe sobre as informações toxicológicas para rótulos e bulas de agrotóxicos, afins e preservativos de madeira, Resolução RDC n 296 de julho de 2019. Brasília, DF, 2019. Disponível em: < http://portal.anvisa.gov.br>. Acesso em: 02 dez. 2019.

ANVISA. Agência Nacional de Vigilância Sanitária. Estabelece e dá publicidade à lista de componentes não autorizados para uso em agrotóxicos e afins, Instrução Normativa $\mathrm{n}^{\circ} 34$ de julho de 2019. Brasília, DF, 2019. Disponível em: < http://portal.anvisa.gov.br>. Acesso em: 02 dez. 2020.

ANVISA. Agência Nacional de Vigilância Sanitária. Guia para elaboração de rótulo e bula de agrotóxicos, afins e preservativos de madeira. Brasília, DF, 2018.

ANVISA. Agência Nacional de Vigilância Sanitária. Legislação de boas práticas de fabricação. Brasília, 2015b. Disponível em: $<$ http://portal.anvisa.gov.br/registros-e-autorizacoes/alimentos/empresas/boaspraticas-de-fabricacao >. Acesso em: 29 out. 2019.

ANVISA. Agência Nacional de Vigilância Sanitária. Programa de análise de resíduos de agrotóxicos em alimentos (PARA). Disponível em: $<$ http://portal.anvisa.gov.br/programa-de-analise-de-registro-de-agrotoxicospara>. Acesso em: $01 \mathrm{dez} .2019$.

AYHAN, M.B. A fuzzy AHP approach for supplier selection problem: a case study in a gear motor company. International Journal of Managing Value and Supply Chains, v.4, n.3, p. 11-23, 2013.

BAGHERI, A.; EMAMI, N.; DAMALAS, C.A. Farmers behavior in reading and using risk information displayed on pesticide labels: a test with the theory of planned behavior. Pest Management Science, v.77; p. 2903-2913, 2021.

BAGHERI, A.; PIRMOAZEN, S.; ALLAHYARI, M. S. Assessment of farmers understanding of the pictograms displayed on pesticide labels. Environmental Science and Pollution Research, v.28, p. 17812-17825, 2021.

BOELHOUWER, E. et al. Comprehension of hazard communication: Effects of pictograms on safety data sheets and labels. Journal of Safety Research, v.46, p. 145-155, 2013.

BONNEFOY, J. C.; ARMIJO, M. Indicadores de desempeño en el sector público. Santiago de Chile: ONU e Instituto Latinoamericano e del Caribe de Planificación Económica y Social, 2005. ISBN 9213228007/16808878. Disponível em: http://repositorio.cepal.org/bitstream/handle/11362/5611/S05900_es.pdf >.Acesso em: 07 set. 2020.

BRANS, J. P.; MARESCHAL, B.; VINCKE, P. PROMETHEE: A new family of outranking methods in multicriteria analysis. In: Proceedings of International Conference of Operational Research, 1984. 
BRASIL. Agência Nacional de Vigilância Sanitária. Relatório de Gestão 2020. Brasília: Agência Nacional de Vigilância Sanitária, 2021. Disponível em:< https://www.gov.br/anvisa/pt-br/centraisdeconteudo/publicacoes/gestao/relatoriosde-gestao/relatorio-de-gestao-2020.pdf>. Acesso em: 12 mai. 2021.

BRASIL. Decreto no 24.114, de 12 de abril de 1934. Aprova o regulamento de defesa sanitária vegetal. Disponível em: < http://www.planalto.gov.br/ccivil_03/decreto/1930-1949/d24114.htm>. Acesso em: 20 fev. 2021.

BRASIL. Decreto $\mathbf{n}^{\mathbf{0}}$ 4.074, de 04 de janeiro de 2002. Regulamenta a Lei $\mathrm{n}^{\circ}$ 7.802, de 1989, que dispõe sobre a pesquisa, a experimentação, a produção, a embalagem e rotulagem o transporte, o armazenamento, a comercialização, a propaganda comercial, a utilização, a importação, exportação, o destino final dos resíduos e embalagens, o registro, a classificação, o controle, a inspeção e a fiscalização de agrotóxicos, seus componentes e afins, e dá outras providências. Disponível em: <http://www.planalto.gov.br/ccivil_03/decreto/2002/d4074.htm>. Acesso em: 20 fev. 2021.

BRASIL. Indicadores de programas. Guia metodológico. Brasília: Ministério do Planejamento, Orçamento e Gestão: 128 p. 2010.

BRASIL. Indicadores: Orientações básicas aplicadas à gestão pública. Brasília DF: Ministério do Planejamento, Orçamento e Gestão. 2012.

BRASIL. Lei $\mathbf{n}^{\mathbf{0}} \mathbf{7 . 8 0 2}$, de 11 de julho de 1989. Dispõe sobre a pesquisa, a experimentação, a produção, a embalagem e rotulagem, o transporte, o armazenamento, a comercialização, a propaganda comercial, a utilização, a importação, a exportação, o destino final dos resíduos e embalagens, o registro, a classificação, o controle, a inspeção e a fiscalização de agrotóxicos, seus componentes e afins, e dá outras providências. Disponível em: <http://www.planalto.gov.br/ccivil_03/leis/L7802.htm>. Acesso em: 20 fev. 2021.

BRASIL. Ministério da Saúde. Secretaria de Atenção Primária à Saúde. Departamento de Saúde da Família. Nota Técnica no 11. Brasília: Ministério da Saúde, 2020.

BRASIL. Ministério da Saúde. Secretaria de Vigilância em Saúde. Departamento de Vigilância em Saúde Ambiental e Saúde do Trabalhador. Agrotóxicos na ótica do Sistema Único de Saúde. Brasília: Ministério da Saúde, 2018.

BRASIL. Ministério do Meio Ambiente. Disponível em:< https://www.gov.br/mma/pt-br >. Acesso em: 15 jun. 2020.

BRASIL. Norma Regulamentadora $\mathrm{n}^{\circ}$ 26. Sinalização de segurança. Diário Oficial da República Federativa do Brasil, Brasília, DF, 24 de maio de 2011. Disponível em:< http://www.normaslegais.com.br/legislacao/portariasit229_2011.htm>. Acesso em: 07 set. 2020. 
BRASIL. Portaria $\mathrm{n}^{\circ}$ 229, de 24 de maio de 2011. Altera a Norma Regulamentadora $n^{\circ}$ 26. Diário Oficial da República Federativa do Brasil, Brasília, DF, 27 de maio de 2011. Disponível em:< http://www.normaslegais.com.br/legislacao/portariasit229_2011.htm>. Acesso em: 07 set. 2020.

BRASIL. Portaria SNVS no 03, de 16 de janeiro de 1992. Ratifica os termos das diretrizes e orientações referentes à autorização de registros, renovação de registro e extensão de uso de produtos agrotóxicos e afins. Diário Oficial da República Federativa do Brasil, Brasília, DF, 16 de janeiro de 1992. Disponível em:< http://bvsms.saude.gov.br/bvs/saudelegis/svs1/1992/prt0003_16_01_1992.html>. Acesso em: 07 set. 2020.

BUCKLEY, J. J. Fuzzy hierarchical analysis. Fuzzy Sets Systems, v.17, n.1, p. 233-247, 1985.

CASSIOLATO, M.; GUERESI, S. Como elaborar modelo lógico de programas: roteiro para formular programas e organizar avaliação. Nota Técnica, n.6. Brasília: IPEA, 2010.

CHANG, D.Y. Applications of the extent analysis method on fuzzy AHP. European Journal of Operational Research, v.95, p. 649-655, 1996.

CHEN, C. T. Extensions of the TOPSIS for group decision-making under fuzzy environment. Fuzzy Sets and Systems, v. 114, p. 1-9, 2000.

CHOI, Y.-H.; KANG, M.-S.; HUH, D.-A.; CHAE, W.-R.; MOON, K. W. Priority Setting for Management of Hazardous Biocides in Korea Using Chemical Ranking and Scoring Method. International Journal of Environmental Research and Public Health, v.17, p. 1970, 2020.

CHOU, S-W.; CHANG, Y-C. The implementation factors that influence the ERP (Enterprise Resource Planning) benefits. Decision Support Systems, v.46, n.1, p.149-157, 2008.

COSTA, H. G. Auxilio multicritério à decisão: método AHP. Rio de Janeiro: Abepro, 2006. ISBN 85-88478-30-7.

CRIOLLO, L. F. R. Monitoramento e avaliação sobre rotulagem de alimentos alergênicos no Brasil: proposição de indicadores e métricas. Rio de Janeiro, 2016, 116 p. Dissertação (Mestrado) - Programa de Pós-Graduação em Metrologia, Qualidade e Inovação. Pontifícia Universidade Católica do Rio de Janeiro.

EMERY, S.B.; HART, A.; BUTLER-ELLIS, C.; GERRITSEN-EBBEN, M.G.; MACHERA, K.; SPANOGHE, P.; FREWER, L.J. A Review of the use of pictograms for communicating pesticide hazards and safety instructions: implications for EU policy, human and ecological risk assessment. Human and Ecological Risk Assessment: An International Journal, v.21, n.4, p. 10621080, 2015. 
EUROPEAN CHEMICALS AGENCY. ECHA database. Disponível em:< https://echa.europa.eu/pt/scip>. Acesso em: 13 set. 2020.

EUROPEAN UNION. Pesticides Database from European Comission. Disponível em:< https://ec.europa.eu/food/plant/pesticides/eu-pesticides-db_en>. Acesso em: 13 set. 2020.

FAO. Site institucional da FAO. Disponível em: <http://www.fao.org/pesticideregistration-toolkit/tool/page>. Acessso em: 21 fev. 2021.

FARÍAS, P. Promoting the absence of pesticides through product labels: the role of showing a specific description of the harmful effects, environmental attitude, and familiarity with pesticides. Sustainability, v.12 n.21, p. 8912, 2020.

FERREIRA, H.; CASSIOLATO, M.; GONZALEZ, R. Uma experiência de desenvolvimento metodológico para avaliação de programas: o modelo lógico do Programa Segundo o Tempo. Texto para discussão $n^{\circ}$ 1.369. Brasília, DF: IPEA, 2009.

FONSECA, J. M. A regulação de registro de novas moléculas do setor de defensivos agrícolas. São Paulo, 2018, 47 p. Dissertação (Mestrado). Escola de Economia de São Paulo. Fundação Getúlio Vargas.

FREITAS, C. M. et al. Segurança química, saúde e ambiente: perspectivas para a governança no contexto brasileiro. Cadernos de Saúde Pública, Rio de Janeiro, v.18, n.1, p. 249-256, 2002 .

GARCIA, E.; BUSSACOS, M. A.; FISCHER, F. M. Harmonização e classificação toxicológica de agrotóxicos em 1992 no Brasil e a necessidade de prever os impactos da futura implantação do GHS. Ciência Saúde Coletiva, Rio de Janeiro, v.13, p. 2279-2287, 2008.

GOMES, L. F. A. M.; FREITAS Jr., A. A. A importância do apoio multicritério à decisão na formação do administrador. Revista ANGRAD, v.1, n.1, p. 82-87, jul./set. 2000.

HWANG, C. L.; YOON, K. Multiple attribute decision making methods and applications: A state-of-the-art survey. New York: Springer, 1981.

IBAMA. Instituto Brasileiro do Meio Ambiente e dos Recursos Naturais Renováveis. Disponível em: <https://www.gov.br/ibama/pt-br>. Acesso em: 12 ago. 2020 .

IBGE. Instituto Brasileiro de Geografia e Estatística. Indicadores de desenvolvimento sustentável - Brasil 2008. Estudos e Pesquisas Informação Geográfica $\mathrm{n}^{\mathrm{o}}$ 5. Rio de Janeiro: IBGE, 2008. Disponível em: <ftp://geoftp.ibge.gov.br/documentos/recursos_naturais/indicadores_desenvolvim ento_sustentavel/ids2008.pdf>. Acesso em: 16 jan. 2020.

ILO. International Chemical Safety Cards. Disponível em:< https://www.ilo.org/safework/info/publications/WCMS_113134/lang-en/index.htm/>. Acesso em: 13 jun. 2020. 
JANNUZZI, P. M. Considerações sobre o uso, mau uso e abuso dos indicadores sociais na formulação e avaliação de políticas públicas municipais. Revista do Serviço Público, 1.ed., v.36, p. 51-72. 2002.

MCLAUGHLIN, J.; JORDAN, G. Using logic models. In: Wholley, J. Hatry, H. P. Newcomer, K. E. (Orgs.). Handbook of Practical Program Evaluation, 2ed. São Francisco: John Wiley \& Sons, 2004.

MELLO, A. F. P. Monitoramento e avaliação da regulamentação sobre recolhimento de alimentos no Brasil: proposição de indicadores e métricas. Rio de Janeiro, 2015, 185 p. Dissertação (Mestrado) - Programa de PósGraduação em Metrologia, Qualidade e Inovação. Pontifícia Universidade Católica do Rio de Janeiro.

OIT. Convenção $n^{0}$ 174. Convenção sobre a prevenção de acidentes industriais. Genebra, 1993. Disponível em:< https://www.ilo.org/brasilia/convencoes>. Acesso em: 12 jun. 2020.

OIT. Organização Internacional do Trabalho. Convenção $\mathrm{n}^{0}$ 170. Convenção sobre a prevenção de acidentes industriais. Genebra, 1990. Disponível em:< https://www.ilo.org/brasilia/convencoes>. Acesso em: 12 jun. 2020.

OIT. Organização Internacional do Trabalho. Site institucional. Disponível em:< https://www.ilo.org/brasilia/lang--es/index.htm>. Acesso em: 13 jun. 2020.

ONLINEOUTPUT. Software fuzzy AHP. Disponível em: <http://www.onlineoutput.com/fuzzy-ahp-software/>. Acesso em: 05 dez. 2020.

PAN, C. A. Sistema globalmente harmonizado de classificação e rotulagem de produtos químicos - GHS: uma ferramenta na gestão da segurança química. Revista de Ciências Exatas e Tecnologia, v.7, n.7, p. 21:33, 2012.

PELAEZ, V.; SILVA, L.; ARAÚJO, E. Regulation of pesticides: A comparative analysis. Science and Public Policy, v. 40, p. 644-656, 2013.

PELAEZ, V.; TERRA, F. H. B.; SILVA, L. R. A regulamentação dos agrotóxicos no Brasil: entre o poder de mercado e a defesa da saúde do meio ambiente. Revista de Economia, v.36, n.1, p.27-48, 2011.

PERSSON, L. et al. The Globally Harmonized System of Classification and Labelling of Chemicals - Explaining the Legal Implementation Gap. Sustainability, v.9, p. 2176, 2017.

PETERSON, P. J.; MOKHTAR, M.; CHANG, C.; KRUEGER, J. Indicators as a tool for the evaluation of effective national implementation of the Globally Harmonized System of Classification and Labelling of Chemicals (GHS). Journal of Environmental Management, v.91, p. 1202-1208, 2010.

ROTHER, H. A. Pesticide labels: protecting liability or health? - Unpacking "misuse" of pesticides. Environmental Science \& Health, V.4, p. 10-15, 2018. 
ROY, B.; BOUYSSOU, D. Aide multicritère à la décision: méthodes et cas. Paris: Economica, 1993.

SÁ, A. F. Mensuração e avaliação dos ativos intangíveis e criação de valor das atividades de laboratórios de diagnóstico e ensaios de equipamentos elétricos. Rio de Janeiro, 2018, 144 p. Dissertação (Mestrado) - Programa de PósGraduação em Metrologia, Qualidade e Inovação. Pontifícia Universidade Católica do Rio de Janeiro.

SAATY, T. L. A scaling method for priorities in hierarchical structures. Journal of Mathematical Psychology, v. 15, n. 3, p. 234-281, 1977.

SAATY, T. L. Decision making for leaders. University of Pittsburgh, 2000.

SAATY, T. L. Desicion making by the analytic hierarchy process: Theory and applicationsPhysics as a decision theory. European Journal of Operational Research, v. 48, n. 1, p. 98-104.

SAATY, T. L. Método de análise hierárquica. São Paulo: Mc - Graw Hill, 1991.

SAFE WORK AUSTRALIA. Site institucional. Disponível em:< http://hcis.safeworkaustralia.gov.au/>. Acesso em: 13 jun. 2020.

SAICM. Strategic Approach to International Chemicals Management. 2021. Disponível em: <http://www.saicm.org>. Acesso em: 20 fev. 2021.

SHIN, S.; MOON, H.I.; LEE, K.S.; HONG, M.K.; BYEON1, S-H. A chemical risk ranking and scoring method for the selection of harmful substances to be specially controlled in occupational environments. International Journal of Environmental Research and Public Health, v.11, p. 12001-12014, 2014.

SILVA, A. C. G.; SOUSA, I. P.; SANTOS, T. R. M.; VALADARES, M. C. Avaliação da Toxicidade Agrícola no Brasil: Avanços e Oportunidades no Século 21. Ciências Toxicológicas, v.177, n.2, p. 316-324, 2020.

SOUSA JR., A. M.; MENDES, F.S. Identificação de método adequado para auxílio na tomada de decisão em recuperação de reservatório de poços de petróleo na região RN/CE. Revista Eletrônica de Petróleo e Gás, v.2, n. 2, p. 19-29, 2014.

TANAKA, O. Y.; MELO, C. Avaliação de programas de saúde do adolescente: um modo de fazer. Universidade de São Paulo: Universidade de São Paulo, 2001.

UNECE. Globally Harmonized System of Classification and Labelling of Chemicals. Disponível em:<https://unece.org>. Acesso em: 13 jun. 2020.

UNECE. Site institucional da UNECE. 2021. Disponível em: <http://www.unece.org/trans/danger/publi/ghs/ghs_welcome_e.html>. Acesso em: 20 fev. 2021. 
UNEP. Site institucional. 2021. Disponível em: http://ozone.unep.org/Publications/MP_Handbook/index.shtml>. Acesso em: 20 fev. 2021.

US EPA. Carcinogenicity Evaluation from EPA: Database. Disponível em: https://www.epa.gov/fera/risk-assessment-carcinogenic-effects>. Acesso em: 13 jun. 2020.

US EPA. Chemical Classification and Information Database from EPA: banco de dados. Disponível em:< https://www.epa.govt.nz/database-search/chemicalclassification-and-information-database-ccid/>. Acesso em: 13 jun. 2020.

VASCONCELLOS, R. A. J. P. O Brasil e o regime internacional de segurança química. Brasília : FUNAG, 2014.

VERGARA, S.C. Metodologia do trabalho científico. $22^{\mathrm{a}}$ ed. São Paulo: Cortez. 2002 .

VILLELA, T. M. D. A. et al. Metodologia para desenvolvimento e seleção de indicadores para planejamento de transportes. CEFTRU, 2007. Disponível em: $\quad<100$ https://www.researchgate.net/publication/267962892_metodologia_para_desenvol vimento_e_selecao_de_indicadores_para_planejamento_de_transportes $>$. Acesso em: 20. fev.2021.

W. K. KELLOGG FOUNDATION. Logic model development guide: using logic models to bring together planning, evaluation, and action. Michigan: W. K. Kellog Foundation, 2004.

WALLAU, W. M; SANTOS JUNIOR, J. A. O sistema globalmente harmonizado de classificação e rotulagem de produtos químicos (GHS): uma introdução para sua aplicação em laboratórios de ensino e pesquisa acadêmica. Química Nova, v.36, n. 4, p. 607-617, 2013.

WHO. International Agency for Research on Cancer Monographs. Disponível em:< https://monographs.iarc.who.int/>. Acesso em: 13 jun. 2020.

WHO. Site institucional da WHO. Disponível em: $<$ https://www.who.int/ipcs/publications/pesticides_hazard/en/>. Acesso em: 20 fev. 2021.

YAZID, M. F. H. A.; CHOO, G.; MOKHTAR, M. Classified Chemicals in Accordance with the Globally Harmonized System of Classification and Labeling of Chemicals: Comparison of Lists of the European Union, Japan, Malaysia and New Zealand. Safety and Health at Work, v.11, n.2, p. 152-158, 2020. 


\section{Apêndice 1 - Listas de indicadores candidatos para as categorias 'Modelo de rótulo', 'Modelo de bula, e 'Instruções para preenchimento do quadro de informações médicas'}

Quadro A.1 - Lista inicial de indicadores de MA para a categoria "Modelo de rótulo" - coluna central

\begin{tabular}{|c|c|}
\hline Referencia & Indicadores/métricas \\
\hline Indicador 1 & Inadequação do rótulo por ausência da marca comercial do produto. \\
\hline Métrica 1.1 & de rótulos não conformes de embalagens de agrotóxicos devido à ausência da marca comercial do produto (por classe do agrotóxico) \\
\hline Métrica 1.2 & $\begin{array}{l}\text { № de rótulos não conformes de embalagens de agrotóxicos devido à ausência da marca comercial do produto/total rótulos de embalagens de agrotóxicos (por } \\
\text { classe do agrotóxico) [\%]. }\end{array}$ \\
\hline Indicador 2 & ladequação do rótulo por ausência da composição do produto. \\
\hline Métrica 2.1 & o de rótulos não conformes de embalagens de agrotóxicos devido à ausência da composição do produto (por classe do agrotóxico). \\
\hline Métrica 2.2 & $\begin{array}{l}\text { № de rótulos não conformes de embalagens de agrotóxicos devido à ausência da composição do produto/total rótulos de embalagens de agrotóxicos (por } \\
\text { classe do agrotóxico) [\%]. }\end{array}$ \\
\hline Indicador 3 & Inadequação do rótulo por ausência de informação do conteúdo, em unidade de massa ou volume. \\
\hline Métricé & № de rótulos não conformes de embalagens de agrotóxicos devido à ausência da informação do conteúdo (por classe do agrotóxico) \\
\hline Métrica 3.2 & $\begin{array}{l}\text { № de rótulos não conformes de embalagens de agrotóxicos devido à ausência da informação do conteúdo /total rótulos de embalagens de agrotóxicos (por } \\
\text { classe do agrotóxico) [\%]. }\end{array}$ \\
\hline Indicador 4 & ladequação do rótulo por ausência da especificação da classe do agrotóxico. \\
\hline Métrica 4.1 & № de rótulos não conformes de embalagens de agrotóxicos devido à ausência especificação da classe do agrotóxico (por classe do agrotóxico). \\
\hline Métrica 4.2 & $\begin{array}{l}\text { № de rótulos não conformes de embalagens de agrotóxicos devido à ausência da especificação da classe do agrotóxico/total rótulos de embalagens de } \\
\text { agrotóxicos (por classe do agrotóxico) [\%]. }\end{array}$ \\
\hline Indicador 5 & Inadequação do rótulo por ausência da identificação do grupo químico. \\
\hline & № de rótulos não conformes de embalagens de agrotóxicos devido à ausência da identificação do grupo químico (por classe do agrotóxico). \\
\hline Métrica 5.2 & $\begin{array}{l}\text { № de rótulos não conformes de embalagens de agrotóxicos devido à ausência da identificação do grupo químico/total rótulos de embalagens de agrotóxicos } \\
\text { (por classe do agrotóxico) [\%]. }\end{array}$ \\
\hline Indicador 6 & Inadequação do rótulo por ausência do tipo de formulação. \\
\hline Métrica 6.1 & № de rótulos não conformes de embalagens de agrotóxicos devido à ausência do tipo de formulação (por classe do agrotóxico). \\
\hline Métrica 6.2 & $\begin{array}{l}\text { № de rótulos não conformes de embalagens de agrotóxicos devido à ausência do tipo de formulação/total rótulos de embalagens de agrotóxicos (por classe do } \\
\text { agrotóxico) [\%]. }\end{array}$ \\
\hline Indicador 7 & Inadequação do rótulo por ausência do titular do registro \\
\hline Métrica 7.1 & o de rótulos não conformes de embalagens de agrotóxicos devido à ausência do titular do registro (por classe do agrotóxico). \\
\hline Métrica 7.2 & $\begin{array}{l}\text { de rótulos não conformes de embalagens de agrotóxicos devido à ausência do titular do registro /total rótulos de embalagens de agrotóxicos (por classe do } \\
\text { otóxico) [\%]. }\end{array}$ \\
\hline
\end{tabular}




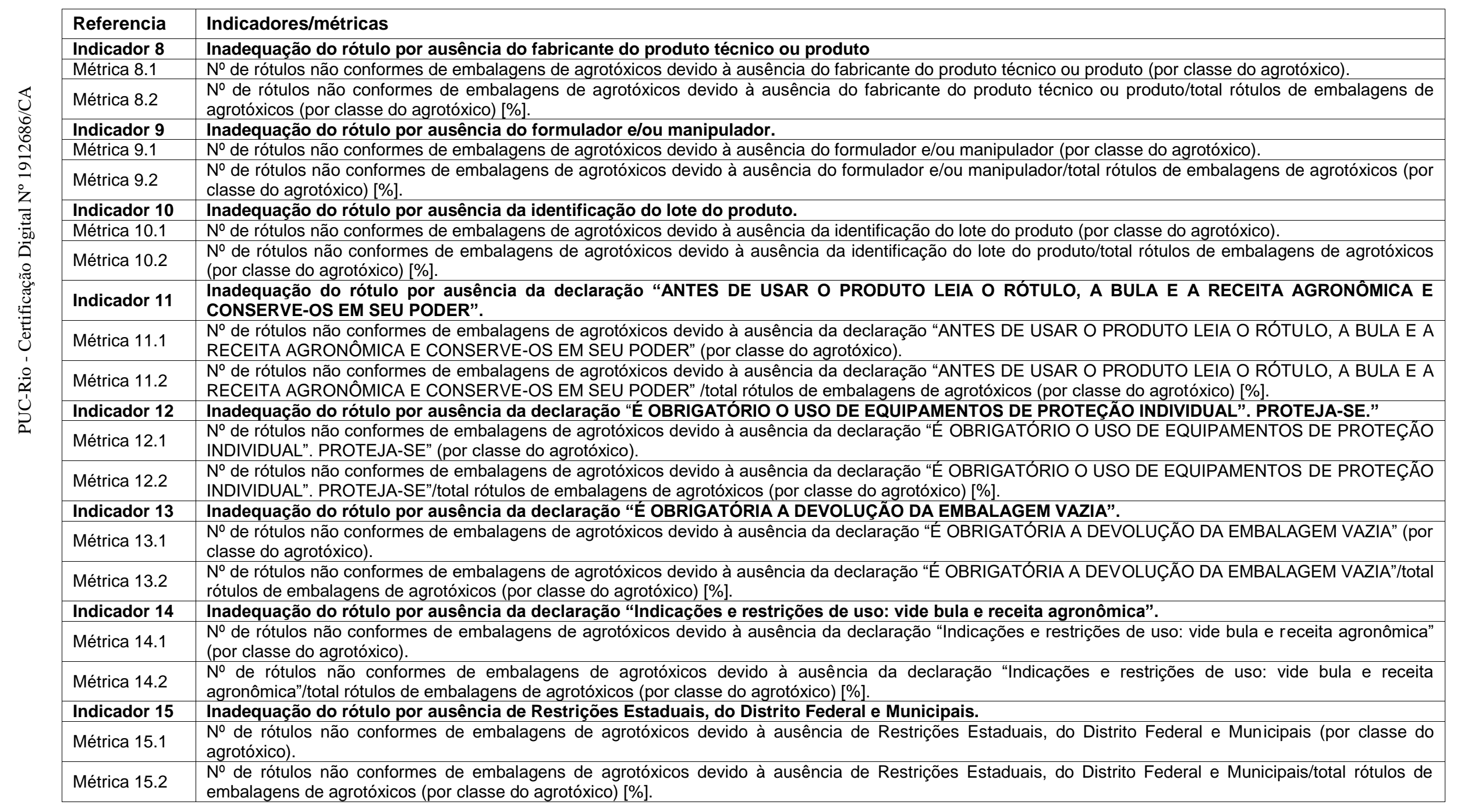




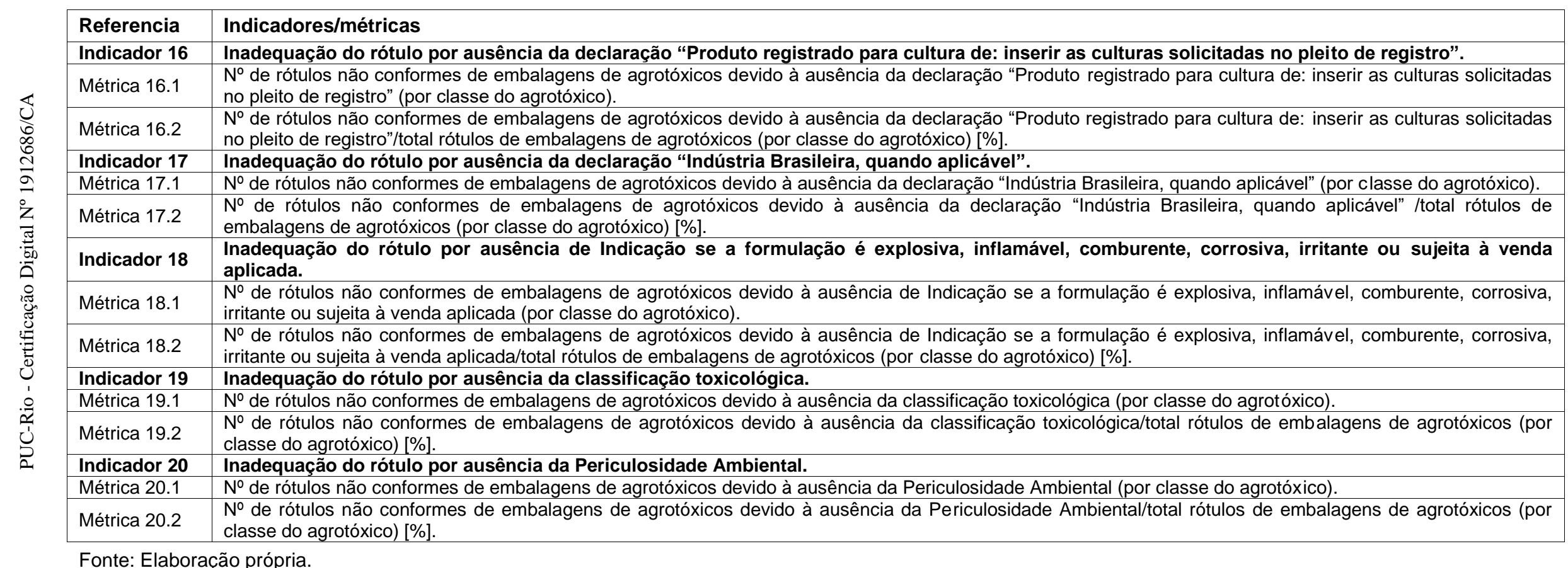


Quadro A.2. - Lista inicial de indicadores de MA para a categoria "Modelo de rótulo" - coluna da direita

\begin{tabular}{|c|c|}
\hline \multirow{2}{*}{\begin{tabular}{|l|} 
Referência \\
Indicador $\mathbf{2 1}$ \\
Métrica 21.1 \\
\end{tabular}} & Indicadores/métricas \\
\hline & Inadequação do rótulo por ausência da declaração “ANTES DE USAR O PRODUTO, LEIA COM ATENÇÃO AS INSTRUÇÕES DA BULA". \\
\hline Métrica 21.2 & $\begin{array}{l}\text { No de rótulos não conformes de embalagens de agrotóxicos devido à ausência da declaração "ANTES DE USAR O PRODUTO, LEIA COM ATENÇĀO AS } \\
\text { INSTRUÇÕES DA BULA"/total rótulos de embalagens de agrotóxicos (por classe do agrotóxico) [\%]. }\end{array}$ \\
\hline Métrica 22.1 & № de rótulos não conformes de embalagens de agrotóxicos devido à ausência de frases relacionadas a precauções gerais (por classe do agrotóxico). \\
\hline Métrica 22.2 & $\begin{array}{l}\text { № de rótulos não conformes de embalagens de agrotóxicos devido à ausência de frases relacionadas a precauçōes gerais/total rótulos de embalagens de } \\
\text { agrotóxicos (por classe do agrotóxico) [\%]. }\end{array}$ \\
\hline Indicador 23 & Inadequação do rótulo por ausência de frases relacionadas a precauções gerais. \\
\hline Métrica 23.2 & $\begin{array}{l}\text { No de rótulos não conformes de embalagens de agrotóxicos devido à ausência de frases relacionadas a precauções gerais/total rótulos de embalagens de } \\
\text { agrotóxicos (por classe do agrotóxico) [\%]. }\end{array}$ \\
\hline Indicador 24 & Inadequação do rótulo por ausência de frases relacionadas a precauções durante a preparação da calda. \\
\hline Métrica 24.1 & $\begin{array}{l}\text { No de rótulos não conformes de embalagens de agrotóxicos devido à ausência de frases relacionadas a precauções durante a preparação da calda (por classe } \\
\text { do agrotóxico). }\end{array}$ \\
\hline Métrica 24.2 & $\begin{array}{l}\text { No de rótulos não conformes de embalagens de agrotóxicos devido à ausência de frases relacionadas a precauções durante a preparação da calda/total rótulos } \\
\text { de embalagens de agrotóxicos (por classe do agrotóxico) [\%]. }\end{array}$ \\
\hline Indicador 25 & Inadequação do rótulo por ausência de frases relacionadas a precauções durante o manuseio. \\
\hline Métrica 25.1 & № de rótulos não conformes de embalagens de agrotóxicos devido à ausência de frases relacionadas a precauções o manuseio (por classe do agrotóxico). \\
\hline Métrica 25.2 & $\begin{array}{l}\text { No de rótulos não conformes de embalagens de agrotóxicos devido à ausência de frases relacionadas a precauções o manuseio/total rótulos de embalagens de } \\
\text { agrotóxicos (por classe do agrotóxico) [\%]. }\end{array}$ \\
\hline Indicador 26 & Inadequação do rótulo por ausência de frases relacionadas a precauções para o tratamento de sementes. \\
\hline Métrica 26.1 & $\begin{array}{l}\text { № de rótulos não conformes de embalagens de agrotóxicos devido à ausência de frases relacionadas a precauções para o tratamento de sementes (por classe } \\
\text { do agrotóxico). }\end{array}$ \\
\hline Métrica 26.2 & $\begin{array}{l}\text { № de rótulos não conformes de embalagens de agrotóxicos devido à ausência de frases relacionadas a precauções para o tratamento de sementes/total } \\
\text { rótulos de embalagens de agrotóxicos (por classe do agrotóxico) [\%]. }\end{array}$ \\
\hline Indicador 27 & Inadequação do rótulo por ausência de frases relacionadas a precauções durante a aplicação do produto. \\
\hline Métrica 27.1 & $\begin{array}{l}\text { № de rótulos não conformes de embalagens de agrotóxicos devido à ausência de frases relacionadas a precauções durante a aplicação do produto (por classe } \\
\text { do agrotóxico). }\end{array}$ \\
\hline Métrica 27.2 & $\begin{array}{l}\text { No de rótulos não conformes de embalagens de agrotóxicos devido à ausência de frases relacionadas a precauções durante a aplicação do produto/total } \\
\text { rótulos de embalagens de agrotóxicos (por classe do agrotóxico) [\%]. }\end{array}$ \\
\hline
\end{tabular}


Indicador 28

Métrica 28.1

Métrica 28.2

Indicador 29

Métrica 29.1

Métrica 29.2

Indicador $\mathbf{3 0}$

Métrica 30.1

Métrica 30.2

Indicador $\mathbf{3 1}$

Métrica 31.1

Métrica 31.2

Indicador 32

Métrica 32.1

Métrica 32.2

Inadequacão do rótulo por ausência de frases relacionadas a precaucões após a aplicacão do produto.

№ de rótulos não conformes de embalagens de agrotóxicos devido à ausência de frases relacionadas após a aplicação do produto (por classe do agrotóxico).

№ de rótulos não conformes de embalagens de agrotóxicos devido à ausência de frases relacionadas após a aplicação do produto/total rótulos de embalagens de agrotóxicos (por classe do agrotóxico) [\%].

Inadequação do rótulo por ausência de quadro de primeiros socorros

№ de rótulos não conformes de embalagens de agrotóxicos devido à ausência de quadro de primeiros socorros (por classe do agrotóxico).

№ de rótulos não conformes de embalagens de agrotóxicos devido à ausência de quadro de primeiros socorros/total rótulos de embalagens de agrotóxicos (por classe do agrotóxico) [\%].

Inadequação do rótulo por ausência de quadro de antídotos e tratamento.

№ de rótulos não conformes de embalagens de agrotóxicos devido à ausência de quadro de antídotos e tratamento (por classe do agrotóxico).

№ de rótulos não conformes de embalagens de agrotóxicos devido à ausência de quadro de antídotos e tratamento/total rótulos de embalagens de agrotóxicos (por classe do agrotóxico) [\%].

Inadequação do rotulo por ausência de quadro de telefones em caso de emergência.

№ de rótulos não conformes de embalagens de agrotóxicos devido à ausência de quadro de telefones em caso de emergência (por classe do agrotóxico).

№ de rótulos não conformes de embalagens de agrotóxicos devido à ausência de quadro de telefones em caso de emergência/total rótulos de embalagens de

agrotóxicos (por classe do agrotóxico) [\%].

№ de rótulos não conformes de embalagens de agrotóxicos devido à ausência de faixa do rótulo de acordo com o guia da Anvisa/total rótulos de embalagens

Fonte: Elaboração própria. 
Quadro A.3 - Lista inicial de indicadores de MA para a categoria "Modelo de bula"

\begin{tabular}{|c|c|}
\hline Referência & Indicadores/métricas \\
\hline Indicador 33 & Inadequação de bulas por ausência da composição do produto. \\
\hline Métrica 33.1 & jo de bulas não conformes de embalagens de agrotóxicos devido à ausência da composição do produto (por classe do agrotóxico). \\
\hline Métrica 33.2 & $\begin{array}{l}\text { № de bulas não conformes de embalagens de agrotóxicos devido à ausência da composição do produto/total bulas de embalagens de agrotóxicos (por } \\
\text { classe do agrotóxico) [\%]. }\end{array}$ \\
\hline Indicador 34 & Inadequação de bulas por ausência de informação do conteúdo, em unidade de massa ou volume. \\
\hline Métrica 34.1 & № de bulas não conformes de embalagens de agrotóxicos devido à ausência da informação do conteúdo (por classe do agrotóxico) \\
\hline Métrica 34.2 & $\begin{array}{l}\text { № de bulas não conformes de embalagens de agrotóxicos devido à ausência da informação do conteúdo /total bulas de embalagens de grotóxicos (por } \\
\text { classe do agrotóxico) [\%]. }\end{array}$ \\
\hline Indicador 35 & Inadequação de bulas por ausência da especificação da classe do agrotóxico. \\
\hline Métrica 35.1 & № de bulas não conformes de embalagens de agrotóxicos devido à ausência especificação da classe do agrotóxico (por classe do agrotóxico). \\
\hline Métrica 35.2 & $\begin{array}{l}\text { № de bulas não conformes de embalagens de agrotóxicos devido à ausência da especificação da classe do agrotóxico/total bulas de embalagens de } \\
\text { agrotóxicos (por classe do agrotóxico) [\%]. }\end{array}$ \\
\hline Indicador 36 & Inadequação de bulas por ausência da identificação do grupo químico. \\
\hline Métrica 36.1 & № de bulas não conformes de embalagens de agrotóxicos devido à ausência da identificação do grupo químico (por classe do agrotóxico). \\
\hline Métrica 36.2 & $\begin{array}{l}\text { № de bulas não conformes de embalagens de agrotóxicos devido à ausência da identificação do grupo químico/total bulas de embalagens de agrotóxicos } \\
\text { (por classe do agrotóxico) [\%]. }\end{array}$ \\
\hline Indicador 37 & Inadequação de bulas por ausência do tipo de formulação. \\
\hline Métrica 37.1 & № de bulas não conformes de embalagens de agrotóxicos devido à ausência do tipo de formulação (por classe do agrotóxico). \\
\hline Métrica 37.2 & $\begin{array}{l}\text { № de bulas não conformes de embalagens de agrotóxicos devido à ausência do tipo de formulação/total bulas de embalagens de agrotóxicos (por classe do } \\
\text { agrotóxico) [\%]. }\end{array}$ \\
\hline Indicador 38 & Inadequação de bulas por ausência do titular do registro. \\
\hline Métrica 38.1 & № de bulas não conformes de embalagens de agrotóxicos devido à ausência do titular do registro (por classe do agrotóxico). \\
\hline Métrica 38.2 & $\begin{array}{l}\text { № de bulas não conformes de embalagens de agrotóxicos devido à ausência do titular do registro /total bulas de embalagens de agrotóxicos (por classe do } \\
\text { agrotóxico) [\%]. }\end{array}$ \\
\hline Indicador 39 & Inadequação de bulas por ausência do fabricante do produto técnico ou produto. \\
\hline Métrica 39.1 & № de bulas não conformes de embalagens de agrotóxicos devido à ausência do fabricante do produto técnico ou produto (por classe do agrotóxico). \\
\hline Métrica 39.2 & $\begin{array}{l}\text { № de bulas não conformes de embalagens de agrotóxicos devido à ausência do fabricante do produto técnico ou produto/total bulas de embalagens de } \\
\text { agrotóxicos (por classe do agrotóxico) [\%]. }\end{array}$ \\
\hline Indicador 40 & Inadequação de bulas por ausência do formulador e/ou manipulador. \\
\hline Métrica 40.1 & № de bulas não conformes de embalagens de agrotóxicos devido à ausência do formulador e/ou manipulador (por classe do agrotóxico). \\
\hline Métrica 40.2 & $\begin{array}{l}\text { № de bulas não conformes de embalagens de agrotóxicos devido à ausência do formulador e/ou manipulador/total bulas de embalagens de agrotóxicos (por } \\
\text { classe do agrotóxico) [\%]. }\end{array}$ \\
\hline Indicador 41 & Inadequação de bulas por ausência de informações de fabricação. \\
\hline Métrica 41.1 & № de bulas não conformes de embalagens de agrotóxicos devido à ausência de de informações de fabricação (por classe do agrotóxico). \\
\hline Métrica 42.2 & $\begin{array}{l}\text { № de bulas não conformes de embalagens de agrotóxicos devido à ausência de informações de fabricação/total bulas de embalagens de agrotóxicos (por } \\
\text { classe do agrotóxico) [\%]. }\end{array}$ \\
\hline
\end{tabular}




\begin{tabular}{|c|c|}
\hline Indicador 43 & $\begin{array}{l}\text { Inadequação de bulas por ausência da declaração "ANTES DE USAR O PRODUTO LEIA O RÓTULO, A BULA E A RECEITA AGRONÔMICA E } \\
\text { CONSERVE-OS EM SEU PODER". }\end{array}$ \\
\hline Métrica 43.1 & $\begin{array}{l}\text { o de bulas não conformes de embalagens de agrotóxicos devido à ausência da declaração "ANTES DE USAR O PRODUTO LEIA O RÓTULO, A BULA E A } \\
\text { ECEITA AGRONÔMICA E CONSERVE-OS EM SEU PODER" (por classe do agrotóxico). }\end{array}$ \\
\hline Métrica 43.2 & $\begin{array}{l}\text { No de bulas não conformes de embalagens de agrotóxicos devido à ausência da declaração "ANTES DE USAR O PRODUTO LEIA O RÓTULO, A BULA E A } \\
\text { RECEITA AGRONÔMICA E CONSERVE-OS EM SEU PODER" /total bulas de embalagens de agrotóxicos (por classe do agrotóxico) [\%]. }\end{array}$ \\
\hline Indicador 44 & Inadequação de bulas por ausência da declaração “É OBRIGATÓRIO O USO DE EQUIPAMENTOS DE PROTEÇÃO INDIVIDUAL”. PROTEJA-SE." \\
\hline Métrica 44.1 & $\begin{array}{l}N^{\circ} \text { de bulas não conformes de embalagens de agrotóxicos devido à ausência da declaração "É OBRIGATÓRIO O USO DE EQUIPAMENTOS DE } \\
\text { PROTEÇÃO INDIVIDUAL". PROTEJA-SE" (por classe do agrotóxico). }\end{array}$ \\
\hline Métrica 44.2 & $\begin{array}{l}\text { № de bulas não conformes de embalagens de agrotóxicos devido à ausência da declaração "É OBRIGATÓRIO O USO DE EQUIPAMENTOS DE } \\
\text { PROTEÇÃO INDIVIDUAL". PROTEJA-SE"/total bulas de embalagens de agrotóxicos (por classe do agrotóxico) [\%]. }\end{array}$ \\
\hline Indicador 45 & Inadequação de bulas por ausência da declaração "É OBRIGATÓRIA A DEVOLUÇÃO DA EMBALAGEM VAZIA". \\
\hline Métrica 45.1 & $\begin{array}{l}N^{\circ} \text { de bulas não conformes de embalagens de agrotóxicos devido à ausência da declaração "É OBRIGATÓRIA A DEVOLUÇÃO DA EMBALAGEM VAZIA" } \\
\text { (por classe do agrotóxico). }\end{array}$ \\
\hline Métrica 45.2 & $\begin{array}{l}N^{\circ} \text { de bulas não conformes de embalagens de agrotóxicos devido à ausência da declaração "É OBRIGATÓRIA A DEVOLUÇÃO DA EMBALAGEM } \\
\text { VAZIA"/total bulas de embalagens de agrotóxicos (por classe do agrotóxico) [\%]. }\end{array}$ \\
\hline Indicador 46 & Inadequação de bulas por ausência da declaração "Indicações e restrições de uso: vide bula e receita agronômica". \\
\hline Métrica 46.1 & $\begin{array}{l}N^{\circ} \text { de bulas não conformes de embalagens de agrotóxicos devido à ausência da declaração "Indicações e restrições de uso: vide bula e receita agronômica" } \\
\text { (por classe do agrotóxico). }\end{array}$ \\
\hline Métrica 46.2 & $\begin{array}{l}\mathrm{N}^{\circ} \text { de bulas não conformes de embalagens de agrotóxicos devido à ausência da declaração "Indicações e restrições de uso: vide bula e receita } \\
\text { agronômica"/total bulas de embalagens de agrotóxicos (por classe do agrotóxico) [\%]. }\end{array}$ \\
\hline Indicador 47 & Inadequação de bulas por ausência de Restrições Estaduais, do Distrito Federal e Municipais. \\
\hline Métrica 47.1 & $\begin{array}{l}\text { № de bulas não conformes de embalagens de agrotóxicos devido à ausência de Restrições Estaduais, do Distrito Federal e Municipais (por classe do } \\
\text { agrotóxico). }\end{array}$ \\
\hline Métrica 47.2 & $\begin{array}{l}\text { № de bulas não conformes de embalagens de agrotóxicos devido à ausência de Restrições Estaduais, do Distrito Federal e Municipais/total bulas de } \\
\text { embalagens de agrotóxicos (por classe do agrotóxico) [\%]. }\end{array}$ \\
\hline Indicador 48 & Inadequação de bulas por ausência da declaração "Produto registrado para cultura de: inserir as culturas solicitadas no pleito de registro". \\
\hline Métrica 48.1 & $\begin{array}{l}\text { № de bulas não conformes de embalagens de agrotóxicos devido à ausência da declaração "Produto registrado para cultura de: inserir as culturas solicitadas } \\
\text { no pleito de registro" (por classe do agrotóxico). }\end{array}$ \\
\hline Métrica 48.2 & $\begin{array}{l}N^{\circ} \text { de bulas não conformes de embalagens de agrotóxicos devido à ausência da declaração "Produto registrado para cultura de: inserir as culturas solicitadas } \\
\text { no pleito de registro"/total bulas de embalagens de agrotóxicos (por classe do agrotóxico) [\%]. }\end{array}$ \\
\hline Indicador 49 & Inadequação de bulas por ausência da declaração "Indústria Brasileira, quando aplicável”. \\
\hline Métrica 49.1 & $\begin{array}{l}N^{0} \text { de bulas não conformes de embalagens de agrotóxicos devido à ausência da declaração "Indústria Brasileira, quando aplicável" (por classe do } \\
\text { agrotóxico). }\end{array}$ \\
\hline Métrica 49.2 & $\begin{array}{l}\text { № de bulas não conformes de embalagens de agrotóxicos devido à ausência da declaração "Indústria Brasileira, quando aplicável" /total bulas de } \\
\text { embalagens de agrotóxicos (por classe do agrotóxico) [\%]. }\end{array}$ \\
\hline
\end{tabular}




\begin{tabular}{|c|c|}
\hline Indicador 50 & $\begin{array}{l}\text { Inadequação de bulas por ausência de Indicação se a formulação é explosiva, inflamável, comburente, corrosiva, irritante ou sujeita à venda } \\
\text { aplicada. }\end{array}$ \\
\hline Métrica 50.1 & $\begin{array}{l}\text { № de bulas não conformes de embalagens de agrotóxicos devido à ausência de Indicação se a formulação é explosiva, inflamável, comburente, corrosiva, } \\
\text { irritante ou sujeita à venda aplicada (por classe do agrotóxico). }\end{array}$ \\
\hline Métrica 50.2 & $\begin{array}{l}\text { № de bulas não conformes de embalagens de agrotóxicos devido à ausência de Indicação se a formulação é explosiva, inflamável, comburente, corrosiva, } \\
\text { irritante ou sujeita à venda aplicada/total bulas de embalagens de agrotóxicos (por classe do agrotóxico) [\%]. }\end{array}$ \\
\hline Métrica 51.1 & № de bulas não conformes de embalagens de agrotóxicos devido à ausência da classificação toxicológica (por classe do agrotóxico). \\
\hline Métrica 51.2 & $\begin{array}{l}\text { № de bulas não conformes de embalagens de agrotóxicos devido à ausência da classificação toxicológica/total bulas de embalag ens de agrotóxicos (por } \\
\text { classe do agrotóxico) [\%]. }\end{array}$ \\
\hline Indicador 52 & Inadequação de bulas por ausência da Periculosidade Ambiental. \\
\hline Métrica 52.1 & № de bulas não conformes de embalagens de agrotóxicos devido à ausência da Periculosidade Ambiental (por classe do agrotóxico). \\
\hline Métrica 53.1 & № de bulas não conformes de embalagens de agrotóxicos devido à ausência da faixa de classificação toxicológica (por classe do agrotóxico). \\
\hline Métrica 53.2 & $\begin{array}{l}\text { № de bulas não conformes de embalagens de agrotóxicos devido à ausência da faixa de classificação toxicológica/total bulas de embalagens de agrotóxicos } \\
\text { (por classe do agrotóxico) [\%]. }\end{array}$ \\
\hline Indicador 54 & Inadequação de bulas por ausência de instruções de uso. \\
\hline Métrica 54.1 & № de bulas não conformes de embalagens de agrotóxicos devido à ausência de instruções de uso (por classe do agrotóxico). \\
\hline Métrica 54.2 & $\begin{array}{l}\text { № de bulas não conformes de embalagens de agrotóxicos devido à ausência de instruçães de uso/total bulas de embalagens de agrotóxicos (por classe do } \\
\text { agrotóxico) [\%]. }\end{array}$ \\
\hline Indicador 55 & $\begin{array}{l}\text { Inadequação de bulas por ausência de frases relacionadas a precauções gerais. } \\
\text { № de bulas não conformes de embalagens de agrotóxicos devido à ausência de frases relacionadas a precauções gerais (por classe do agrotóxico). }\end{array}$ \\
\hline Métrica 55.2 & $\begin{array}{l}\text { № de bulas não conformes de embalagens de agrotóxicos devido à ausência de frases relacionadas a precauções gerais (por classe do agrotóxico). } \\
\text { № de bulas não conformes de embalagens de agrotóxicos devido à ausência de frases relacionadas a precauções gerais/total bulas de embalagens de } \\
\text { agrotóxicos (por classe do agrotóxico) [\%]. }\end{array}$ \\
\hline Indicador 56 & Inadequação de bulas por ausência de frases relacionadas a precauções gerais. \\
\hline Métrica 56.1 & № de bulas não conformes de embalagens de agrotóxicos devido à ausência de frases relacionadas a precauções gerais (por classe do agrotóxico). \\
\hline Métrica 56.2 & $\begin{array}{l}\text { № de bulas não conformes de embalagens de agrotóxicos devido à ausência de frases relacionadas a precauções gerais/total bulas de embalagens de } \\
\text { agrotóxicos (por classe do agrotóxico) [\%]. }\end{array}$ \\
\hline Indicador 57 & Inadequação de bulas por ausência de frases relacionadas a precauções durante a preparação da calda. \\
\hline Métrica 57.1 & $\begin{array}{l}\text { № de bulas não conformes de embalagens de agrotóxicos devido à ausência de frases relacionadas a precauções durante a preparação da calda (por classe } \\
\text { do agrotóxico). }\end{array}$ \\
\hline Métrica 57.2 & $\begin{array}{l}\text { № de bulas não conformes de embalagens de agrotóxicos devido à ausência de frases relacionadas a precauções durante a preparação da calda/total bulas } \\
\text { de embalagens de agrotóxicos (por classe do agrotóxico) [\%]. }\end{array}$ \\
\hline Indicador 58 & Inadequação de bulas por ausência de frases relacionadas a precauções durante o manuseio. \\
\hline Métrica 58.1 & $\begin{array}{l}\text { № de bulas não conformes de embalagens de agrotóxicos devido à ausência de frases relacionadas a precauções o manuseio (por classe do agrotóxico). } \\
\text { № de bulas não conformes de embalagens de agrotóxicos devido à ausência de frases relacionadas a precaucões o manuseio/total bulas de embalagens de }\end{array}$ \\
\hline Métrica 58.2 & $\begin{array}{l}\text { № de bulas não conformes de embalagens de agrotóxicos devido à ausência de frases relacionadas a precauções o manuseio/total bulas de embalagens de } \\
\text { agrotóxicos (por classe do agrotóxico) [\%]. }\end{array}$ \\
\hline
\end{tabular}




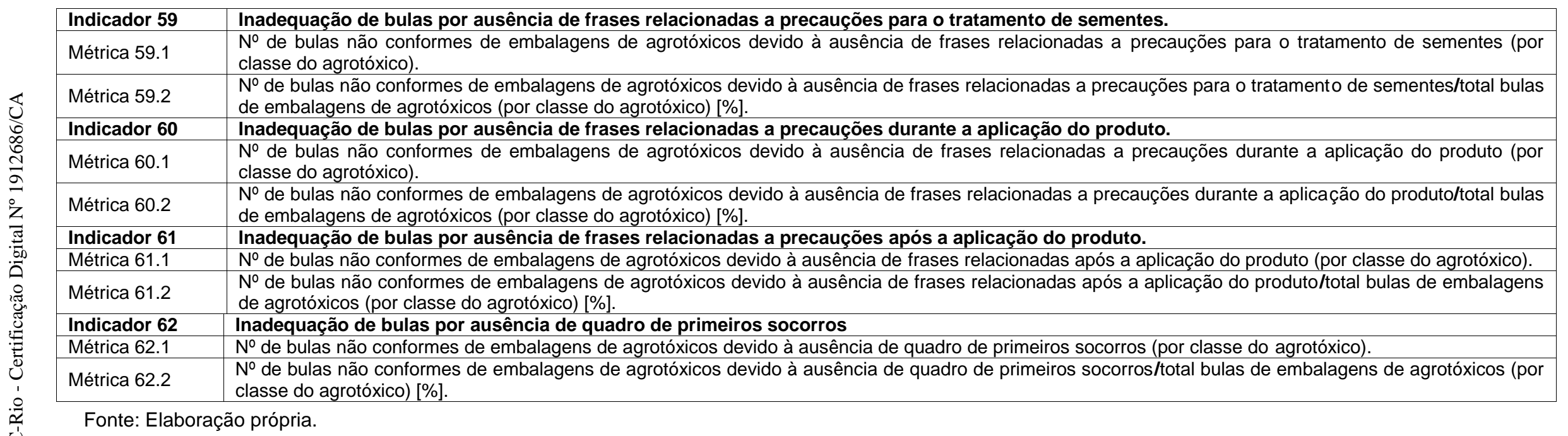

Quadro A.4- Lista inicial de indicadores de MA para a categoria "Instruções para preenchimento do quadro de informações médicas"

\begin{tabular}{|l|l|}
\hline Referência & Indicadores/métricas \\
\hline Indicador 63 & Informar grupo químico para cada ingrediente ativo. \\
\hline Métrica 63.1 & $\begin{array}{l}\text { № de bulas não conformes de embalagens de agrotóxicos devido à ausência da informação do grupo químico para cada ingrediente ativo (por classe do } \\
\text { agrotóxico). }\end{array}$ \\
\hline Métrica 63.2 & $\begin{array}{l}\text { № de bulas não conformes de embalagens de agrotóxicos devido à ausência da informação do grupo químico para cada ingrediente ativo/total bulas de } \\
\text { embalagens de agrotóxicos (por classe do agrotóxico) [\%]. }\end{array}$ \\
\hline Indicador 64 & Informar a classe toxicológica, baseada nos estudos aportados do produto e aprovada pela Anvisa. \\
\hline Métrica 64.1 & № de bulas não conformes de embalagens de agrotóxicos devido à ausência da informação da classe toxicológica (por classe do agrotóxico). \\
\hline Métrica 64.2 & $\begin{array}{l}\text { № de bulas não conformes de embalagens de agrotóxicos devido à ausência da informação da classe toxicológica/total bulas de embalagens de agrotóxicos } \\
\text { (por classe do agrotóxico) [\%]. }\end{array}$ \\
\hline Indicador 65 & Informar as potenciais vias de exposição (oral, inalatória, ocular e dérmica) considerando a indicação de uso. \\
\hline Métrica 65.1 & № de bulas não conformes de embalagens de agrotóxicos devido à ausência da informação sobre as potenciais vias de exposição (por classe do agrotóxico). \\
\hline Métrica 65.2 & $\begin{array}{l}\text { № de bulas não conformes de embalagens de agrotóxicos devido à ausência da informação sobre as potenciais vias de exposição/total bulas de embalagens } \\
\text { de agrotóxicos (por classe do agrotóxico) [\%]. }\end{array}$ \\
\hline
\end{tabular}




\begin{tabular}{|c|c|}
\hline Indicador 66 & $\begin{array}{l}\text { Informar os dados relativos à toxicocinética de cada ingrediente ativo com potencial tóxico, e também dos componentes toxicologicamente } \\
\text { relevantes. }\end{array}$ \\
\hline Métrica 66.1 & № de bulas não conformes de embalagens de agrotóxicos devido à ausência de informações relativas à toxicocinética (por classe do agrotóxico). \\
\hline Métrica 66.2 & $\begin{array}{l}\text { № de bulas não conformes de embalagens de agrotóxicos devido à ausência de informações relativas à toxicocinética/total bulas de embalagens de } \\
\text { agrotóxicos (por classe do agrotóxico) [\%]. }\end{array}$ \\
\hline Indicador 67 & Informar a toxicodinâmica de cada ingrediente com potencial tóxico. \\
\hline Métrica 67.1 & № de bulas não conformes de embalagens de agrotóxicos devido à ausência de informações relativas à toxicodinâmica (por classe do agrotóxico). \\
\hline Métrica 67.2 & $\begin{array}{l}\text { № de bulas não conformes de embalagens de agrotóxicos devido à ausência de informações relativas à toxicodinâmica/total bulas de embalagens de } \\
\text { agrotóxicos (por classe do agrotóxico) [\%]. }\end{array}$ \\
\hline Indicador 68 & Informar sintomas e sinais clínicos para cada ingrediente ativo e demais ingredientes com potencial tóxico. \\
\hline Métrica 68.1 & № de bulas não conformes de embalagens de agrotóxicos devido à ausência de informações sobre sintomas e sinais clínicos (por classe do agrotóxico). \\
\hline Métrica 68.2 & $\begin{array}{l}\text { № de bulas não conformes de embalagens de agrotóxicos devido à ausência de informações sobre sintomas e sinais clínicos/total bulas de embalagens de } \\
\text { agrotóxicos (por classe do agrotóxico) [\%]. }\end{array}$ \\
\hline Indicador 69 & Informar o diagnóstico com a descrição dos exames que permitem diagnosticar a intoxicação pelo produto. \\
\hline Métrica 69.1 & $\begin{array}{l}\text { № de bulas não conformes de embalagens de agrotóxicos devido à ausência de informações sobre diagnóstico de intoxicação por produto (por classe do } \\
\text { agrotóxico). }\end{array}$ \\
\hline Métrica 69.2 & $\begin{array}{l}\text { № de bulas não conformes de embalagens de agrotóxicos devido à ausência de informações sobre diagnóstico de intoxicação por produto/total bulas de } \\
\text { embalagens de agrotóxicos (por classe do agrotóxico) [\%]. }\end{array}$ \\
\hline Indicador 70 & $\begin{array}{l}\text { Informar e descrever medidas sobre tratamento a ser adotado pelos profissionais de saúde, com a indicação do tratamento específico ou os } \\
\text { antagonistas e antídotos, quando existirem, ou tratamento sintomático e de suporte: descontaminação e manutenção das funções vitais. }\end{array}$ \\
\hline Métrica 70.1 & $\begin{array}{l}\text { № de bulas não conformes de embalagens de agrotóxicos devido à ausência de informações sobre medidas de tratamento a serem adotadas por profissionais } \\
\text { de saúde (por classe do agrotóxico). }\end{array}$ \\
\hline Métrica 70.2 & $\begin{array}{l}\text { № de bulas não conformes de embalagens de agrotóxicos devido à ausência de informações sobre medidas de tratamento a serem adotadas por profissionais } \\
\text { de saúde/total bulas de embalagens de agrotóxicos (por classe do agrotóxico) [\%]. }\end{array}$ \\
\hline Indicador 71 & $\begin{array}{l}\text { Informar as contraindicações, abordando os procedimentos a serem adotados, os tratamentos propostos e informando as possíveis interações } \\
\text { químicas medicamentosas. }\end{array}$ \\
\hline Métrica 71.1 & № de bulas não conformes de embalagens de agrotóxicos devido à ausência de informações sobre contraindicações (por classe do agrotóxico). \\
\hline Métrica 72.2 & $\begin{array}{l}\text { № de bulas não conformes de embalagens de agrotóxicos devido à ausência de informações sobre contraindicações/total bulas de embalagens de agrotóxicos } \\
\text { (por classe do agrotóxico) [\%]. }\end{array}$ \\
\hline Indicador 73 & $\begin{array}{l}\text { Informar os efeitos das interações químicas, tais como os efeitos aditivos, sinérgicos ou potencializadores relacionados aos diferentes } \\
\text { componentes. }\end{array}$ \\
\hline Métrica 73.1 & № de bulas não conformes de embalagens de agrotóxicos devido à ausência de informações os efeitos das interações químicas (por classe do agrotóxico). \\
\hline Métrica 73.2 & $\begin{array}{l}\text { № de bulas não conformes de embalagens de agrotóxicos devido à ausência de informações os efeitos das interações químicas/total bulas de embalagens de } \\
\text { agrotóxicos (por classe do agrotóxico) [\%]. }\end{array}$ \\
\hline
\end{tabular}




\section{Apêndice 2 - Instrumento de coleta de dados: matriz de avaliação quantitativa de indicadores candidatos}

Prezado participante,

Esta ferramenta é objeto de uma pesquisa de mestrado do Programa de Pós-Graduaçãoem Metrologia da Pontifícia Universidade Católica do Rio de Janeiro. A pesquisa tem por objetivo propor indicadores e métricas para o monitoramento e avaliação da implementação da regulamentação sobre rotulagem e bulas de agrotóxicos, afins e preservativos de madeira no Brasil.

A ferramenta foi construída com base na metodologia divulgada pelo Ministério do Planejamento, Orçamento e Gestão e a matriz inicial de indicadores foi concebida paraser respondida em 120 minutos, no máximo.

Antecipadamente, expressamos os nossos agradecimentos pela sua participação.

Atenciosamente,

Jéssica Peres de Medeiros

Mestranda do Programa de Pós-Graduação em Metrologia (Pós MQI/PUC-Rio)

Maria Fatima Ludovico de Almeida

Professora orientadora da pesquisa 


\section{Preenchimento das matrizes de avaliação quantitativa de indicadores candidatos}

\section{Tipo de indicador candidato}

Indicador-chave: expressa o conceito ou dimensão mais relevante de um ou mais critérios e procedimentos do regulamento de recolhimento de alimentos;

Indicador complementar: complementa os indicadores chave, buscando conferir maior confiabilidade da mensuração e rastreabilidade da informação;

Indicador específico: expressa as necessidades de informação próprias de determinadas partes interessadas ou outras especificidades quaisquer inerentes ao que será medido, quando os dois tipos já descritos acima não cumprirem essa função.

\section{Critérios}

C1- Alinhamento aos objetivos da regulamentação: o indicador deve estar alinhado a um ou mais critérios e procedimentos estabelecidos no regulamento para recolhimento de alimentos.

C2- Atendimento às necessidades de informação dos interessados: o indicador deve atender às necessidades de informação dos interessados na efetiva implementação do regulamento.

C3- Disponibilidade quando necessário: o indicador deve estar disponível em tempo hábil para permitir a adoção de quaisquer medidas.

C4- Simplicidade de construção e entendimento: o indicador deve ser simples, claro e inteligível, para facilitar a mensuração e resultados obtidos através dele.

C5- Confiabilidade da fonte: o indicador deve ser proveniente de fontes seguras, íntegras, sem a possibilidade de manipulação para disfarçar resultados.

C6- Aderência à escala temporal desejada: o indicador deve representar o momento atual da característica a ser observada;

e ser atualizado com a regularidade necessária para permitir a adoção de medidas e em unidades de tempo comparáveis.

C7- Rastreabilidade ao longo do tempo: o indicador deve ser rastreável, com disponibilização das informações necessárias (fontes confiáveis).

\section{Escalas do grau de atendimento}

Atendimento ao critério eliminatório: não atende (0); atende (1).

Atendimento ao critério classificatório: não atende (0); atende parcialmente (graus de 1 a 9); atende totalmente (10).

Aplicar somente aqueles que atenderam aos critérios eliminatórios. 


\section{Matriz de Avaliação Quantitativa de Indicadores referentes à etapa de 'Modelo de rótulo coluna central'}

\begin{tabular}{|c|c|c|c|c|c|c|c|c|c|}
\hline \multirow{3}{*}{ Indicador } & \multirow{2}{*}{\multicolumn{3}{|c|}{ Tipo de Indicador }} & \multicolumn{6}{|c|}{ Natureza do indicador } \\
\hline & & & & \multicolumn{2}{|c|}{ Eliminatórios } & \multicolumn{2}{|c|}{ Classificatórios } & \multirow[b]{2}{*}{\begin{tabular}{|c|} 
C6 \\
Atend.
\end{tabular}} & \multirow[b]{2}{*}{\begin{tabular}{|l} 
C7 \\
Atend.
\end{tabular}} \\
\hline & Chave & Complem. & Espec. & C1 & $\mathbf{C 2}$ & \begin{tabular}{|c|} 
C4 \\
Atendimento \\
\end{tabular} & \begin{tabular}{|c|} 
C5 \\
Atend.
\end{tabular} & & \\
\hline \multicolumn{10}{|l|}{ IMR1- Inadequação do rótulo por ausência da marca comercial do produto. } \\
\hline \multicolumn{10}{|l|}{ IMR2- Inadequação do rótulo por ausência da composição do produto. } \\
\hline \multicolumn{10}{|l|}{$\begin{array}{l}\text { IMR3- Inadequação do rótulo por ausência de informação do conteúdo, em } \\
\text { unidade de massa ou volume. }\end{array}$} \\
\hline \multicolumn{10}{|l|}{$\begin{array}{l}\text { IMR4- Inadequação do rótulo por ausência da especificação da classe do } \\
\text { agrotóxico. }\end{array}$} \\
\hline \multicolumn{10}{|l|}{ IMR5- Inadequação do rótulo por ausência da identificação do grupo químico. } \\
\hline \multicolumn{10}{|l|}{ IMR6- Inadequação do rótulo por ausência do tipo de formulação. } \\
\hline \multicolumn{10}{|l|}{ IMR7- Inadequação do rótulo por ausência do titular do registro } \\
\hline \multicolumn{10}{|l|}{$\begin{array}{l}\text { IMR8- Inadequação do rótulo por ausência do fabricante do produto técnico ou } \\
\text { produto }\end{array}$} \\
\hline \multicolumn{10}{|l|}{ IMR9- Inadequação do rótulo por ausência do formulador e/ou manipulador. } \\
\hline \multicolumn{10}{|l|}{ IMR10- Inadequação do rótulo por ausência da identificação do lote do produto. } \\
\hline \multicolumn{10}{|l|}{$\begin{array}{l}\text { IMR11- Inadequação do rótulo por ausência da declaração "ANTES DE USAR } \\
\text { O PRODUTO LEIA O RÓTULO, A BULA E A RECEITA AGRONÔMICA E } \\
\text { CONSERVE-OS EM SEU PODER". }\end{array}$} \\
\hline \multicolumn{10}{|l|}{$\begin{array}{l}\text { IMR12- Inadequação do rótulo por ausência da declaração "É OBRIGATÓRIO } \\
\text { O USO DE EQUIPAMENTOS DE PROTEÇÃO INDIVIDUAL". PROTEJA-SE." }\end{array}$} \\
\hline \multicolumn{10}{|l|}{$\begin{array}{l}\text { IMR13- Inadequação do rótulo por ausência da declaração "É OBRIGATÓRIA } \\
\text { A DEVOLUÇÃO DA EMBALAGEM VAZIA". }\end{array}$} \\
\hline \multicolumn{10}{|l|}{$\begin{array}{l}\text { IMR14- Inadequação do rótulo por ausência da declaração "Indicações e } \\
\text { restrições de uso: vide bula e receita agronômica". }\end{array}$} \\
\hline \multicolumn{10}{|l|}{$\begin{array}{l}\text { IMR15- Inadequação do rótulo por ausência de Restrições Estaduais, do } \\
\text { Distrito Federal e Municipais. }\end{array}$} \\
\hline \multicolumn{10}{|l|}{$\begin{array}{l}\text { IMR16- Inadequação do rótulo por ausência da declaração "Produto registrado } \\
\text { para cultura de: inserir as culturas solicitadas no pleito de registro". }\end{array}$} \\
\hline \multicolumn{10}{|l|}{$\begin{array}{l}\text { IMR17- Inadequação do rótulo por ausência da declaração "Indústria Brasileira, } \\
\text { quando aplicável". }\end{array}$} \\
\hline \multicolumn{10}{|l|}{$\begin{array}{l}\text { IMR18- Inadequação do rótulo por ausência de Indicação se a formulação é } \\
\text { explosiva, inflamável, comburente, corrosiva, irritante ou sujeita à venda } \\
\text { aplicada. }\end{array}$} \\
\hline \multirow{2}{*}{\multicolumn{10}{|c|}{$\begin{array}{l}\text { IMR19- Inadequação do rótulo por ausência da classificação toxicológica. } \\
\text { IMR20- Inadequacão do rótulo por ausência da Periculosidade Ambiental. }\end{array}$}} \\
\hline & & & & & & & & & \\
\hline $\begin{array}{l}\text { Necessidade de novo indicador para esta etapa? Utilize esse espaço para suas } \\
\text { proposições }\end{array}$ & & & & & & & & & \\
\hline
\end{tabular}


Matriz de Avaliação Quantitativa de Indicadores referentes à etapa de 'Modelo de rótulo coluna da direita'

\begin{tabular}{|c|c|c|c|c|c|c|c|c|c|}
\hline \multirow{4}{*}{ Indicador } & \multirow{2}{*}{\multicolumn{3}{|c|}{ Tipo de Indicador }} & \multicolumn{6}{|c|}{ Natureza do indicador } \\
\hline & & & & \multicolumn{2}{|c|}{ Eliminatórios } & \multirow{2}{*}{\multicolumn{2}{|c|}{\begin{tabular}{c|c}
\multicolumn{2}{c}{ Classificatórios } \\
C4
\end{tabular}}} & \multirow{3}{*}{\begin{tabular}{|c|} 
C6 \\
Atend. \\
\end{tabular}} & \multirow{3}{*}{$\begin{array}{c}\text { C7 } \\
\text { Atend. }\end{array}$} \\
\hline & \multirow{2}{*}{ Chave } & \multirow{2}{*}{ Complem. } & \multirow{2}{*}{ Espec. } & & & & & & \\
\hline & & & & C1 & C2 & Atendimento & Atend. & & \\
\hline \multicolumn{10}{|l|}{$\begin{array}{l}\text { IMR1- Inadequação do rótulo por ausência da declaração } \\
\text { "ANTES DE USAR O PRODUTO, LEIA COM ATENÇÃO AS } \\
\text { INSTRUÇÕES DA BULA". }\end{array}$} \\
\hline \multicolumn{10}{|l|}{$\begin{array}{l}\text { IMR2- Inadequação do rótulo por ausência de frases } \\
\text { relacionadas a precauções gerais. }\end{array}$} \\
\hline \multicolumn{10}{|l|}{$\begin{array}{l}\text { IMR3- Inadequação do rótulo por ausência de frases } \\
\text { relacionadas a precauções durante a preparação da calda. }\end{array}$} \\
\hline \multicolumn{10}{|l|}{$\begin{array}{l}\text { IMR4- Inadequação do rótulo por ausência de frases } \\
\text { relacionadas a precauções durante o manuseio. }\end{array}$} \\
\hline \multicolumn{10}{|l|}{$\begin{array}{l}\text { IMR5- Inadequação do rótulo por ausência de frases } \\
\text { relacionadas a precauções para o tratamento de sementes. }\end{array}$} \\
\hline \multicolumn{10}{|l|}{$\begin{array}{l}\text { IMR6- Inadequação do rótulo por ausência de frases } \\
\text { relacionadas a precauções durante a aplicação do produto. }\end{array}$} \\
\hline \multicolumn{10}{|l|}{$\begin{array}{l}\text { IMR7- Inadequação do rótulo por ausência de frases } \\
\text { relacionadas a precauções após a aplicação do produto. }\end{array}$} \\
\hline \multicolumn{10}{|l|}{$\begin{array}{l}\text { IMR8- Inadequação do rótulo por ausência de quadro de } \\
\text { primeiros socorros }\end{array}$} \\
\hline \multicolumn{10}{|l|}{$\begin{array}{l}\text { IMR9- Inadequação do rótulo por ausência de quadro de } \\
\text { antídotos e tratamento. }\end{array}$} \\
\hline \multicolumn{10}{|l|}{$\begin{array}{l}\text { IMR10- Inadequação do rótulo por ausência de quadro de } \\
\text { telefones em caso de emergência. }\end{array}$} \\
\hline \multicolumn{10}{|l|}{$\begin{array}{l}\text { IMR11- Inadequação do rótulo por ausência de faixa do rótulo } \\
\text { de acordo com o guia da Anvisa. }\end{array}$} \\
\hline $\begin{array}{l}\text { Necessidade de novo indicador para esta etapa? Utilize esse } \\
\text { espaço para suasproposições }\end{array}$ & & & & & & & & & \\
\hline
\end{tabular}




\section{Matriz de Avaliação Quantitativa de Indicadores referentes à etapa de 'Modelo de bula'}

\begin{tabular}{|c|c|c|c|c|c|c|c|c|c|}
\hline \multirow{4}{*}{ Indicador } & \multirow{2}{*}{\multicolumn{3}{|c|}{ Tipo de Indicador }} & \multicolumn{6}{|c|}{ Natureza do indicador } \\
\hline & & & & \multicolumn{2}{|c|}{ Eliminatórios } & \multicolumn{4}{|c|}{ Classificatórios } \\
\hline & Chave & Complem. & Espec. & C1 & C2 & \begin{tabular}{|c|} 
C4 \\
\end{tabular} & C5 & C6 & $\mathbf{C 7}$ \\
\hline & Cilave & comprem. & Espec. & ( & 62 & Atendimento & Atend. & Atend. & Atend. \\
\hline \multicolumn{10}{|l|}{ IMB1- Inadequação da bula por ausência da composição do produto. } \\
\hline \multicolumn{10}{|l|}{$\begin{array}{l}\text { IMB2- Inadequação da bula por ausência de informação do conteúdo, } \\
\text { em unidade de massa ou volume. }\end{array}$} \\
\hline \multicolumn{10}{|l|}{$\begin{array}{l}\text { IMB3- Inadequação da bula por ausência da especificação da classe } \\
\text { do agrotóxico. }\end{array}$} \\
\hline \multicolumn{10}{|l|}{$\begin{array}{l}\text { IMB4- Inadequação da bula por ausência da identificação do grupo } \\
\text { químico. }\end{array}$} \\
\hline IMB5- Inadequação da bula por ausência do tipo de formulação. & & & & & & & & & \\
\hline \multicolumn{10}{|l|}{ IMB6- Inadequação da bula por ausência do titular do registro. } \\
\hline \multicolumn{10}{|l|}{$\begin{array}{l}\text { IMB7- Inadequação da bula por ausência do fabricante do produto } \\
\text { técnico ou produto. }\end{array}$} \\
\hline \multicolumn{10}{|l|}{$\begin{array}{l}\text { IMB8- Inadequação da bula por ausência do formulador e/ou } \\
\text { manipulador. }\end{array}$} \\
\hline \multicolumn{10}{|l|}{$\begin{array}{l}\text { IMB9- Inadequação da bula por ausência de informações de } \\
\text { fabricação. }\end{array}$} \\
\hline \multicolumn{10}{|l|}{$\begin{array}{l}\text { IMB10- Inadequação da bula por ausência da declaração "ANTES DE } \\
\text { USAR O PRODUTO LEIA O ROTULO, A BULA E A RECEITA } \\
\text { AGRONÔMICA E CONSERVE-OS EM SEU PODER". }\end{array}$} \\
\hline \multicolumn{10}{|l|}{$\begin{array}{l}\text { IMB11- Inadequação da bula por ausência da declaração "É } \\
\text { OBRIGATÓRIO O USO DE EQUIPAMENTOS DE PROTEÇÃO } \\
\text { INDIVIDUAL". PROTEJA-SE." }\end{array}$} \\
\hline \multicolumn{10}{|l|}{$\begin{array}{l}\text { IMB12- Inadequação da bula por ausência da declaração "É } \\
\text { OBRIGATÓRIA A DEVOLUÇÃO DA EMBALAGEM VAZIA". }\end{array}$} \\
\hline \multicolumn{10}{|l|}{$\begin{array}{l}\text { IMB13- Inadequação da bula por ausência da declaração "Indicações } \\
\text { e restrições de uso: vide bula e receita agronômica". }\end{array}$} \\
\hline \multicolumn{10}{|l|}{$\begin{array}{l}\text { IMB14- Inadequação da bula por ausência de Restrições Estaduais, } \\
\text { do Distrito Federal e Municipais. }\end{array}$} \\
\hline \multicolumn{10}{|l|}{$\begin{array}{l}\text { IMB15- Inadequação da bula por ausência da declaração "Produto } \\
\text { registrado para cultura de: inserir as culturas solicitadas no pleito de } \\
\text { registro". }\end{array}$} \\
\hline \multicolumn{10}{|l|}{$\begin{array}{l}\text { IMB16- Inadequação da bula por ausência da declaração "Indústria } \\
\text { Brasileira, quando aplicável". }\end{array}$} \\
\hline $\begin{array}{l}\text { IMB17- Inadequação da bula por ausência de Indicação se a } \\
\text { formulação é explosiva, inflamável, comburente, corrosiva, irritante ou } \\
\text { sujeita à venda aplicada. }\end{array}$ & & & & & & & & & \\
\hline
\end{tabular}




\section{Matriz de Avaliação Quantitativa de Indicadores referentes à etapa de 'Modelo de bula' (cont.)}

\begin{tabular}{|c|c|c|c|c|c|c|c|c|c|}
\hline \multirow{3}{*}{ Indicador } & \multirow{2}{*}{\multicolumn{3}{|c|}{ Tipo de Indicador }} & \multicolumn{6}{|c|}{ Natureza do indicador } \\
\hline & & & & \multicolumn{2}{|c|}{ Eliminatórios } & \multicolumn{4}{|c|}{ Classificatórios } \\
\hline & Chave & Complem. & Espec. & C1 & C2 & \begin{tabular}{|c|} 
C4 \\
Atendimento
\end{tabular} & \begin{tabular}{|l|} 
C5 \\
Atend.
\end{tabular} & \begin{tabular}{|l|} 
C6 \\
Atend. \\
\end{tabular} & \begin{tabular}{|l|} 
C7 \\
Atend.
\end{tabular} \\
\hline $\begin{array}{l}\text { IMB18- Inadequação da bula por ausência da classificação } \\
\text { toxicológica. }\end{array}$ & & & & & & & & & \\
\hline $\begin{array}{l}\text { IMB19- Inadequação da bula por ausência da Periculosidade } \\
\text { Ambiental. }\end{array}$ & & & & & & & & & \\
\hline $\begin{array}{l}\text { IMB20- Inadequação da bula por ausência da faixa de } \\
\text { classificação toxicológica. }\end{array}$ & & & & & & & & & \\
\hline IMB21- Inadequação da bula por ausência de instruções de uso. & & & & & & & & & \\
\hline $\begin{array}{l}\text { IMB22- Inadequação da bula por ausência de frases relacionadas } \\
\text { a precauções gerais. }\end{array}$ & & & & & & & & & \\
\hline $\begin{array}{l}\text { IMB23- Inadequação da bula por ausência de frases relacionadas } \\
\text { a precauções durante a preparação da calda. }\end{array}$ & & & & & & & & & \\
\hline $\begin{array}{l}\text { IMB24- Inadequação da bula por ausência de frases relacionadas } \\
\text { a precauções durante o manuseio. }\end{array}$ & & & & & & & & & \\
\hline $\begin{array}{l}\text { IMB25- Inadequação da bula por ausência de frases relacionadas } \\
\text { a precauções para o tratamento de sementes. }\end{array}$ & & & & & & & & & \\
\hline $\begin{array}{l}\text { IMB26- Inadequação da bula por ausência de frases relacionadas } \\
\text { a precauções durante a aplicação do produto. }\end{array}$ & & & & & & & & & \\
\hline $\begin{array}{l}\text { IMB27- Inadequação da bula por ausência de frases relacionadas } \\
\text { a precauções após a aplicação do produto. }\end{array}$ & & & & & & & & & \\
\hline $\begin{array}{l}\text { IMB28- Inadequação da bula por ausência de quadro de primeiros } \\
\text { socorros. }\end{array}$ & & & & & & & & & \\
\hline $\begin{array}{l}\text { Necessidade de novo indicador para esta etapa? Utilize esse } \\
\text { espaço para suasproposições }\end{array}$ & & & & & & & & & \\
\hline
\end{tabular}




\section{Matriz de Avaliação Quantitativa de Indicadores referentes à etapa de 'Instruções para preenchimento do quadro de informações médicas'}

\begin{tabular}{|c|c|c|c|c|c|c|c|c|c|}
\hline \multirow{3}{*}{ Indicador } & \multirow{2}{*}{\multicolumn{3}{|c|}{ Tipo de Indicador }} & \multicolumn{6}{|c|}{ Natureza do indicador } \\
\hline & & & & \multicolumn{2}{|c|}{ Eliminatórios } & \multicolumn{4}{|c|}{ Classificatórios } \\
\hline & Chave & Complem. & Espec. & C1 & $\mathrm{C2}$ & \begin{tabular}{|c|} 
C4 \\
Atendimento
\end{tabular} & \begin{tabular}{|c|} 
C5 \\
Atend.
\end{tabular} & \begin{tabular}{|c|} 
C6 \\
Atend.
\end{tabular} & C7 \\
\hline \multicolumn{10}{|l|}{$\begin{array}{l}\text { IIM1- Inadequação da bula por ausência/erro/incompletude da } \\
\text { informação sobre o grupo químico de cada ingrediente ativo. }\end{array}$} \\
\hline \multicolumn{10}{|l|}{$\begin{array}{l}\text { IIM2- Inadequação da bula por ausência da informação sobre a classe } \\
\text { toxicológica. }\end{array}$} \\
\hline \multicolumn{10}{|l|}{$\begin{array}{l}\text { IIM3- Inadequação da bula por ausência da informação sobre as } \\
\text { potenciais vias de exposição (oral, inalatória, ocular e dérmica) } \\
\text { considerando a indicação de uso. }\end{array}$} \\
\hline \multicolumn{10}{|l|}{$\begin{array}{l}\text { IIM4- Inadequação da bula por ausência da informação sobre a } \\
\text { toxicocinética de cada ingrediente ativo com potencial tóxico, e } \\
\text { também dos componentes toxicologicamente relevantes. }\end{array}$} \\
\hline \multicolumn{10}{|l|}{$\begin{array}{l}\text { IIM5- Inadequação da bula por ausência da informação sobre a } \\
\text { toxicodinâmica de cada ingrediente com potencial tóxico. }\end{array}$} \\
\hline \multicolumn{10}{|l|}{$\begin{array}{l}\text { IIM6- Inadequação da bula por ausência da informação sobre os } \\
\text { sintomas e sinais clínicos, que um paciente pode apresentar em caso } \\
\text { de intoxicação, para cada ingrediente ativo e demais ingredientes com } \\
\text { potencial tóxico. }\end{array}$} \\
\hline \multicolumn{10}{|l|}{$\begin{array}{l}\text { IIM7- Inadequação da bula por ausência da descrição dos exames } \\
\text { que permitem diagnosticar a intoxicação pelo produto. }\end{array}$} \\
\hline \multicolumn{10}{|l|}{$\begin{array}{l}\text { IIM8- Inadequação da bula por ausência da informação e descrição } \\
\text { sobre o tratamento a ser adotado pelos profissionais de saúde, com a } \\
\text { indicação do tratamento específico ou os antagonistas e antídotos, } \\
\text { quando existirem, ou tratamento sintomático e de suporte: } \\
\text { descontaminação e manutenção das funções vitais. }\end{array}$} \\
\hline \multicolumn{10}{|l|}{$\begin{array}{l}\text { IIM9- Inadequação da bula por ausência da informação sobre as } \\
\text { contraindicações, abordando os procedimentos a serem adotados, os } \\
\text { tratamentos propostos e informando as possíveis interações químicas } \\
\text { medicamentosas. }\end{array}$} \\
\hline $\begin{array}{l}\text { IIM10- Inadequação da bula por ausência da informação sobre os } \\
\text { efeitos das interações químicas, tais como os efeitos aditivos, } \\
\text { sinérgicos ou potencializadores relacionados aos diferentes } \\
\text { componentes. }\end{array}$ & & & & & & & & & \\
\hline $\begin{array}{l}\text { Necessidade de novo indicador para esta etapa? Utilize esse espaço } \\
\text { para suasproposições }\end{array}$ & & & & & & & & & \\
\hline
\end{tabular}

